\title{
Testosterone replacement therapy and the risk of prostate cancer in men with late-onset hypogonadism
}

\author{
Christina Santella
}

Department of Epidemiology, Biostatistics, and Occupational Health McGill University, Montreal June 2019

A thesis submitted to McGill University in partial fulfillment of the requirements of the degree of Master of Science in Epidemiology

CChristina Santella, 2019 


\section{Table of contents}

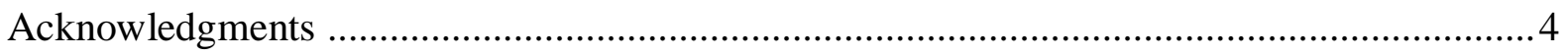

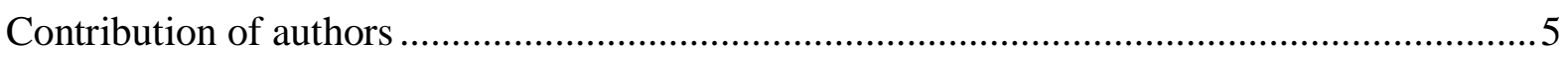

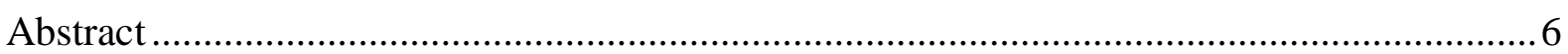

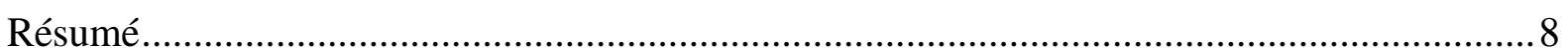

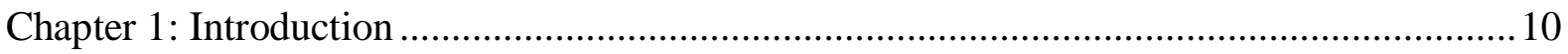

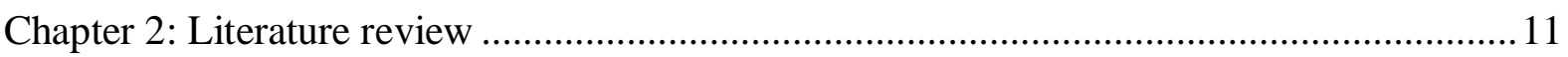

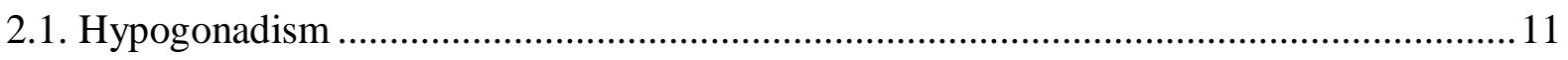

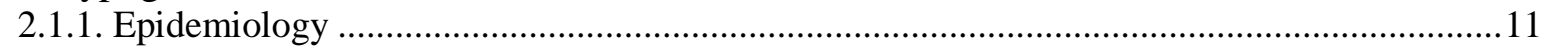

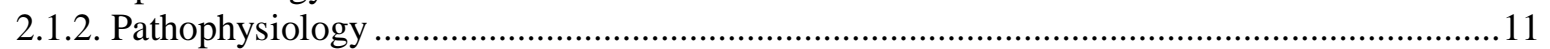

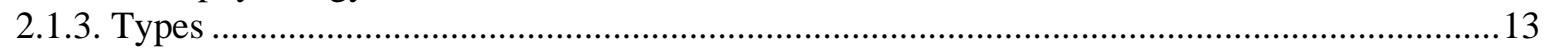

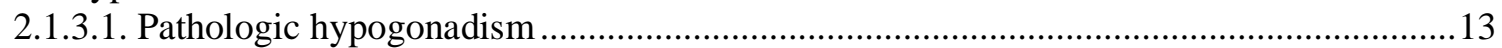

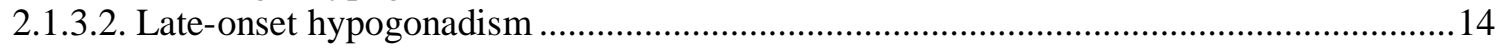

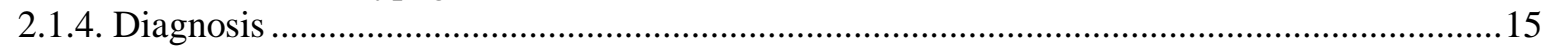

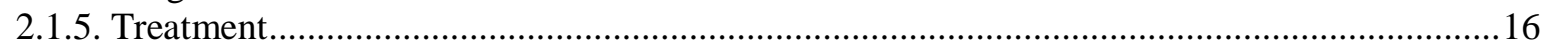

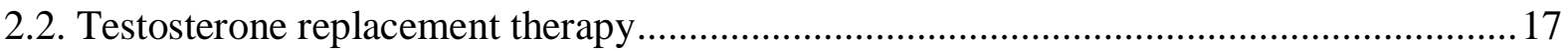

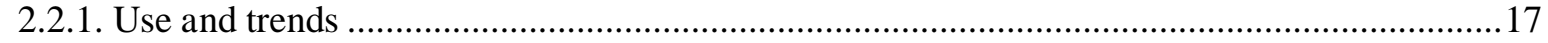

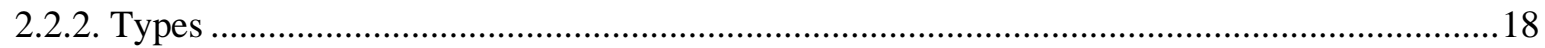

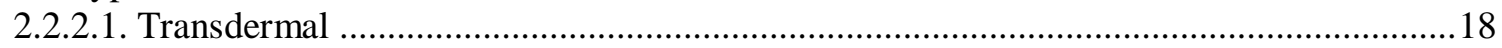

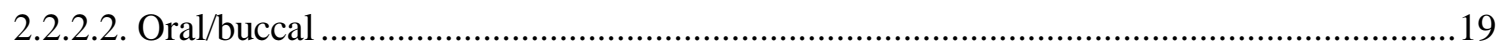

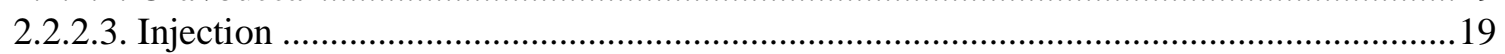

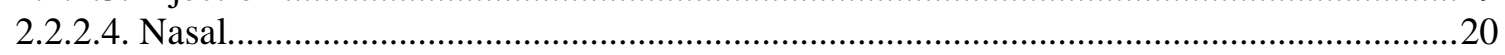

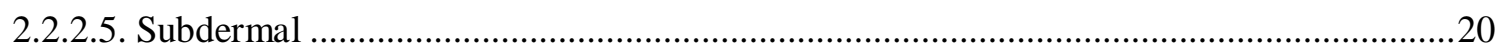

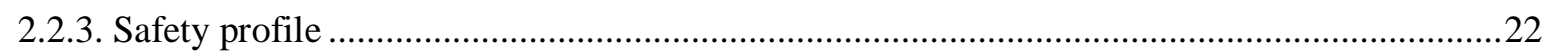

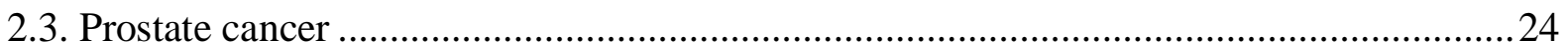

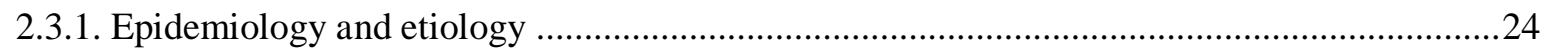

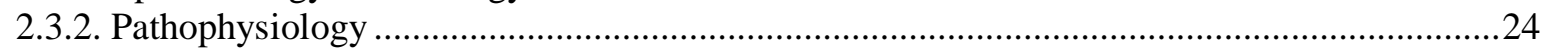

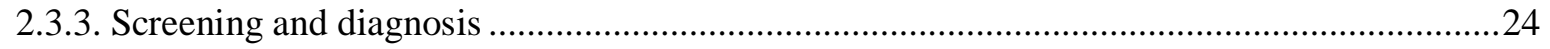

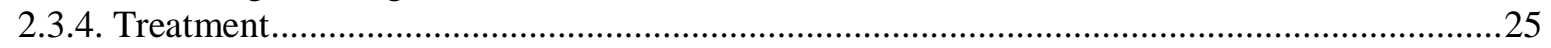

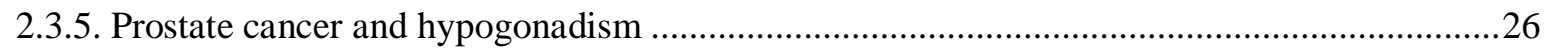

2.4. Testosterone replacement therapy and the risk of prostate cancer ................................2 27

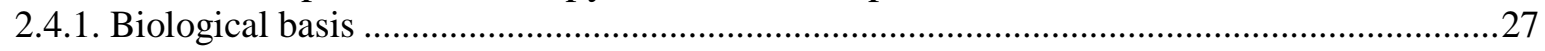

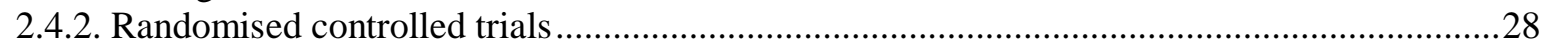

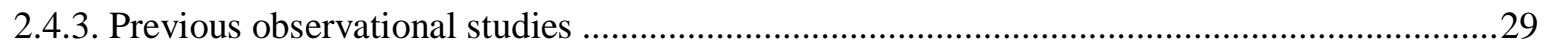

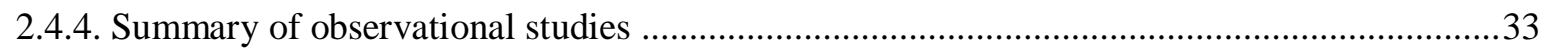

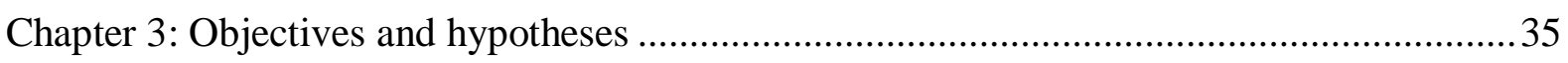

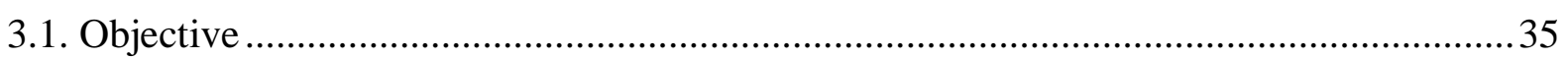

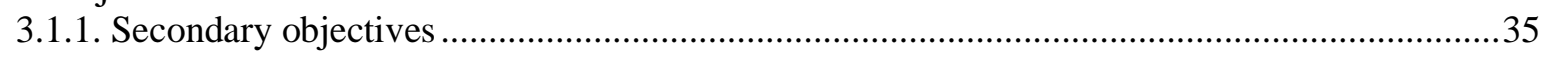

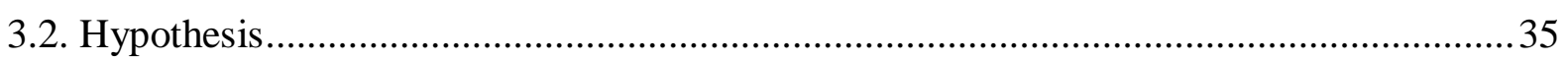

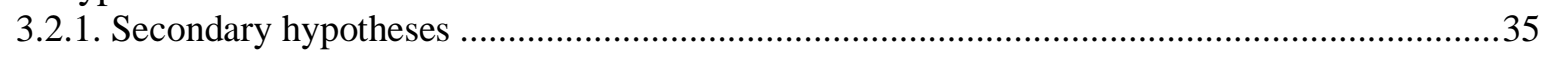

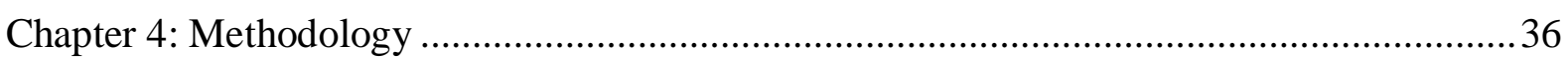

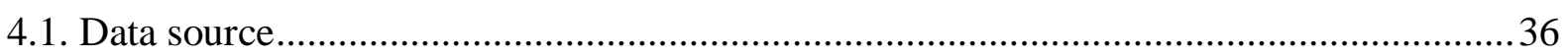

4.1.1. Utility of CPRD to assess the association between TRT and prostate cancer ............................ 


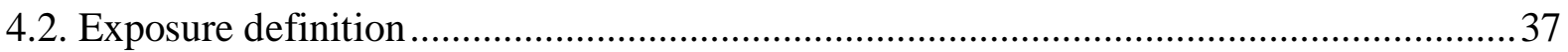

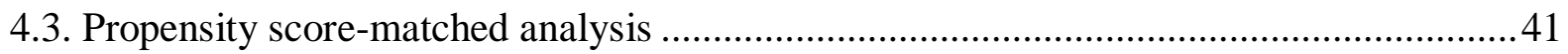

Chapter 5: Testosterone replacement therapy and the risk of prostate cancer in men with late-

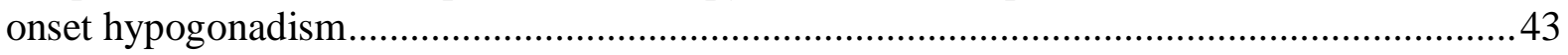

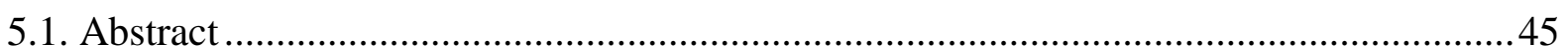

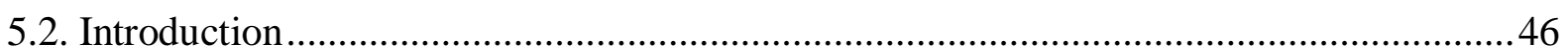

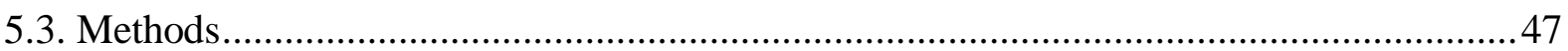

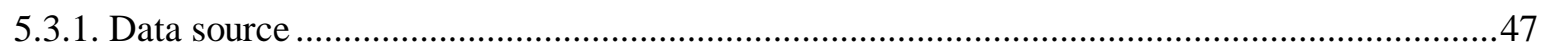

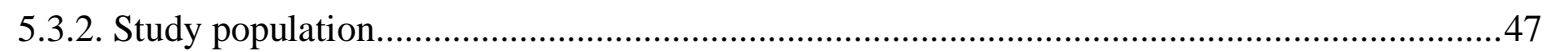

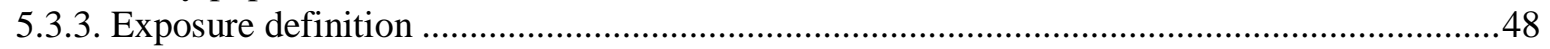

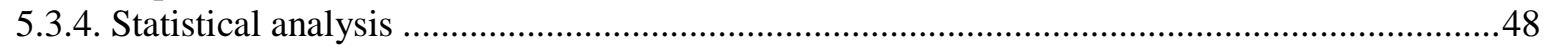

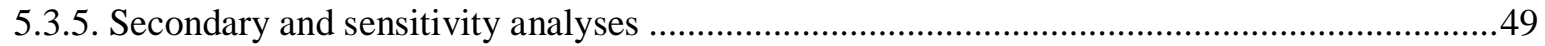

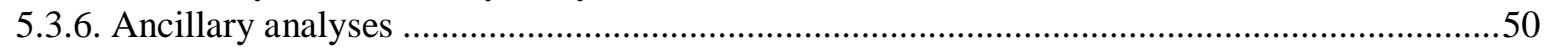

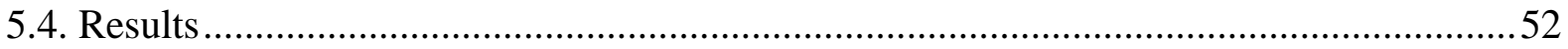

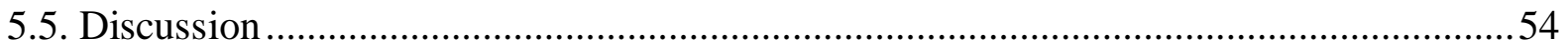

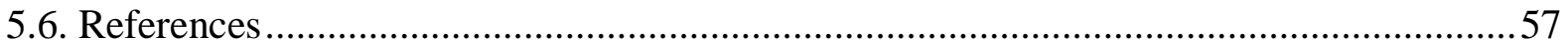

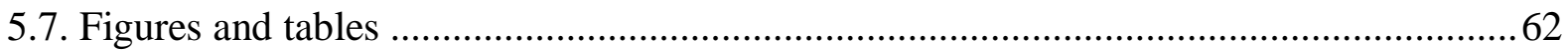

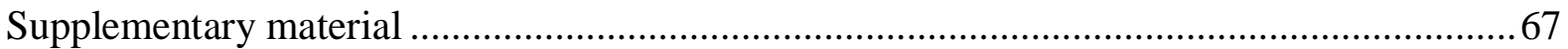

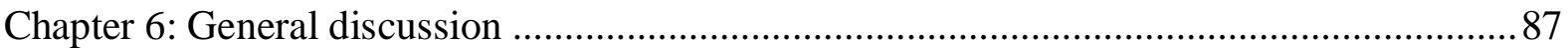

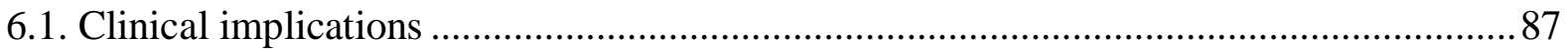

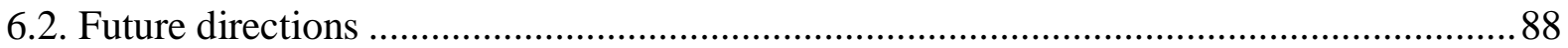

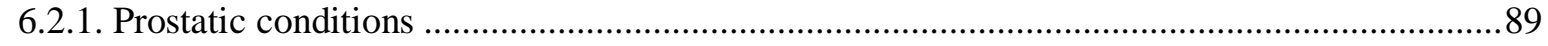

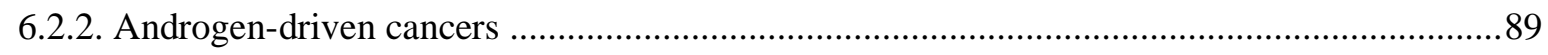

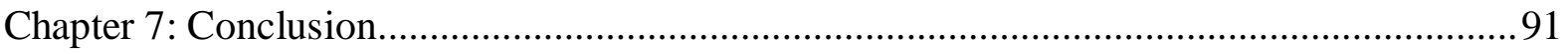

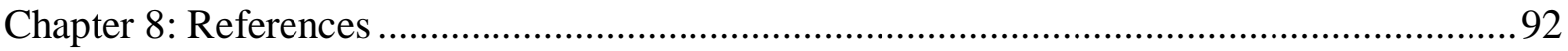




\section{Acknowledgements}

I would like to first thank my thesis supervisor, Dr. Laurent Azoulay, for providing me with invaluable guidance and support for the successful completion of my thesis. He has showed endless patience and has constantly provided me with opportunities throughout the course of my degree. Dr. Azoulay is truly invested in the success of his students and I am extremely grateful for the training I received under his supervision. I would also like to thank my thesis committee member, Dr. Christel Renoux, for her knowledge and perspectives consistently offered throughout the course of this thesis. I would like to thank Hui Yin for her aid in the statistical analyses, and her constant willingness and patience to answer any questions I had. Finally, I would like to thank Dr. Oriana Yu for her clinical expertise and the unique insights she provided. This thesis would not have been possible without the help of each and every one of you, and I am truly appreciative. 


\section{Contribution of authors}

Christina Santella drafted all sections of this thesis and manuscript. Drs. Laurent Azoulay and Christel Renoux conceived of the thesis topic and acquired the data. All authors assisted in designing the study. Christina Santella, Hui Yin, and Dr. Laurent Azoulay contributed to the statistical analyses. All authors contributed to the interpretation of the data, and Drs. Christel Renoux and Oriana Yu provided unique expertise. All authors critically revised the manuscript and approved of the final version. Dr. Laurent Azoulay supervised the study and is the guarantor. 


\section{Abstract}

Background: While testosterone replacement therapy (TRT) has been shown to be an effective treatment for men with pathologic hypogonadism, its benefits among ageing men with late-onset hypogonadism is uncertain. Indeed, there is inconclusive evidence supporting a clinical benefit in this population, which is complicated by concerns that these drugs may increase the risk of certain adverse events, including prostate cancer. To date, however, the studies that have assessed this association had important methodological limitations.

Objective: To determine whether the use of TRT is associated with an increased risk of prostate cancer in men with late-onset hypogonadism.

Patients and methods: We conducted a cohort study using the Clinical Practice Research Datalink, a large primary care database from the United Kingdom. This cohort consisted of men, at least 45 years of age, newly-diagnosed with hypogonadism between 1 January 1995 and 31 August 2016, with follow-up until 31 August 2017. Time-dependent Cox proportional hazards models were used to estimate adjusted hazard ratios (HRs) with 95\% confidence intervals (CIs) of prostate cancer associated with TRT use, compared with non-use. Exposure to TRT was lagged by 1 year to account for cancer latency, as well as to minimize detection bias and reverse causality. Secondary analyses assessed the association by TRT formulation, number of prescriptions received, and time since initiation. In addition, sensitivity analyses were conducted to address different possible sources of bias. Finally, we conducted several ancillary analyses, including a propensity score-matched cohort analysis to further assess the impact of residual confounding.

Results: The cohort included 12,779 patients with hypogonadism. During the follow-up period, a total of 215 patients were newly-diagnosed with prostate cancer during 58,224 person-years of follow-up, generating an incidence rate of 3.7 per 1,000 person-years. Compared with non-use, use of TRT was not associated with an overall increased risk of 
prostate cancer $(3.8 \vee 3.4$ per 1,000 person-years, respectively; adjusted HR, 0.97; 95\% CI, 0.71 to 1.32 ). The association did not vary by type, number of prescriptions received and time since initiation, as well as across sensitivity analyses. Finally, results remained consistent in the propensity score-matched analysis (HR, $0.87 ; 95 \% \mathrm{CI}, 0.56$ to 1.36$)$.

Conclusion: In this population-based cohort study, the use of TRT was not associated with an increased risk of prostate cancer in men with late-onset hypogonadism. Given the increasing use of TRT in the male population and ongoing concerns related to its safety, these findings provide some reassurance on the long-term safety of TRT with respect to prostate cancer. 


\section{Résumé}

Contexte: Bien qu'il ait été prouvé que la thérapie de remplacement de la testostérone (TRT) est un traitement efficace pour les hommes atteints d'hypogonadisme pathologique, ses bénéfices chez les hommes vieillissants atteints d'hypogonadisme de survenue tardive demeurent incertains. En effet, les preuves en faveur d'un bénéfice clinique dans cette population restent non concluantes, et s'accompagnent d'inquiétudes liées à une potentielle augmentation du risque de survenue d'évènements indésirables, dont notamment de cancer de la prostate. Cependant, les études ayant évalué cette association présentaient jusqu'à présent d'importantes limites méthodologiques.

Objectif: Déterminer si l'utilisation de TRT est associée à un risque accru de développer un cancer de la prostate chez les hommes atteints d'hypogonadisme de survenue tardive.

Patients et méthodes: Une étude de cohorte a été réalisée à partir de la Clinical Practice Research Datalink, une vaste base de données sur les soins primaires au Royaume-Uni. Cette cohorte regroupait les hommes âgés d'au moins 45 ans nouvellement diagnostiqués d'hypogonadisme entre le 1er Janvier 1995 et le 31 Août 2016, suivis jusqu'au 31 Août 2017. Des modèles de Cox à risques proportionnels dépendants du temps ont été utilisés pour estimer les rapports de risque instantanés (HRs) et les intervalles de confiance (IC) à 95\% de l'association entre utilisation de TRT et cancer de la prostate, comparativement à la nonutilisation. La mesure d'exposition à la TRT a été décalée d'un an pour tenir compte du délai de survenue du cancer, ainsi que pour minimiser les biais de détection et de causalité inverse. Les analyses secondaires ont évalué l'association selon la formulation de TRT, le nombre de prescriptions reçues, et le temps écoulé depuis l'initiation du traitement. Par ailleurs, plusieurs analyses de sensibilité ont été conduites pour s'intéresser à différentes sources possibles de biais. Enfin, plusieurs analyses supplémentaires ont été menées, dont notamment 
un appariement sur le score de propension afin d'évaluer de façon plus approfondie l'impact de la confusion résiduelle.

Résultats: Une cohorte de 12779 patients atteints d'hypogonadisme a été constituée. Au cours de la période de suivi regroupant 58224 personnes-années, 215 patients ont été diagnostiqués avec un cancer de la prostate, correspondant à un taux d'incidence de 3,7 pour 1000 personnes-années. Comparativement à la non-utilisation, l'utilisation de TRT n'était pas associée à une augmentation globale du risque de cancer de la prostate $(3,8$ contre 3,4 pour 1000 personnes-années, respectivement ; HR ajusté = 0,97 ; IC95\% [0,71-1,32]). L'association ne variait pas selon la formulation de TRT, le nombre de prescriptions reçues et le temps écoulé depuis l'initiation, ni dans les analyses de sensibilité. Enfin, les résultats sont restés stables lors de l'analyse après appariement sur le score de propension $(\mathrm{HR}=0,87$; IC95\% $[0,56-1,36])$.

Conclusion: Dans cette étude populationnelle de cohorte, l'utilisation de TRT n'était pas associée à un risque accru de cancer de la prostate chez les hommes atteints d'hypogonadisme de survenue tardive. Dans ce contexte d'utilisation croissante de la TRT chez les hommes et d'inquiétude vis-à-vis de sa sécurité d'emploi, ces résultats se montrent rassurants quant au risque à long terme de cancer de la prostate en lien avec l'utilisation de TRT. 


\section{Chapter 1: Introduction}

Over the recent decades, there has been growing interest in late-onset hypogonadism, a condition characterized by symptomatic testosterone deficiency and biochemically low testosterone levels among ageing men. ${ }^{1}$ This condition differs from pathologic hypogonadism, which can occur in younger men due to well-established medical conditions or injuries. ${ }^{1}$ While testosterone replacement therapy (TRT) has been shown to be effective in treating pathologic hypogonadism, ${ }^{2}$ it is currently not approved for the treatment of late-onset hypogonadism given its unclear benefits and controversial safety. ${ }^{2}$ Nonetheless, due to aggressive marketing of testosterone products in the past decades, TRT use has increased markedly among middle-aged and elderly men with late-onset hypogonadism. ${ }^{3,4}$ This surge in TRT use in ageing men is occurring despite uncertainties regarding its cardiovascular safety and its potential to increase the risk of prostate cancer. ${ }^{2,5}$

Due to the well-established role of androgens in the growth and development of prostate cancer, current treatment guidelines recommend against the initiation of TRT in men with a history or known risk factors for this cancer. ${ }^{2,6}$ However, this recommendation is based on weak evidence from randomised controlled trials (RCTs) that were not designed to investigate prostate cancer as an outcome, ${ }^{7,8}$ and observational studies with methodological shortcomings that have yielded mixed findings. ${ }^{9-16}$

Taken together, there is insufficient available evidence supporting the safety of TRT in men with late-onset hypogonadism. Given the increasing use of TRT in this population, ${ }^{17}$ it is imperative to determine whether TRT is associated with an increased risk of prostate cancer. Such findings would be of interest to physicians and patients as it would provide crucial information on the long-term safety of TRT and inform future prescribing practice. 


\section{Chapter 2: Literature review}

The following chapter is divided into four sections. The first section provides an overview of male hypogonadism. The second section outlines the different testosterone formulations available to treat hypogonadism, and discusses the overall safety profile of this therapy. The third section provides an overview of prostate cancer and its association with hypogonadism. Finally, the fourth section describes the biological basis of the potential association between TRT and prostate cancer, and discusses previous research on the topic.

\subsection{Hypogonadism}

\subsubsection{Epidemiology}

The global prevalence of all types of male hypogonadism ranges between $10 \%$ and $40 \%$, and increases with age, particularly around 45 to 50 years of age. ${ }^{18}$ According to studies in middle-aged to elderly men, the prevalence of hypogonadism in North America ranges from $24-39 \%$, which is higher than other parts of the world. ${ }^{19}$ Studies conducted in Europe, namely Germany, Spain, and the United Kingdom (UK), reported a prevalence ranging from $8-20 \%$ for a similar age range. ${ }^{20}$ The prevalence of hypogonadism is difficult to estimate, however, which may explain the variation observed across countries. ${ }^{19}$ Particularly, there are differing expert opinions regarding a testosterone threshold for diagnosis, as well as the relevance of the various non-specific symptoms associated with the condition. ${ }^{19}$ The main issues involved in diagnosing hypogonadism are further discussion in section 2.1.4.

\subsubsection{Pathophysiology}

Testosterone plays a vital role in the process of sexual, cognitive and bodily development, and maintains its importance throughout the male lifespan. ${ }^{21}$ It is produced by both the testes and adrenal glands, and is crucial in ensuring proper sexual and reproductive 
function..$^{22}$ The healthy growth of male reproductive organs such as the penis, scrotum, and prostate depend on the presence of testosterone. ${ }^{22}$ Testosterone exerts visible effects at the fetal and prepubertal stages all the way through adulthood, from its involvement in sex determination and acne development to the deepening of the voice and increased muscle mass. ${ }^{21}$ It also plays a crucial role in the maintenance and modulation of aspects of reproductive health, sexual function, bone health, fat metabolism, muscle mass and strength. ${ }^{23}$ Testosterone is produced from cholesterol by testicular Leydig cells, and this production is regulated by the hypothalamic-pituitary-gonadal (HPG) axis (Figure 1). ${ }^{23,24} \mathrm{~A}$ disruption at any level of the HPG axis, and the corresponding slowing of testosterone production, can result in hypogonadism..$^{23,25}$

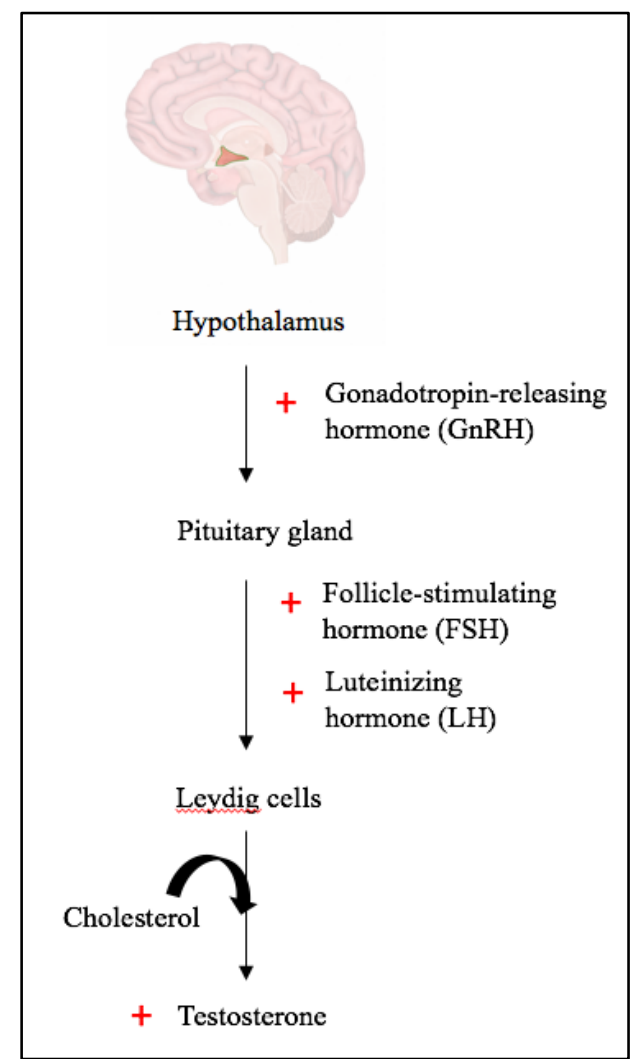

Figure 1. Testosterone production via the hypothalamic pituitary-gonadal axis. 


\subsubsection{Types}

There are two overarching types of hypogonadism: pathologic and late-onset. Both types of hypogonadism share a host of common symptoms listed in Table 1.

Table 1. Most Relevant Signs and Symptoms of Male Hypogonadism as per the European Association of Urology (EAU) and International Society for Sexual Medicine (ISSM) Guidelines

\section{Symptoms of Hypogonadism ${ }^{26,27}$}

Loss of libido

Loss of morning/night time erections

Erectile dysfunction

Ejaculatory dysfunction

Fatigue

Reduced well-being

Depression

Loss of concentration

Hot flushes

Reduced muscle mass/weakness

Reduced body hair

\subsubsection{Pathologic hypogonadism}

Pathologic hypogonadism results from an abnormality in the functioning of the male gonads, hypothalamus, and/or pituitary gland, thus affecting testosterone production. ${ }^{25}$ This condition is characterized by a symptomatic deficiency in testosterone and can affect men of all ages. ${ }^{25}$ There are two subtypes of pathologic hypogonadism: 1) primary, originating from problems in the testes, and 2) secondary, due to diseases of the hypothalamic-pituitary axis. ${ }^{25}$ Both primary and secondary hypogonadism can arise due to an inherited trait or acquired through injury or infection; the most common causes are listed in Table $2 .{ }^{25}$ In other words, both types are caused by an identifiable pathology ultimately leading to unequivocally low testosterone levels. ${ }^{28}$ 
Table 2. Common Causes of Primary and Secondary Pathologic Hypogonadism

Primary Hypogonadism

Secondary Hypogonadism

$\begin{array}{ll}\begin{array}{l}\text { Klinefelter's syndrome (congenital abnormality } \\ \text { of the sex chromosomes) }\end{array} & \begin{array}{l}\text { Kallmann syndrome (abnormal development of } \\ \text { hypothalamus) }\end{array} \\ \begin{array}{l}\text { Undescended testicles } \\ \text { Mumps orchitis (infection) }\end{array} & \begin{array}{l}\text { Inflammatory disease } \\ \text { Hemochromatosis (excess iron in blood) }\end{array} \\ \text { HIV/AIDS }\end{array}$

The distinction between primary and secondary pathologic hypogonadism can be easily identified. The current recommendation by the Endocrine Society Clinical Practice Guideline for distinguishing between primary and secondary hypogonadism is linked to the relative levels of circulating luteinizing hormone ( $\mathrm{LH})$ and follicle-stimulating hormone (FSH). ${ }^{2,29}$ In particular, primary hypogonadism is characterized by low testosterone and high $\mathrm{LH}$ and $\mathrm{FSH} .{ }^{29}$ On the other hand, secondary hypogonadism is characterized by low testosterone and normal or reduced $\mathrm{LH}$ and $\mathrm{FSH} .{ }^{29}$

\subsubsection{Late-onset hypogonadism}

There is a third type of hypogonadism referred to as late-onset hypogonadism. This condition occurs among ageing men without pathologic hypogonadism, and has been defined as "a clinical and biochemical syndrome associated with advancing age and characterized by typical symptoms and a deficiency in serum testosterone levels". ${ }^{1,30,31}$ In other words, in contrast to pathologic hypogonadism, late-onset hypogonadism appears for no other discernable reason other than older age, and similarly presents with abnormally low testosterone levels as well as signs and/or symptoms that may or may not be a result of 
lowered testosterone. ${ }^{30}$ In addition, age-related decline in testosterone levels is accelerated by chronic disease and obesity, which further complicates its diagnosis. ${ }^{32}$

\subsubsection{Diagnosis}

In general, male hypogonadism is a condition characterized by a reduction in serum testosterone, which can lead to a wide range of signs and symptoms..$^{25,33,34}$ The diagnosis of male hypogonadism is based on serum testosterone levels below $300 \mathrm{ng} / \mathrm{dl}$ as measured by a laboratory test, and the presence of at least one known clinical sign or symptom. ${ }^{21,35}$ Due to reasons of intra-individual variability, it has been recommended that low testosterone levels be confirmed by two unique laboratory measurements, as $30 \%$ of men presenting with low testosterone levels show normal levels upon a subsequent measurement. ${ }^{2,36}$ In the case of pathological hypogonadism, the low testosterone and accompanying symptoms are caused by an identifiable injury or medical condition, which makes its diagnosis relatively straightforward. ${ }^{28,30}$ In the case of an absence of a discernable pathology, however, as in lateonset hypogonadism, the diagnosis is less clear-cut. ${ }^{30}$

The diagnosis of late-onset hypogonadism on the basis of testosterone levels has presented a challenge for practicing physicians, mainly attributable to the lack of expert consensus on a threshold for diagnosis. ${ }^{37}$ Whereas the Endocrine Society requires a total testosterone level $<300 \mathrm{ng} / \mathrm{dL}$ for diagnosis, ${ }^{2}$ the European Association for Urology requires $<249 \mathrm{ng} / \mathrm{dL}$ for diagnosis. ${ }^{19}$ In addition, a threshold range between 200 and $400 \mathrm{ng} / \mathrm{dL}$ exists in the literature, making the diagnosis of hypogonadism a controversial one. ${ }^{19,38,39}$ The array of non-specific symptoms associated with hypogonadism also presents a challenge for physicians, as these symptoms are often reminiscent of other conditions such as vascular disease and type 2 diabetes. As well, physicians differ in terms of their emphasis placed on these different symptoms when assessing a patient, which could lead to conflicting 
diagnoses. ${ }^{19,40}$ Ultimately, whereas treatment decisions for pathologic hypogonadism are well-established, the ill-defined diagnostic criteria for late-onset hypogonadism leaves physicians questioning whether treatment is beneficial in this population. ${ }^{30}$

\subsubsection{Treatment}

TRT is the primary treatment option for men with hypogonadism. ${ }^{2}$ It acts by restoring levels of testosterone back to the normal physiological range, and helps improve sex characteristics and other symptoms of hypogonadism. ${ }^{2,41}$ Testosterone products have been approved by Health Canada, the Food and Drug Administration (FDA), and European Medicines Agency (EMA) for treatment among men diagnosed with pathologic hypogonadism, which has in fact long been considered the standard of care. ${ }^{30,42}$ As such, clinical guidelines recommend that testosterone replacement be initiated in men with symptomatic pathologic androgen deficiency with unequivocally low testosterone levels confirmed with repeated measurements..$^{43}$

On the other hand, TRT has not been approved by regulatory agencies for treatment in men with late-onset hypogonadism as there is insufficient available evidence supporting a benefit of testosterone replacement in this population..$^{30,42,44}$ Despite this uncertainty, the prescribing of TRT has been increasing over the recent decades, particularly among ageing men with non-pathologic testosterone deficiency. ${ }^{30}$ 


\subsection{Testosterone replacement therapy}

\subsubsection{Use and trends}

TRT prescribing has been on the rise over the past two decades..$^{3,4,17,43,45}$ In the UK, for instance, TRT prescriptions increased by $90 \%$ from 2001 to $2010 .{ }^{20}$ A study assessing the global trends of testosterone sales between 2000-2011 across 41 different countries including Canada, UK, and United States (US) showed a 12-fold increase in sales of testosterone products ( $\$ 150$ million in 2000 to $\$ 1.8$ billion in 2011). ${ }^{17}$ While there has been a wider recognition of declining testosterone levels in ageing men as well as increased marketing for testosterone replacement products, testosterone lab testing has similarly increased markedly over the past decades. ${ }^{43}$

Whereas testosterone prescribing has increased substantially over recent decades (Figure 2), the prevalence of pathologic hypogonadism has remained stable. This is then suggestive that the increase is reflecting off-label use, namely in men with symptomatic lateonset hypogonadism. In addition, despite increased lab testing for testosterone levels, substantial TRT initiation has been seen in symptomatic men without recent testing. ${ }^{43}$ Several studies associated increased testosterone prescribing with increased direct-to-consumer advertising for new testosterone formulations, with marketing efforts particularly targeted at ageing men without a clear diagnosis of hypogonadism. ${ }^{3,43,46,47}$ This surge in heavy marketing for new testosterone products has led to a greater interest in hypogonadism and its symptoms in ageing men, leading to higher testosterone prescribing in this population. ${ }^{30}$

Interestingly, it has been observed that the spike in TRT is largely due to increased uptake of transdermal TRT formulations in men with late-onset hypogonadism. ${ }^{20}$ Indeed, the recent increase in testosterone sales and prescriptions is largely coincident with the introduction of new testosterone formulations with non-invasive routes of administration. ${ }^{48}$ 
Figure 2. Estimated number of men with a prescription claim for a testosterone product from US outpatient retail pharmacies stratified according to age, 2010-2013.

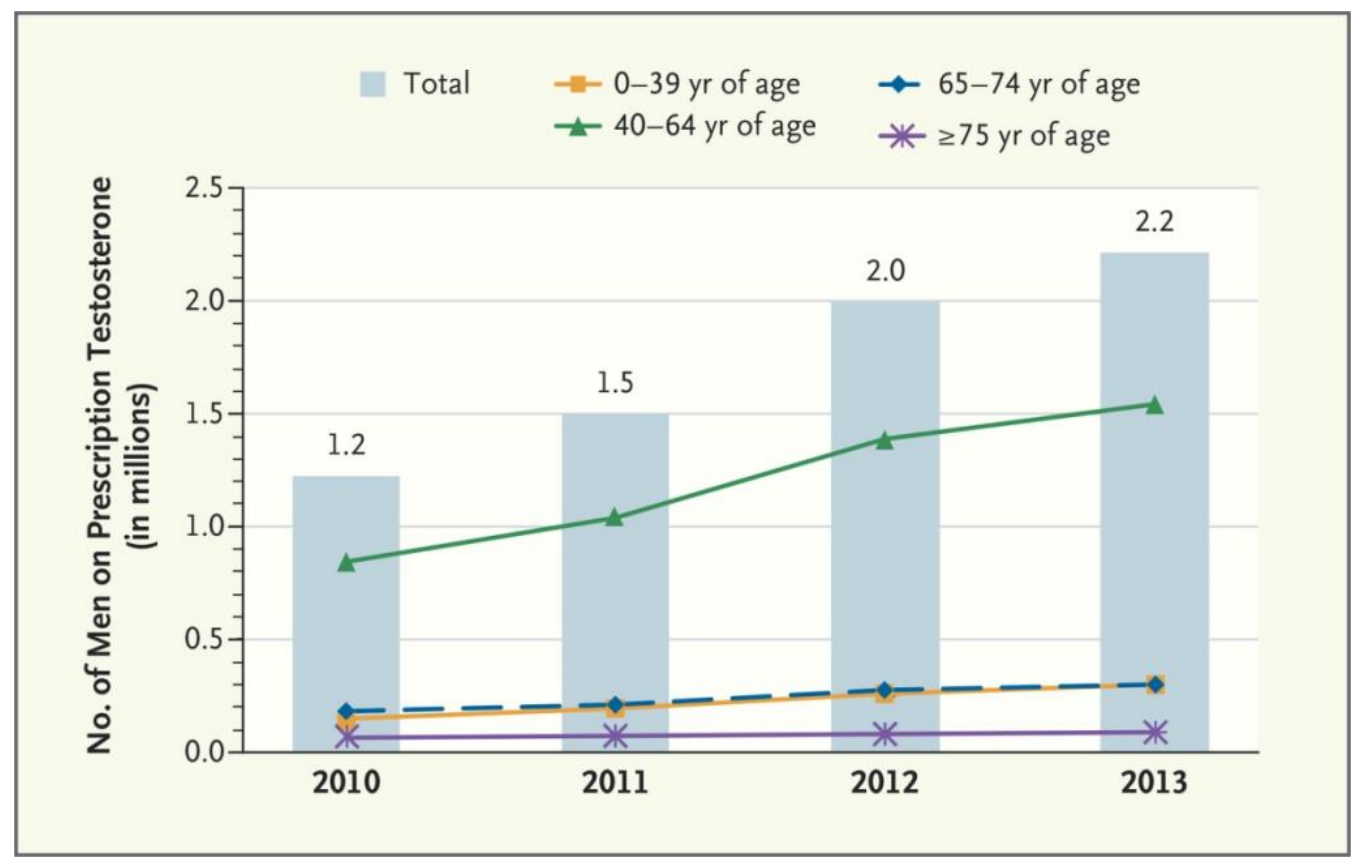

Reproduced with permission from Nguyen CP et al. N Engl J Med 2015;373:689-691., Copyright Massachusetts Medical Society.

\subsubsection{Formulation Types}

There are several different types of testosterone formulations with five main routes of administration: transdermal, oral/buccal, injection, nasal and subdermal ${ }^{43}$ Each type of formulation along with its risk/benefit profile is described below and summarized in Table 3 .

\subsubsection{Subdermal}

Subdermal implantable testosterone pellets were the first effective form of TRT to be introduced into the market in the $1940 \mathrm{~s} .{ }^{48}$ Pellets can vary in terms of dosing, ranging from 600-1200-mg of testosterone per pellet. ${ }^{2}$ The pellets consist of crystalline testosterone, and are implanted subcutaneously. ${ }^{2}$ This form of TRT guarantees adherence and requires infrequent administration, as the testosterone concentrations are typically maintained within normal range for 3-6 months after implantation. ${ }^{2,48}$ Implantable testosterone pellets carry clear 
disadvantages, however, given the need for surgical incision and complicated removal in the case of adverse side effects. ${ }^{2,48}$ Furthermore, the most common side effect is spontaneous extrusion of pellets, occurring in approximately $10 \%$ of treated men. ${ }^{2,48}$

\subsubsection{Injection}

Testosterone replacement is also available as an intra-muscular injection, in both a short- and long-acting form, first introduced in $1954 .^{2}$ The short acting form requires either a 150-200-mg IM injection every 2 weeks or 75-100-mg every week. ${ }^{2}$ It acts by inducing an initial peak in testosterone levels within normal physiological ranges, which then declines gradually until the end of the dosing interval. ${ }^{2}$ While this form is relatively inexpensive and can be self-administered, the shifts in testosterone concentrations has been associated with adverse side effects, such as fluctuating hypogonadal symptoms. ${ }^{2}$

On the other hand, the long-acting form requires the following treatment regimen: 750-mg IM initial injection, followed by 750-mg at 4 weeks, and ultimately 750-mg every 10 weeks. ${ }^{2}$ Although the long-acting form requires a very large volume for initial injection, the administration is less frequent and the large dose allows the testosterone levels to be maintained within normal range throughout the course of treatment. ${ }^{2}$

Overall, the disadvantage of this route of TRT administration in both short- and longacting forms is the need for IM injection, which is invasive and can sometimes trigger severe pain at the site of injection. ${ }^{48}$

\subsubsection{Transdermal}

The transdermal formulation is a non-invasive method of administration whereby the drug is applied in direct contact with the skin and is absorbed in a controlled fashion into the systemic circulation. ${ }^{49}$ There are two types of TRT that act through this route of 
administration: 1) patches, introduced in 1994, and 2) topical gels, introduced in $2000 .{ }^{49}$ The daily dose for a patch is between 2-4mg, whereas the daily dose for gels can be up to 70100mg. ${ }^{48}$ Despite the risk of secondary transfer, the testosterone gels are often preferred over the patches as the latter are associated with reduced efficacy due to poor adherence as well as discontinuation due to skin reactions. ${ }^{48}$ Indeed, as alluded to in the previous section, the testosterone gel formulations are the most commonly prescribed TRT in both the US and UK in the recent decades. ${ }^{41,43}$

\subsubsection{Oral/buccal}

There are also oral and buccal forms of testosterone administration, via capsules and mucoadhesive tablets, respectively. ${ }^{48}$ Currently, there are no oral testosterone formulations approved by the US FDA, due to variable clinical responses as well as previously reported gastrointestinal and liver adverse events. ${ }^{2,48}$ Nevertheless, one oral testosterone formulation is still available outside of the US. ${ }^{2}$ Mucoadhesive tablets, introduced into the marked in 2003, are applied to the gum inside the mouth twice daily, and deliver a total of 30-mg testosterone directly into the systematic circulation via controlled release. Buccal testosterone tablets have been shown to be relatively well-tolerated in RCTs, with only $15 \%$ of treated men experiencing minor gum-related adverse events. ${ }^{2,48}$

\subsubsection{Nasal}

The newest form of TRT is the nasal gel formulation, which was approved and introduced into the market in $2014 .{ }^{48}$ This product contains a dose pump applicator enabling it to be easily self-administered, and requires 2-3 doses daily. ${ }^{38,48,50}$ Each dose is relatively low, with $5.5 \mathrm{mg}$ testosterone per pump, totalling to $11 \mathrm{mg}$ after being administered into each nostril, as recommended. ${ }^{48}$ This non-invasive and simple form of TRT comes with minimal 
nasal side effects in a small proportion of treated men. ${ }^{2}$ In addition, contrary to the gel formulation, nasal TRT has a very low risk of secondary transference making it a reasonable non-invasive alternative. ${ }^{50}$

Table 3. Summary of Testosterone Routes of Administration, Dosing, Advantages and Disadvantages

\begin{tabular}{|c|c|c|c|c|}
\hline Route & Year introduced & Typical daily dosing & Advantages & Disadvantages \\
\hline Subdermal & 1940 & $600-1200 \mathrm{mg} / \mathrm{pellet}$ & $\begin{array}{l}\text { Guaranteed adherence } \\
\text { Infrequent } \\
\text { administration }\end{array}$ & $\begin{array}{l}\text { Requirement of } \\
\text { surgical incision } \\
\text { Potential } \\
\text { spontaneous } \\
\text { extrusion of pellet }\end{array}$ \\
\hline \multirow[t]{3}{*}{ Injection } & \multirow[t]{3}{*}{1954} & $\begin{array}{l}\text { Short-acting: } \\
\text { - 150-200mg/2 weeks } \\
\text { - 75-100mg/week }\end{array}$ & $\begin{array}{l}\text { Short-acting: } \\
\text { - Relatively } \\
\text { inexpensive } \\
\text { - Self-administration }\end{array}$ & $\begin{array}{l}\text { Short-acting: } \\
\text { - Fluctuating } \\
\text { hypogonadal } \\
\text { symptoms }\end{array}$ \\
\hline & & $\begin{array}{l}\text { Long-acting: } \\
\text { - 750mg initial } \\
\text { - 750mg at } 4 \text { weeks } \\
\text { - 750mg every } 10 \text { weeks } \\
\text { thereafter }\end{array}$ & \multirow[t]{2}{*}{$\begin{array}{l}\text { Long-acting: } \\
\text { - Infrequent } \\
\text { administration } \\
\text { - Testosterone levels } \\
\text { maintained within } \\
\text { normal range } \\
\text { throughout course of } \\
\text { treatment; }\end{array}$} & $\begin{array}{l}\text { Long-acting: } \\
\text { - Large volume } \\
\text { for initial } \\
\text { injection } \\
\text { - Potential } \\
\text { coughing } \\
\text { episode after } \\
\text { injection }\end{array}$ \\
\hline & & & & $\begin{array}{l}\text { Both: } \\
\text { - Invasive } \\
\text { - Potential for } \\
\text { severe pain at } \\
\text { site of injection }\end{array}$ \\
\hline \multirow[t]{4}{*}{ Transdermal } & Patch: 1994 & Patch: $2-4 \mathrm{mg}$ & \multirow{2}{*}{$\begin{array}{l}\text { Patch: } \\
\text { - Ease of application }\end{array}$} & \multirow{4}{*}{$\begin{array}{l}\text { Patch: } \\
\text { - Skin irritation at } \\
\text { application site } \\
\text { - Poor adherence } \\
\text { Gel: } \\
\text { - Potential } \\
\text { secondary } \\
\text { transfer by skin- } \\
\text { to-skin contact }\end{array}$} \\
\hline & \multirow[t]{3}{*}{ Gel: 2000} & \multirow[t]{3}{*}{ Gel: $70-100 \mathrm{mg}$} & & \\
\hline & & & $\begin{array}{l}\text { Gel: } \\
\quad \text { - Ease of application }\end{array}$ & \\
\hline & & & $\begin{array}{l}\text { - Flexibility of } \\
\text { dosing } \\
\text { - } \quad \text { Good skin } \\
\text { tolerability }\end{array}$ & \\
\hline Oral/buccal & 2003 & $30 \mathrm{mg}$ & $\begin{array}{l}\text { Convenient application } \\
\text { Discreet }\end{array}$ & $\begin{array}{l}\text { Gum-related } \\
\text { adverse events }\end{array}$ \\
\hline Nasal & 2014 & $2-3$ doses of $11 \mathrm{mg}$ & Ease of administration & $\begin{array}{l}\text { Minimal nasal side } \\
\text { effects }\end{array}$ \\
\hline
\end{tabular}




\subsubsection{Safety profile}

As discussed in section 2.1.5., TRT is the main and most effective treatment option for men with pathologic hypogonadism, having been approved for use in this population by regulatory agencies including Health Canada, FDA, and EMA. ${ }^{30,42}$ However, restoration of testosterone levels in ageing men with late-onset hypogonagism is unauthorized in North America and Europe. ${ }^{5,42}$ In fact, it is required that testosterone product manufacturers ensure that labelling is clear regarding the approved uses of the medication. ${ }^{5,42}$ In other words, the use of TRT in men with late-onset hypogonadism comes with unclear benefits and a controversial safety profile..$^{30}$

Common concerns have been regarding the cardiovascular and cerebrovascular safety of TRT. The first study to motivate these concerns was the Testosterone in Older Men (TOM) trial, which reported an increased risk of cardiovascular events in the TRT versus placebo group, and was in fact discontinued because of this imbalance. ${ }^{51}$ In contrast, other RCTs have consistently reported no association between exogenous testosterone and cardiovascular events. ${ }^{44,51-53}$ Observational studies have similarly reported conflicting findings. While some reported an increased risk of cardiovascular outcomes with testosterone therapy, ${ }^{54-56}$ others reported a null or even protective association. ${ }^{57-60} \mathrm{~A}$ brief overview of the main studies on the topic is summarized in Table 4. After reviewing the evidence, Health Canada, FDA, and EMA issued a drug safety communication and a labeling change in 2015 to reflect the potential risk of cardiovascular events with the use of testosterone products. ${ }^{5}$

Further safety concerns have been surrounding TRT and its potential to increase the risk of prostate cancer (discussed in detail in section 2.4.). Current treatment guidelines recommend against the initiation of TRT in men with known risk factors or a history of prostate cancer, and suggest that physicians monitor PSA levels over the course of the first year of treatment. ${ }^{2,29}$ 
Table 4. Summary of main studies addressing the association between TRT use and cardiovascular outcomes

Year Main outcome Measure of effect

\section{Randomised controlled trials}

\begin{tabular}{|c|c|c|c|}
\hline Emmelot-Vonk et al. ${ }^{53}$ & 2008 & $\begin{array}{l}\text { Safety of TRT } \\
\text { compared to placebo }\end{array}$ & $\begin{array}{l}\text { No difference in cardiovascular-related } \\
\text { adverse events between the groups }\end{array}$ \\
\hline Basaria et al. ${ }^{51}$ & 2010 & $\begin{array}{l}\text { Safety and efficacy of } \\
\text { TRT compared to } \\
\text { placebo }\end{array}$ & $\begin{array}{l}23 \text { in the testosterone group versus } 5 \text { in } \\
\text { the placebo had cardiovascular-related } \\
\text { adverse events }\end{array}$ \\
\hline Snyder et al. ${ }^{44}$ & 2016 & $\begin{array}{l}\text { Risks and benefits of } \\
\text { TRT compared to } \\
\text { placebo }\end{array}$ & $\begin{array}{l}\text { No difference in cardiovascular-related } \\
\text { adverse events between the groups }\end{array}$ \\
\hline
\end{tabular}

\section{Observational studies}

\begin{tabular}{|c|c|c|c|}
\hline Vigen et al. ${ }^{55}$ & 2013 & $\begin{array}{l}\text { All-cause mortality, MI, } \\
\text { ischemic stroke }\end{array}$ & HR: 1.29 (95\% CI: 1.04-1.58) \\
\hline Finkle et al. ${ }^{54}$ & 2014 & Acute non-fatal MI & RR: 1.36 (95\% CI: 1.03-1.81) \\
\hline Etminan et al. ${ }^{59}$ & 2015 & MI & RR: 1.01 (95\% CI: 0.89-1.16) \\
\hline Sharma et al. ${ }^{57}$ & 2015 & $\begin{array}{l}\text { MI, stroke, all-cause } \\
\text { mortality }\end{array}$ & $\begin{array}{l}\text { MI - HR: } 0.76 \text { (95\% CI: 0.63-0-93) } \\
\text { Stroke - HR: } 0.64 \text { (95\% CI: 0.43-0.96) } \\
\text { All-cause mortality - } \\
\text { HR: } 0.44 \text { (95\% CI: 0.42-0.46) }\end{array}$ \\
\hline Maggi et al. ${ }^{61}$ & 2016 & Cardiovascular safety & $\begin{array}{l}\text { Cardiovascular event rates were not } \\
\text { statisitically different between the TRT } \\
\text { treated and untreated group }(\mathrm{P}=.70)\end{array}$ \\
\hline Martinez et al. ${ }^{62}$ & 2016 & $\begin{array}{l}\text { Venous } \\
\text { thromboembolism }\end{array}$ & HR: 1.25 (95\% CI: 0.94-1.66) \\
\hline Wallis et al. ${ }^{60}$ & 2016 & Cardiovascular safety & HR: 0.84 (95\% CI: 0.72-0.98) \\
\hline Cheetham et al. ${ }^{58}$ & 2017 & $\begin{array}{l}\text { Composite of } \\
\text { cardiovascular } \\
\text { endpoints }\end{array}$ & HR: 0.67 (95\% CI: 0.62-0.73) \\
\hline Loo et al. ${ }^{56}$ & 2019 & $\begin{array}{l}\text { Ischemic stroke, } \\
\text { transient ischemic } \\
\text { attack, MI }\end{array}$ & HR: 1.21 (95\% CI: 1.00-1.46) \\
\hline
\end{tabular}




\subsection{Prostate cancer}

\subsubsection{Epidemiology and etiology}

Prostate cancer is the second most frequently diagnosed cancer and the fifth leading cause of cancer mortality among men worldwide. ${ }^{63}$ Moreover, it remains as the number one most diagnosed cancer among men in the Americas, North and Western Europe, Australia/New Zealand, and parts of Sub-Saharan Africa. ${ }^{63}$ Each year, there are nearly 21,300 new cases of prostate cancer diagnosed in Canada, more than 160,000 new cases in the US, and more than 47,700 new cases in the UK. ${ }^{64-66}$ The most well-established risk factors for prostate cancer are older age, black race, and having a first-degree relative with prostate cancer. $^{67}$

\subsubsection{Pathophysiology}

The growth and development of prostate cancer is contingent on the activity of androgens and the androgen receptor. ${ }^{6,68}$ Specifically, testosterone and dihydrotestosterone exert their effects by binding to the androgen receptor, and initiating a downstream pathway involving co-regulators and growth factors. ${ }^{6}$ This pathway remains important in prostate carcinogenesis, and up to $90 \%$ of cases depend on androgens. ${ }^{6}$

Approximately $95 \%$ of all prostate cancers are adenocarcinomas, which are initiated in the gland cells. ${ }^{69}$ Other prostate malignancies are more rare, such as urothelial carcinoma, sarcoma, small cell carcinoma, carcinoid tumours, and squamous cell carcinoma. ${ }^{69}$

\subsubsection{Screening and diagnosis}

Screening for prostate cancer is performed by prostate-specific antigen (PSA) tests or digital rectal examination. ${ }^{70}$ If PSA levels are abnormally high in PSA tests , or if abnormalities are detected during digital rectal examination, a histological examination of the 
prostatic tissue must be conducted to confirm a diagnosis. ${ }^{69}$ Despite the available screening tools, most prostate cancer cases are diagnosed because of presentation of symptoms rather than routine screening. ${ }^{69}$ In fact, countries such as the UK do not have a formal prostate cancer screening programme altogether due to considerable controversy surrounding overdiagnosis and over-treatment. ${ }^{70-72}$ For example, there have been potential harms associated with routine PSA screening, such as the risk of adverse effects of subsequent prostate biopsies, anxiety, false-positives, as well as over-diagnosis and unnecessary treatment of lowrisk cancers that would not have caused harm throughout the patient's lifetime. ${ }^{73,74}$

Given the many potential harms and inconsistent evidence of a modest mortality benefit with PSA screening, some countries have recently released statements advising against existing prostate screening programmes. For instance, the US Preventative Services Task Force released a recommendation that men over 70 years of age should not undergo PSA screening due to the associated harms. ${ }^{75}$ Moreover, it states that those between 55 and 69 at high risk of the disease may undergo PSA testing only on a strictly individual-basis, whereby all the risks of screening are understood and considered before making a decision. ${ }^{75}$ Likewise, the Canadian Task Force on Preventative Health Care recommends against PSA screening in men of all ages, with the exception of those at a higher risk, due to similar concerns with the many associated harms which outweigh the small mortality benefit. ${ }^{76}$

\subsubsection{Treatment}

Common treatments for prostate cancer include radical prostatectomy (surgical removal of the prostate gland), radical radiotherapy (such as external-beam radiation therapy or interstitial radiation therapy (brachytherapy)), and androgen deprivation therapy (ADT). ${ }^{77}$ For low-risk localised prostate cancer (Gleason score $\leq 6$, stage T1 to T2), active surveillance (or "watchful waiting") is often offered as an option instead of treatment, during 
which patients are regularly monitored. ${ }^{78}$ If the disease presents as high risk (Gleason score $\geq$ 7, stage T3), then patients qualify for curative treatment and are treated with radical prostatectomy or with radiation therapy alone or in combination with ADT. ${ }^{78}$ More aggressive or metastatic cases (stage T4) may receive ADT as the sole treatment. ${ }^{78}$

Although active surveillance aims to reduce overtreatment of early detected low-risk cancers, it is not perceived as a reasonable approach by patients given the stress associated with a cancer diagnosis. ${ }^{79,80}$ Thus, many physicians opt for the more radical treatment options, which are more invasive and come with a range of serious side effects including loss of sexual function, infertility, and urinary incontinence. ${ }^{73}$ Ultimately, given the side effects of treatment, and the very high prevalence of prostate cancer, minimizing the risk of this disease would be widely beneficial.

\subsubsection{Prostate cancer and hypogonadism}

There is some evidence that low testosterone levels may be associated with a lower risk of prostate cancer. ${ }^{81,82}$ Indeed, one study associated hypogonadal levels of testosterone with a $49 \%$ decreased risk of prostate cancer compared to men with normal testosterone levels. ${ }^{81}$ Another study found a $23 \%$ decreased risk of prostate cancer compared to men with higher testosterone concentrations. ${ }^{82}$ According to this logic, increasing testosterone concentrations may in turn have the potential to increase the risk of prostate cancer. ${ }^{83}$ The next section (section 2.4.1.) will discuss potential mechanisms by which TRT may increase the risk of prostate cancer. 


\subsection{Testosterone replacement therapy and the risk of prostate cancer}

\subsubsection{Biological basis}

The notion that testosterone contributes to the development and progression of prostate cancer has been a longstanding and widely accepted phenomenon in the medical community. ${ }^{83}$ This theory dates back to 1941 , when Huggins and Hodges demonstrated that castration led to regression of metastatic prostate cancer, while testosterone administration resulted in prostate cancer growth. ${ }^{84}$ Thus, the "androgen hypothesis" asserts that prostate cancer incidence and progression is primarily driven by androgens. ${ }^{83}$ Indeed, studies have shown that higher levels of testosterone was associated with an increased incidence of prostate cancer, and administration of exogenous testosterone has been shown to stimulate growth of metastatic prostate cancer. ${ }^{81}$ Similarly, clinically low testosterone levels, or hypogonadism, is associated with a decreased development and progression of prostate cancer. ${ }^{81,82}$ Furthermore, androgen deprivation therapy is essentially the induction of hypogonadism via androgen ablation, which remains a mainstay treatment option for men with prostate cancer.$^{85}$ As a whole, the androgen hypothesis implies that prostate growth is sensitive to circulating testosterone concentrations, and suggests that TRT may have the ability to increase the risk of prostate cancer development or progression. ${ }^{81}$

A competing hypothesis comes from the recently proposed "saturation model", which challenges this association between testosterone and prostate cancer ${ }^{86}$ This model states that the prostate is sensitive to testosterone only at low serum concentrations, after which it becomes progressively insensitive at increasing testosterone levels. The theory asserts that the androgen receptors will reach an eventual point of "saturation", whereby testosterone can have no further effect on the prostate. ${ }^{87}$ This new model has prompted many authors to make general claims about the relationship between testosterone levels and prostate cancer, and recommend that TRT be considered for a wider scope of symptomatic hypogonadal 
patients. ${ }^{86,88,89}$ Importantly, however, this shift in view has been grounded on studies failing to show an increased risk of prostate cancer in men receiving TRT, which have been limited in size and duration. ${ }^{86,89}$

Taken together, these two conflicting hypotheses do not explain the varying results found in observational studies investigating the risk of prostate cancer with the use of TRT (described in section 2.4.3.), nor do they offer reassurance for the long-term safety of TRT in men presenting with late-onset hypogonadism. Additionally, RCTs assessing the safety and efficacy of TRT have reported no association with prostate cancer (described in section 2.4.2.), but were limited by inappropriate study design and insufficient power to assess cancer as a safety outcome. ${ }^{7,8}$ Due to the high number of men on this therapy, and the contradictory beliefs regarding its prostate safety, further research in this area is warranted.

\subsubsection{Randomised controlled trials}

There was one RCT which investigated the association between TRT use and prostate safety specifically. ${ }^{8}$ This trial included 44 men with confirmed low testosterone levels randomised to either TRT or placebo for a period of 6 months. ${ }^{8}$ Outcome measures included changes in prostate tissue androgen levels, as well as prostate-related clinical features, such as changes in serum PSA levels. ${ }^{8}$ The authors observed that TRT use had little effect on prostate tissue over the 6 month time window. ${ }^{8}$

More generally, other RCTs have investigated the safety and efficacy of TRT, with the longest follow-up being up to 12 months. ${ }^{51,90,91}$ Similarly, in these trials, there were no imbalances in prostate cancer events between the TRT and placebo groups. ${ }^{51,90,91}$ Moreover, a systematic review and meta-analysis of RCTs on the topic reported that TRT use did not appear to promote prostate cancer on the short-term. ${ }^{7}$ Taken together, the data from the RCTs 
were only preliminary, and longer durations of TRT use as well as adequate power are required to confirm these findings.

\subsubsection{Previous observational studies}

To date, there have been 8 observational studies assessing the association between TRT and prostate cancer (Table 5) ${ }^{9-16}$ However, these studies had important methodological shortcomings, including potential confounding by indication, potential detection bias, inappropriate comparators, and immortal time bias, thereby limiting the interpretability of the published results.

Three previous registry studies by Coward et al., ${ }^{9}$ Feneley et al., ${ }^{12}$ and Haider et al., ${ }^{13}$ did not include an appropriate comparator group. Coward et al. ${ }^{9}$ evaluated the incidence of prostate cancer among 81 men with hypogonadism initiating TRT. ${ }^{9}$ Four of the 81 men (4.9\%) developed prostate cancer after a mean (range) follow-up of 32.5 (22-41) months after starting TRT. The authors concluded that the incidence of prostate cancer in men taking TRT is no greater than that of the general population. ${ }^{9}$ Feneley et al. ${ }^{12}$ drew a similar conclusion in a study following 1,365 hypogonadal men receiving TRT. ${ }^{12}$ With a follow-up of up to 20 years, 14 new cases of prostate cancer were diagnosed. This led the authors to conclude that the incidence of prostate cancer in men on long-term testosterone treatment is equivalent to that expected in the general population. ${ }^{12}$ The third study by Haider et al. ${ }^{13}$ studied 1,023 hypogonadal men from 3 different registries receiving TRT. Similarly, 11 prostate cancer cases were diagnosed, which led the authors to conclude that testosterone treatment did not increase the risk of prostate cancer compared to the general population. ${ }^{13}$ For all three studies, the lack of an appropriate comparator group severely limits the interpretability of the findings, especially given that hypogonadal men may be at a lower risk of prostate cancer than healthy men from the general population. ${ }^{92}$ 
Eisenberg et al. ${ }^{11}$ used the Urology Clinic Hormone Database linked to the Texas Cancer registry to determine the incidence of prostate cancer in hypogonadal men treated with TRT. ${ }^{11}$ Overall, 47 of 247 men on TRT developed prostate cancer, and 27 of 211 men not on TRT developed prostate cancer, generating an HR of 1.0, 95\% CI: $0.57,1.90 .{ }^{11}$ Yassin et al. ${ }^{16}$ conducted a study using a cohort of 553 patients, consisting of 42 treated and 162 untreated hypogonadal men, and 349 eugonadal men. ${ }^{16}$ The authors calculated proportions of those with positive biopsies, and reported that $16.7 \%$ of treated hypogonadal men, $51.9 \%$ of untreated hypogonadal men, and $37.8 \%$ eugonadal men had positive biopsies. ${ }^{16}$ To conclude, by direct comparison of proportions only, the authors stated that TRT might have a protective effect against high-grade prostate cancer. ${ }^{16}$ However, in both studies, there was no adjustment for important confounders, such as age and smoking, which may have severely impacted the results. ${ }^{11,16}$

In a study by Loeb et al., ${ }^{14}$ the authors used a nested case-control design within the National Prostate Cancer Register of Sweden, which included 38,570 prostate cancer cases diagnosed between 2009 and 2012, and 192,838 age-matched controls. The authors found no association between TRT and overall risk of prostate cancer (odds ratio $=1.03,95 \%$ CI: 0.90 , 1.17). ${ }^{14}$ However, this overall point estimate may simply be a result of two biases pulling in opposite directions. This is made clearer in secondary analyses, where $<1$ year of TRT use was associated with an increased risk of low- to intermediate-risk prostate cancer (defined by PSA $<20 \mathrm{ng} / \mathrm{mL}$, stage T1 to T2, Gleason score $\leq 7$ - odds ratio $=1.61,95 \%$ CI: $1.10,2.34$ ), and $>1$ year of TRT use was associated with a decreased risk of high-risk or metastatic prostate cancer (defined by PSA $20-50 \mathrm{ng} / \mathrm{mL}$, stage T1 to T2, Gleason score 8-10; PSA <50 ng/mL, T3; PSA 50-100 ng/mL, T4; and metastases or PSA > 100 ng/mL- odds ratio = 0.44, 95\% CI: $0.32,0.61) .{ }^{14}$ The increased risk of low- to intermediate-risk prostate cancer may be suggestive of detection bias, in which there is an over-detection of early prostate cancer cases 
in the TRT group, potentially attributable to more frequent physician contact and monitoring upon treatment initiation. ${ }^{14}$ In contrast, the very strong protective effect observed with $>1$ year of TRT use may be highly suggestive of confounding by indication. ${ }^{14}$ Specifically, it is likely that the vast majority of the age-matched controls from the general male Swedish population consisted of non-hypogonadal men. ${ }^{14}$ This is an issue given that non-hypogonadal men do not have the indication for TRT, and may be at a differential risk of prostate cancer compared to hypogonadal men. ${ }^{92}$ Thus, the two major potential biases in this study may be influencing the overall findings. ${ }^{14}$

Debruyne et al. ${ }^{10}$ used the Registry of Hypogonadism in Men (RHYME) consisting of data on treated and untreated men newly-diagnosed with hypogonadism to investigate several prostate health indicators, including rates of prostate cancer diagnoses. ${ }^{10}$ The study included 999 men, $75 \%$ of which initiated TRT. ${ }^{10}$ The authors calculated an incidence rate ratio (IRR) for treated compared to untreated men (IRR $=0.52,95 \% \mathrm{CI}: 0.22,1.26)$, and concluded that there was no increased prostate cancer risk associated with TRT. ${ }^{10}$ However, this study may have suffered from immortal time bias (Figure 3). ${ }^{10,93}$ Indeed, an exposure definition was used whereby men were considered exposed if they were on active TRT at one or more visits over the follow-up period. ${ }^{10}$ According to this definition, TRT users necessarily had to survive up to the point of having one or two visits to be considered exposed. ${ }^{10}$ Consequently, the time up to the visit was immortal and was misclassified as exposed person-time, downwardly biasing the IRR. ${ }^{10,93}$ 


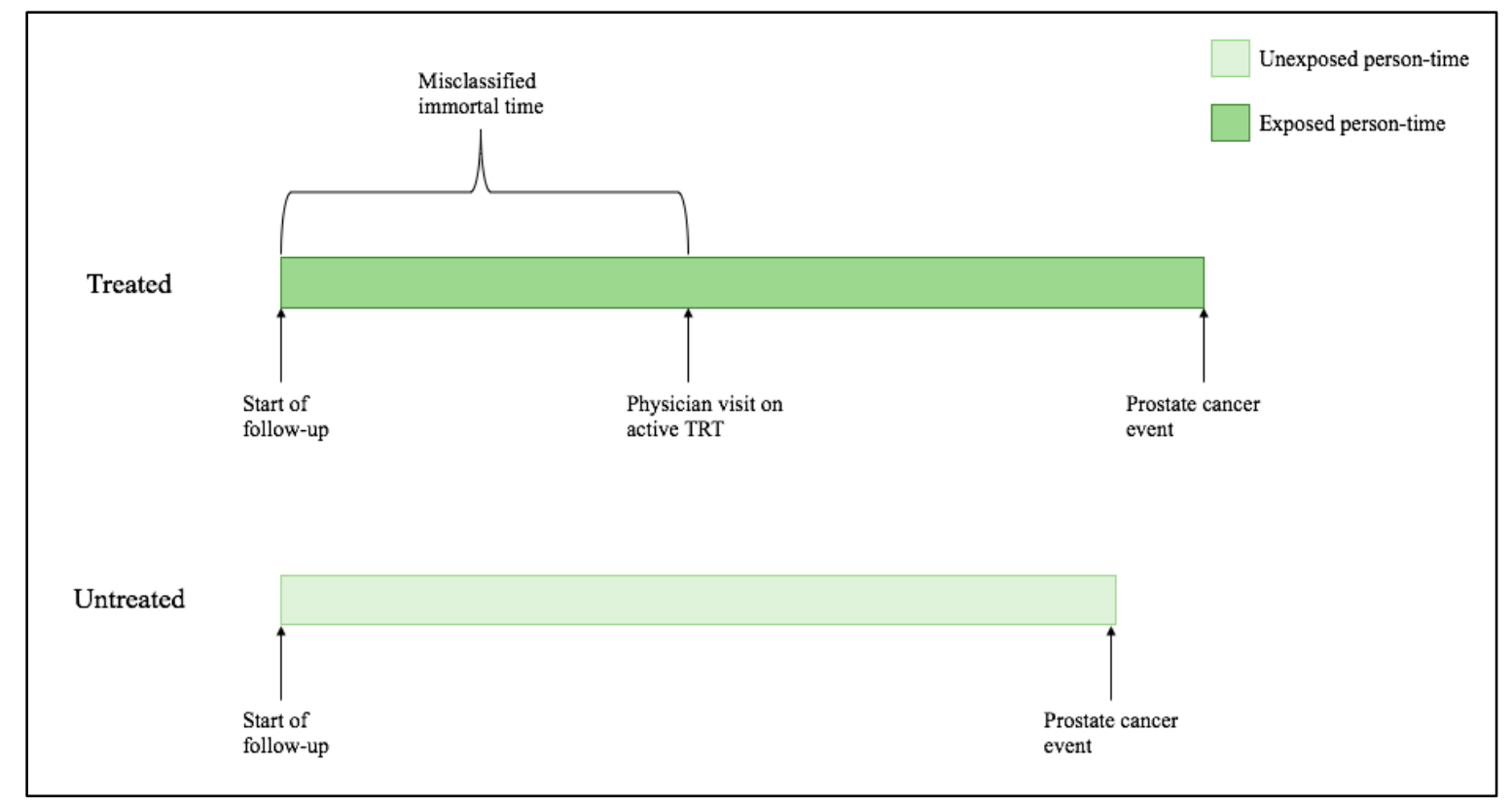

Figure 3. Illustration of immortal time bias, whereby the immortal person-time up to the point of the first physician visit in the treated group is misclassified as exposed person-time.

In a more recent study by Walsh et al., ${ }^{15}$ a retrospective cohort was used including hypogonadal male veterans aged 40 to 89 years old with a laboratory-defined low testosterone measurement and recent PSA testing from 2002 to 2011. In a cohort of 147,593 men, TRT was not associated with incident aggressive prostate cancer (defined by SEER Summary Stage $=7$, American Joint Committee on Cancer Stage Group = 4, any metastasis, tumor grade $=4$, Gleason score $\geq 8$, or PSA $\geq 20 \mathrm{ng} / \mathrm{dL}-\mathrm{HR}=0.89 ; 95 \%$ CI: $0.81,1.01) .{ }^{15}$ While this was a fairly large and well-conducted study, the authors failed to lag the exposure to account for cancer latency. Furthermore, failure to lag the exposure could have also introduced detection bias and reverse causality. ${ }^{15}$ Indeed, increased detection of prostate cancer events could occur around the time of treatment initiation, due to more frequent physician contact and monitoring of patients on the therapy. ${ }^{15}$ In addition, these early cases that occur shortly after TRT initiation are unlikely to be related to TRT use, and likely developed before the start of treatment. Thus, lagging exposure would account for this by treating person-time within this time window as unexposed. Finally, the exposure lag would 
further account for potential reverse causality, which is a result of the termination of TRT due to early signs or symptoms of prostate cancer. An illustration of an exposure lag window and examples of prostate cancer events are provided in Figure 4.

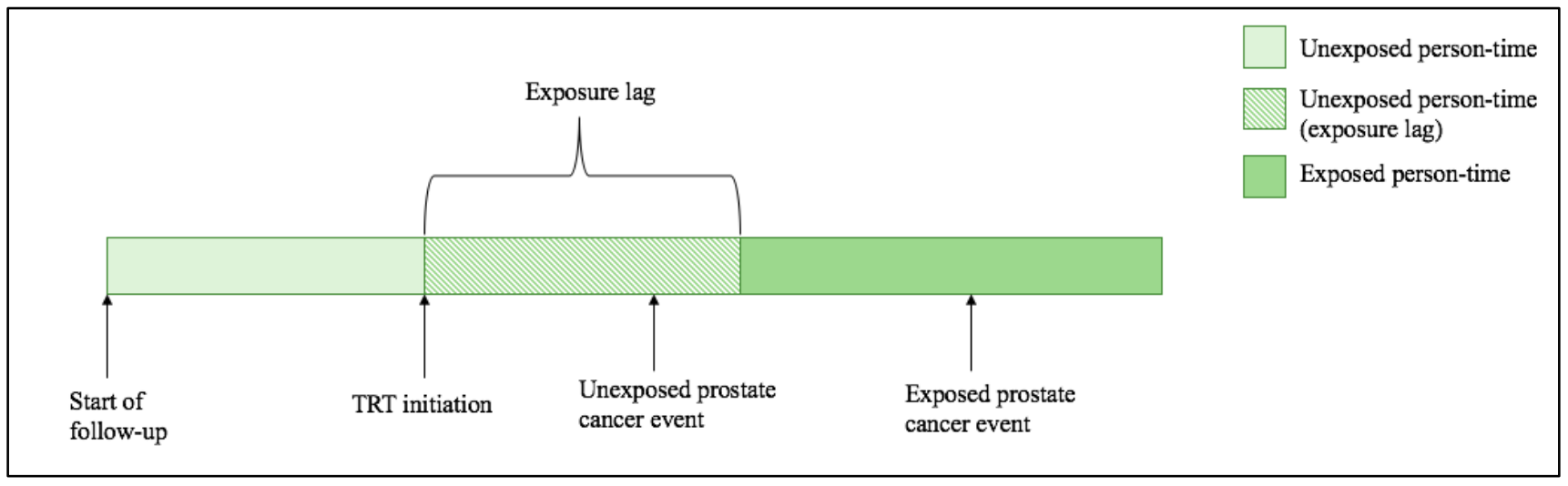

Figure 4. Illustration of an exposure lag window, during which prostate cancer events are considered unexposed

\subsubsection{Summary of observational studies}

To conclude, the available evidence on the association between TRT and prostate cancer is inconclusive. ${ }^{9-16}$ In particular, confounding, potential immortal time bias and detection bias, as well as inappropriate comparators limit the interprebability of the published studies. Nevertheless, increasing numbers of prescriptions are being seen globally, largely in men with late-onset hypogonadism. ${ }^{17,43}$ Thus, further study addressing the limitations of the previous studies is imperative in order to ensure the long-term safety of this therapy. The remainder of this thesis will outline the details of a study assessing the association between TRT and prostate cancer in men with late-onset hypogonadism using a population-based cohort design. 
Table 5. Summary of Previous Observational Studies

\begin{tabular}{|c|c|c|c|c|c|c|}
\hline Authors & Year & Sample size & Study design & Incidence rate $(95 \%$ CI) & Measure of effect & Main Limitation \\
\hline Coward et al. ${ }^{9}$ & 2008 & 81 & $\begin{array}{l}\text { Retrospective } \\
\text { cohort study }\end{array}$ & Not reported & $\begin{array}{l}4 \text { out of } 81(4.9 \%) \text { developed } \\
\text { prostate cancer }\end{array}$ & No comparator \\
\hline Feneley et al. ${ }^{12}$ & 2012 & 1,365 & $\begin{array}{l}\text { Prospective } \\
\text { cohort study }\end{array}$ & Not reported & $\begin{array}{l}14 \text { out of } 1,365(1.0 \%) \\
\text { developed prostate cancer }\end{array}$ & No comparator \\
\hline Haider et al. ${ }^{13}$ & 2015 & 1,023 & $\begin{array}{l}\text { Prospective } \\
\text { cohort study }\end{array}$ & 54.4 per 10,000 person-years & $\begin{array}{l}11 \text { out of } 1,023(1.1 \%) \\
\text { diagnosed with prostate cancer }\end{array}$ & No comparator \\
\hline Eisenberg et al. ${ }^{11}$ & 2015 & 458 & $\begin{array}{l}\text { Retrospective } \\
\text { cohort study }\end{array}$ & Not reported & HR: 1.0 (95\% CI: 0.57-1.9) & No confounder adjustment \\
\hline Yassin et al. ${ }^{16}$ & 2017 & 553 & $\begin{array}{l}\text { Cross-sectional } \\
\text { study }\end{array}$ & Not reported & $\begin{array}{l}16.7 \% \text { of treated men had } \\
\text { positive prostate cancer } \\
\text { biopsies }\end{array}$ & No confounder adjustment \\
\hline Loeb et al. ${ }^{14}$ & 2017 & $\begin{array}{l}38,570 \text { cases } \\
192,838 \\
\text { controls }\end{array}$ & $\begin{array}{l}\text { Nested case- } \\
\text { control study }\end{array}$ & Not reported & OR: 1.03 (95\% CI: 0.90-1.17) & Confounding by indication \\
\hline Debruyne et al. ${ }^{10}$ & 2017 & 999 & $\begin{array}{l}\text { Prospective } \\
\text { cohort study }\end{array}$ & $\begin{array}{l}1221.4 \text { per } 100,000 \text { person- } \\
\text { years }\end{array}$ & IRR: 0.52 (95\% CI: 0.22-1.26) & Immortal time bias \\
\hline Walsh et al. ${ }^{15}$ & 2018 & 147,593 & $\begin{array}{l}\text { Retrospective } \\
\text { cohort study }\end{array}$ & $\begin{array}{l}0.58 \text { per } 1000 \text { person-years } \\
(0.48-0.69)\end{array}$ & HR: 0.90 (95\% CI: 0.81-1.01) & No exposure lag \\
\hline
\end{tabular}




\section{Chapter 3: Objectives and hypotheses}

\subsection{Objective}

The primary objective of this thesis is to determine whether the use of TRT, when compared with non-use, is associated with an increased risk of prostate cancer among men with lateonset hypogonadism.

\subsubsection{Secondary objectives}

This thesis has three secondary objectives:

1. To determine whether there is an association between TRT formulation and prostate cancer risk.

2. To determine whether there is an association between cumulative number of TRT prescriptions and prostate cancer risk.

3. To determine whether there is an association between time since TRT initiation and prostate cancer risk.

\subsection{Hypothesis}

The primary hypothesis of this thesis is that the use of TRT is associated with an increased risk of prostate cancer, when compared with non-use.

\subsubsection{Secondary hypotheses}

This thesis has three secondary hypotheses:

1. There is an association between TRT formulation and prostate cancer risk.

2. There is an association between cumulative number of TRT prescriptions and prostate cancer risk.

3. There is an association between time since TRT initiation and prostate cancer risk. 


\section{Chapter 4: Methodology}

This section will discuss some of the methodology of the manuscript in greater detail. In particular, additional information on the data source is provided, as well as illustrations explaining the exposure definition and propensity score-matched analysis.

\subsection{Data source}

The Clinical Practice Research Datalink (CPRD) was used as a data source for this thesis, consisting of anonymized primary care medical records covering over 15 million patients from approximately 700 practices in the UK. ${ }^{94}$ In fact, the CPRD is one of the largest databases of longitudinal medical records from the primary care setting in the world. ${ }^{94}$ The CPRD was first established in London in 1987 as the Value Added Medical Products (VAMP), then grew to become the General Practice Research Database (GPRD) in 1993, and finally expanded to become the CPRD in $2012 .{ }^{94}$

Patients included in the CPRD are broadly representative of the UK population in terms of age, sex, and ethnicity. ${ }^{94}$ In addition, because general practitioners in the UK serve as a first point of contact for non-emergency health-related issues, the database contains useful information on routinely recorded symptoms, laboratory tests, diagnoses, therapies, health-related behaviours and referrals to secondary care. ${ }^{94}$ The CPRD also provides crucial information on outcomes of patients referred to secondary care, such as diagnoses, as this information is fed back from the secondary care team to the general practitioner. ${ }^{94}$ The CPRD uses Read codes for medical diagnoses and procedures, and a coded drug dictionary based on the UK Prescription Pricing Authority for drug prescriptions. ${ }^{94}$ Moreover, recording of medical diagnoses in the CPRD has been shown to be valid and of high quality. ${ }^{94}$ For over half of the patients in the CPRD, linkage with other datasets such as with mortality records or secondary care is possible. ${ }^{94}$ This along with the valid and high-quality health data makes it a 
favourable data source for epidemiological research, with over 1000 studies published in peer-reviewed journals covering a vast range of health outcomes. ${ }^{94}$

\subsubsection{Utility of CPRD to assess the association between TRT and prostate cancer}

Prostate cancer is primarily diagnosed and managed by general practitioners in the UK, and has been shown to be well recorded in the CPRD. ${ }^{95}$ As such, prostate cancer recording has a sensitivity, specificity, and positive predictive value of $85 \%, 99 \%$, and $92 \%$, respectively, when compared with England cancer registry data. ${ }^{96,97}$ Furthermore, hypogonadism is also predominantly diagnosed and managed in the UK primary care setting, thus largely capturing this clinical population. ${ }^{98}$ Taken together, the CPRD serves as a valuable data source to address the important safety question detailed in this thesis.

\subsection{Exposure definition}

Exposure to TRT was modelled in a time-varying fashion, with each patient capable of moving from a period of non-exposure to exposure, contributing both unexposed and exposed person-time. A one year exposure lag period was applied at TRT initiation, whereby patients were considered exposed starting one year after the first prescription. As such, prostate cancer events occurring within this one year window were considered unexposed events. The one year lag period was necessary to account for latency associated with the incidence of prostate cancer. In addition, it also served to minimize potential detection bias due to increased physician monitoring within the first year of treatment initiation, as well as minimize reverse causality which may occur if TRT is terminated due to early signs or symptoms of prostate cancer. Once patients were exposed to TRT, they were considered exposed until the end of follow-up, analogous to an intention-to-treat approach. According to this approach, the effect of TRT exposure on the outcome is assumed to be irreversible, 
meaning patients remain at risk of developing prostate cancer even after treatment discontinuation. Non-use of TRT was used as the reference category for all analyses.

Figure 5 illustrates four different scenarios under which a prostate cancer event can be classified according to this exposure definition. It is important to note that it was required that all patients have at least one year of follow-up after cohort entry (i.e., diagnosis of hypogonadism), after which person-time at risk begins (i.e., start of follow-up). In other words, the time between the start of follow-up and the end of the one year exposure lag period is considered unexposed person-time, whereas the time afterwards up until an incident prostate cancer event, death, end of registration, or end of study period is considered exposed person-time. Figure 5A-5B represent scenarios for exposed prostate cancer events, whereby patients on TRT experience the outcome after the one year exposure lag. Figure 5C-5D represent scenarios for unexposed prostate cancer events, whereby the prostate cancer event occurs within the one year exposure lag, and where TRT is not initiated over the follow-up, respectively. 
Figure 5. Exposure definition

\begin{tabular}{|l|l|}
\hline$-\begin{array}{l}\text { Excluded person-time } \\
\text { (1 year follow-up) }\end{array}$ \\
Unexposed person-time \\
Exposed person-time \\
Exposed event \\
Unexposed event \\
\hline
\end{tabular}

A. Diagnosis of

hypogonadism

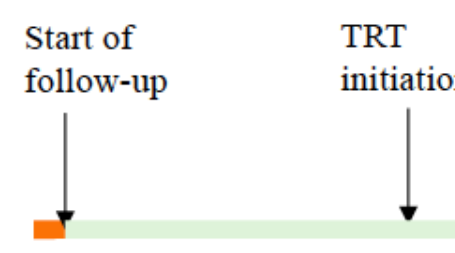

1 year exposure

lag

B. Diagnosis of

hypogonadism

$\begin{array}{ll}\text { TRT } & \text { Start of } \\ \text { initiation } & \text { follow-up }\end{array}$

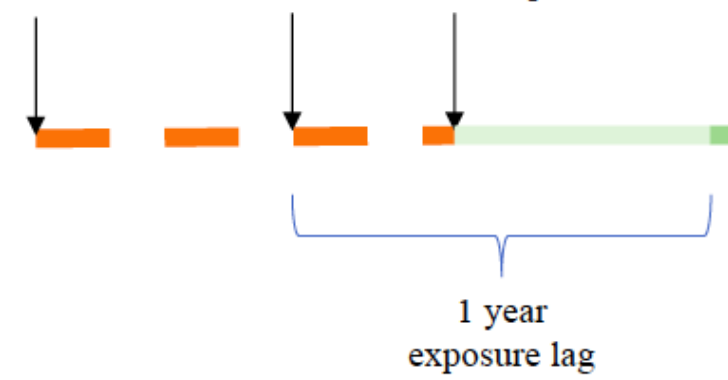


C. Diagnosis of

hypogonadism

Start of

follow-up

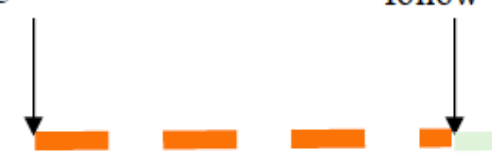

D. Diagnosis of

hypogonadism

$\downarrow \downarrow$
TRT

initiation

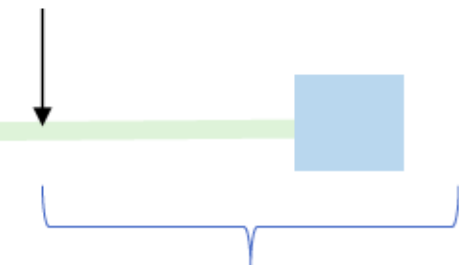

1 year exposure

lag 


\subsection{Propensity score-matched analysis}

To investigate the impact of residual confounding on the study results, we conducted a propensity score-matched analysis based on sequential cohorts (Figure 6) ${ }^{99}$ For this approach, a series of sequential cohorts based on calendar month were first created. To do this, new users of TRT and non-users were identified at each calendar month of the study period. In total, this generated 253 sequential cohorts consisting of TRT users and non-users during the study period. To be identified as a non-user, patients were required to have had a physician visit as well as a testosterone laboratory test with a result below the reference range in a given month. This was done in order to attempt to capture non-users who had an opportunity to receive TRT in that month. In addition, it was possible for non-users to eventually contribute to the TRT group, but only after the time of TRT initiation. The same exclusion criteria used in our main study population, which is further described in Chapter 5, were then applied at cohort entry to each of the sequential cohorts.

Using conditional logistic regression stratified on calendar month, the predicted probability of receiving TRT was estimated, conditional on various important confounding variables used in the primary analysis and further detailed in the manuscript in Chapter 5. ${ }^{99,100}$ We then matched TRT users, in a chronological order starting with the first one of the study period and without replacement, to a non-user on the same calendar month and propensity score using a greedy matching algorithm with a maximum caliper of $0.01 .{ }^{100}$ The matched sets were then followed until an incident diagnosis of prostate cancer, switching from non-use to TRT use, death from any cause, end of registration with the practice, or end of the study period (31 August 2017), whichever occurred first. A Cox proportional hazards model was used to estimate the HR and 95\% CI of prostate cancer comparing TRT users with non-users. Within-person correlation was accounted for using robust standard errors. ${ }^{100}$ 
Figure 6. Propensity score-matched cohort analysis
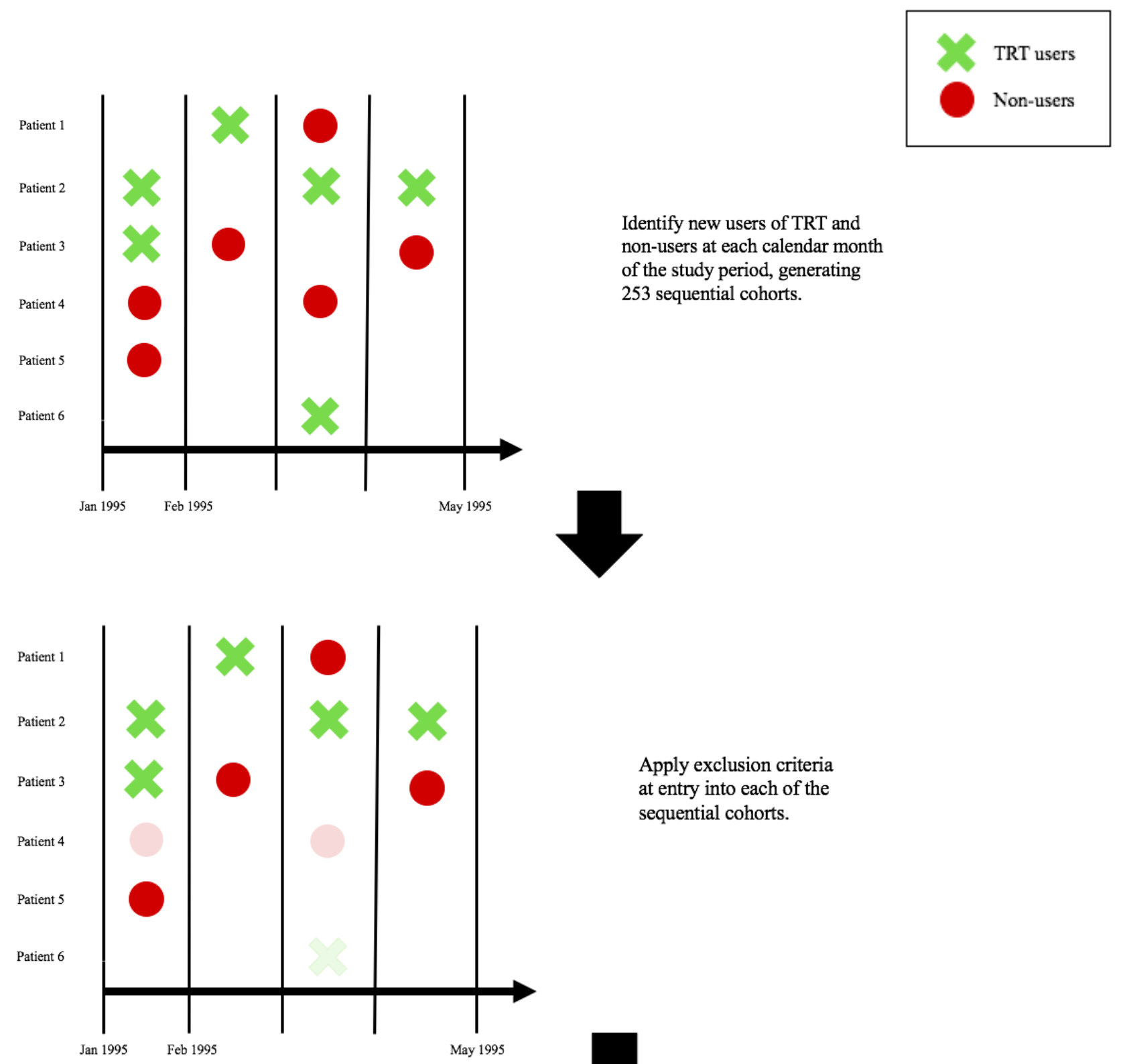

Apply exclusion criteria at entry into each of the sequential cohorts.

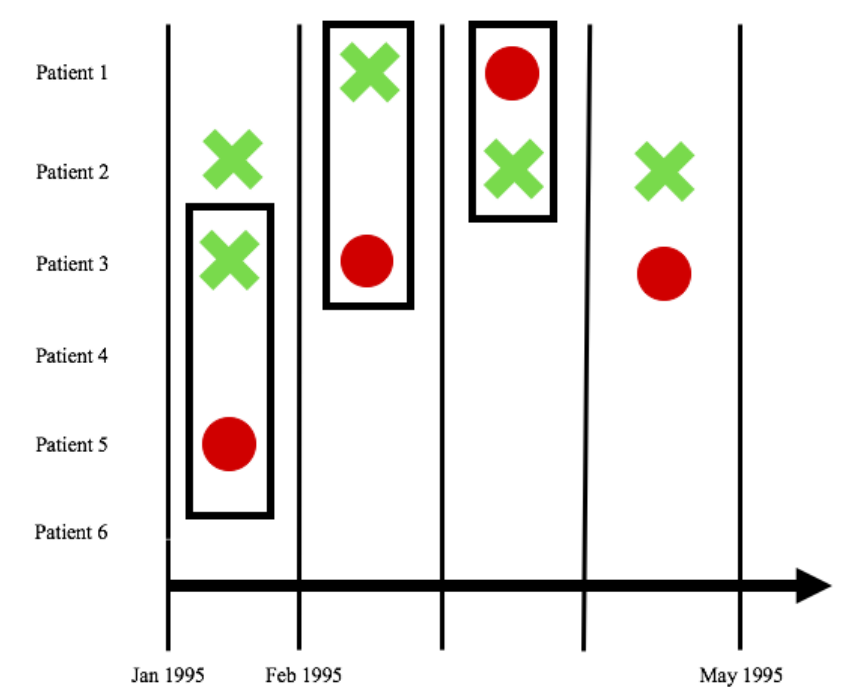

TRT users matched, in a chronological order and without replacement, to a non-user on the same calendar month and propensity score. 


\section{Chapter 5: Testosterone replacement therapy and the risk of prostate cancer in men with late-onset hypogonadism}

This chapter presents a manuscript on the association between TRT and the risk of prostate cancer. First, a background and rationale on the association in question is discussed. Second, the data source, study population, and various statistical analyses used to study the association in question are outlined. Third, descriptive results along with results for the primary, secondary, sensitivity, and ancillary analyses are provided. Finally, findings are discussed and compared with previous research on the topic, along with strengths and limitations of the study. This manuscript has been published in the American Journal of Epidemiology (May 30, 2019; doi: 10.1093/aje/kwz138). 


\section{Testosterone Replacement Therapy and the Risk of Prostate Cancer in Men with Late-Onset Hypogonadism}

Christina Santella BSc ${ }^{12}$, Christel Renoux MD PhD ${ }^{123}$, Hui Yin $\mathrm{MSc}^{1}$, Oriana H. Y. Yu MD $\mathrm{MSc}^{14}$, Laurent Azoulay $\mathrm{PhD}^{125}$

${ }^{1}$ Centre for Clinical Epidemiology, Lady Davis Institute, Jewish General Hospital, Montreal, Quebec, Canada

${ }^{2}$ Department of Epidemiology, Biostatistics, and Occupational Health, McGill University, Montreal, Quebec, Canada

${ }^{3}$ Department of Neurology and Neurosurgery, McGill University, Montreal, Quebec, Canada

${ }^{4}$ Division of Endocrinology, Jewish General Hospital, Montreal, Quebec, Canada

${ }^{5}$ Gerald Bronfman Department of Oncology, McGill University, Montreal, Quebec, Canad 


\subsection{Abstract}

The association between the use of testosterone replacement therapy (TRT) and prostate cancer remains uncertain. Thus, we investigated whether TRT is associated with an increased risk of prostate cancer in men with late-onset hypogonadism. We used the United Kingdom Clinical Practice Research Datalink to assemble a cohort of 12,779 men newly-diagnosed with hypogonadism between 1 January 1995 and 31 August 2016, with follow-up until 31 August 2017. Exposure to TRT was treated as a time-varying variable and lagged by 1 year to account for cancer latency, with non-use as the reference category. During 58,224 personyears of follow-up, a total of 215 patients were newly-diagnosed with prostate cancer, generating an incidence rate of 3.7 per 1,000 person-years. In time-dependent Cox proportional hazards models, use of TRT was not associated with an overall increased risk of prostate cancer (hazard ratio $=0.97 ; 95 \%$ confidence interval: $0.71,1.32$ ), compared with non-use. Results remained consistent in secondary and sensitivity analyses, as well as in a propensity score-matched cohort analysis that further assessed the impact of residual confounding. Overall, the use of TRT was not associated with an increased risk of prostate cancer in men with late-onset hypogonadism. 


\subsection{Introduction}

Testosterone replacement therapy (TRT) is indicated for men with pathologic testosterone deficiency, namely hypogonadism. ${ }^{1,2}$ While this treatment has been approved and shown to be effective in men with pathologic hypogonadism, the benefit of replacing testosterone in aging men with late-onset hypogonadism is less certain. ${ }^{2-4}$ Nonetheless, TRT is increasingly being prescribed off-label in this population, ${ }^{2,5}$ despite concerns of its cardiovascular safety and its potential to increase the risk of prostate cancer. ${ }^{1,4,6}$

Current treatment guidelines recommend against the initiation of TRT in patients with a history or known risk factors for prostate cancer. ${ }^{1,7}$ This recommendation is based on the well-established role of androgens on the incidence of prostate cancer. ${ }^{8-10}$ However, to date, the evidence supporting an association between TRT and prostate cancer incidence is inconclusive. Indeed, meta-analyses of randomized clinical trials designed to assess the efficacy of TRT have reported null associations with respect to prostate cancer. ${ }^{11,12}$ It is important to note that trials included in these meta-analyses were not designed nor powered to assess prostate cancer as a safety outcome. ${ }^{11,12}$ Similarly, the few observational studies that have been conducted have also reported null associations, ${ }^{13-20}$ but these had several methodological limitations, including short durations of follow-up, potential confounding by indication, immortal time bias, and potential detection bias. ${ }^{13-20}$

Given the increasing use of TRT in aging men and the limitations of the available evidence, additional studies are needed to assess the long-term safety of this therapy. Thus, the objective of this population-based study was to determine whether the use of TRT is associated with an increased risk of prostate cancer in men with late-onset hypogonadism. 


\subsection{Methods}

\subsubsection{Data Source}

This study was conducted using the United Kingdom (UK) Clinical Practice Research Datalink (CPRD). The CPRD is a large primary care database that includes approximately 15 million patients from almost 700 general practices in the UK. ${ }^{21}$ Patients included in the CPRD are broadly representative of the general UK population in terms of age, sex, and ethnicity. ${ }^{21}$ It also serves as a useful resource for research as it records information on patient demographics, laboratory tests, diagnoses, procedures, prescriptions written by general practitioners, health-related behaviours, and referrals to secondary care. ${ }^{21}$ The CPRD uses Read codes for medical diagnoses and procedures, and a coded drug dictionary based on the UK Prescription Pricing Authority Dictionary for drug prescriptions. ${ }^{21}$ Recording of medical diagnoses in the CPRD have been shown to be valid and of high quality. ${ }^{22-24}$

The study protocol (\#18_200) was approved by the Independent Scientific Advisory Committee of the CPRD and the Research Ethics Board of the Jewish General Hospital, Montreal, Canada.

\subsubsection{Study Population}

We assembled a cohort of men, at least 45 years of age, diagnosed with hypogonadism between 1 January 1995 and 31 August 2016, and followed until 31 August 2017. A diagnosis of hypogonadism was based on diagnostic codes and/or laboratory test values indicating low levels of serum or free testosterone. The earliest measure of hypogonadism was set as the date of cohort entry. Patients were required to have at least one year of medical history in the CPRD prior to cohort entry. We excluded men with a history of prostate cancer and/or androgen deprivation therapy use, as well as those who used TRT at any time before cohort entry. The latter was done to minimize the inclusion of prevalent 
users. ${ }^{25}$ In order to restrict the cohort to men with late-onset hypogonadism, men diagnosed with pathologic causes of hypogonadism before cohort entry were also excluded. These included diseases of the hypothalamic-pituitary axis, Kallman's syndrome, and eunuchism. Finally, all patients were required to have at least one year of follow-up after cohort entry for cancer latency purposes.

All patients in the cohort were followed starting one year after cohort entry until an incident diagnosis of prostate cancer (defined by Read codes listed in Supplementary Table 1; these have been shown to be well recorded in the $\mathrm{CPRD}^{26,27}$ ), censored upon death from any cause, end of registration with the practice, or end of the study period (31 August 2017), whichever occurred first.

\subsubsection{Exposure Definition}

TRT use was modelled as a time-varying exposure, with each patient capable of moving from a period of non-exposure to a period of exposure, thus contributing both unexposed and exposed person-time to the analysis. Patients prescribed TRT were considered exposed starting one year after the first prescription until the end of follow-up (analogous to an intention-to-treat approach). The one year lag period was necessary to account for a minimum latency time window, while also minimizing detection bias and reverse causality (i.e., TRT may be terminated due to early signs or symptoms of prostate cancer). Patients prescribed TRT were compared with patients who had not used TRT up until the time of the risk set (i.e., time of the event).

\subsubsection{Statistical Analysis}

Crude incidence rates of prostate cancer with $95 \%$ confidence intervals (CIs), based on the Poisson distribution, were calculated by dividing the number of events over the 
person-time at risk for each exposure group. Time-dependent Cox proportional hazards models were used to estimate adjusted hazard ratios (HRs) with $95 \%$ CIs of prostate cancer associated with the use of TRT, compared with non-use.

All models were adjusted for important potential confounders measured at cohort entry. These included year of cohort entry, age, alcohol-related disorders (including alcoholism, alcoholic cirrhosis of the liver, alcoholic hepatitis and hepatic failure; measured at any time before cohort entry), smoking status (current, former, never, unknown), and body mass index ( $<25 \mathrm{~kg} / \mathrm{m}^{2}, 25-29 \mathrm{~kg} / \mathrm{m}^{2}, \geq 30 \mathrm{~kg} / \mathrm{m}^{2}$, unknown). The models were also adjusted for Charlson Comorbidity Index, previous cancers (other than non-melanoma skin cancer), and drug exposures previously associated with prostate cancer incidence (non-steroidal antiinflammatory drugs, aspirin, statins, and metformin), measured at any time before cohort entry. Multiple imputation was used for variables with missing values (i.e., smoking, body mass index). To impute missing data, we used an ordinal regression model with explanatory variables and cumulative hazard, ${ }^{28}$ TRT use at cohort entry and all confounders listed above. Using Rubin's rules, the results of five imputations were combined to estimate the values for missing variables. ${ }^{28,29}$

\subsubsection{Secondary and Sensitivity Analyses}

We performed three secondary analyses. First, we assessed whether the association varied by TRT formulation. The two other analyses assessed whether the association varied with cumulative number of TRT prescriptions received and with time since initiation of TRT. These were defined in a time-dependent fashion by summing the number of prescriptions from cohort entry to time of event, and as the time between first ever prescription of TRT to time of event, respectively. Both number of prescriptions received and time since initiation 
were modelled as continuous variables using restricted cubic spline models, which produced a smooth risk function over time..$^{30}$

We conducted three sensitivity analyses to assess the robustness of our findings. First, given uncertainties related to the length of the latency time window, we repeated the analyses after increasing the exposure lag period to 2 and 3 years. Second, we conducted a competing risk analysis due to death from any cause using the subdistribution model proposed by Fine and Gray. ${ }^{31}$ Finally, to account for potential time-dependent confounding associated with time-varying exposures, we repeated the analyses using marginal structural modelling using inverse probability of treatment and censoring weighting (Supplementary method 1).

\subsubsection{Ancillary Analyses}

Detection bias is an information bias resulting from a differential opportunity of being screened or diagnosed with the outcome between the exposure groups ${ }^{32} \mathrm{We}$ conducted three analyses to assess the potential impact of detection bias on our findings. First, we removed the exposure lag period in order to capture earlier events; an increased or decreased point estimate would be expected in the presence of detection bias. Second, we stratified the cohort based on receiving a prostate-specific antigen (PSA) test in the year prior to cohort entry, and estimated HRs separately for each group. In the presence of detection bias, an over-detection of prevalent prostate cancer events would be expected in the group that was not previously screened for prostate cancer. Finally, we used inverse probability of screening weighting to account for the possibility that TRT users may have a differential probability of receiving or not receiving a PSA test during follow-up (Supplementary method 2). ${ }^{33}$

To investigate the impact of residual confounding, we conducted a time-matched propensity score analysis based on sequential cohorts. ${ }^{34,35}$ This required identifying new users of TRT and non-users at each calendar month of the study period, generating a total of 253 
sequential cohorts. A new TRT user was defined by a first-ever prescription at a given month. To qualify as non-users, patients must have had a physician visit as well as a testosterone laboratory test with a result below the reference range at a given month. We then applied the exclusion criteria listed above at entry in each of these sequential cohorts. It was possible for non-users to eventually contribute to the TRT group, but only after the time of the switch. The predicted probability of receiving TRT was estimated using conditional logistic regression, stratified on calendar month, conditional on the variables listed above. ${ }^{34,35}$ TRT users were then matched, in a chronological order and without replacement, to a non-user on the same calendar month and propensity score using a greedy matching algorithm with a maximum caliper of $0.01 .^{34}$ The matched sets were followed until an incident diagnosis of prostate cancer, switching from non-use to TRT use, death from any cause, end of registration with the practice, or end of study period (31 August 2017), whichever occurred first. Cox proportional hazards model was used to estimate the HR and 95\% CI of incident prostate cancer comparing TRT users with non-users. We accounted for within-person correlation using robust standard errors. ${ }^{34}$ Cumulative incidence curves of prostate cancer were also generated for each exposure group. All analyses were conducted with SAS version 9.4 (SAS institute, Cary, NC) and R (R Foundation for Statistical Computing, Vienna, Austria). 


\subsection{Results}

A total of 12,779 patients met the study inclusion criteria, of which 12,408 (97.1\%) entered the cohort with a low testosterone laboratory value (Supplementary Figure 1). The mean (standard deviation) age at cohort entry was 60.2 (9.5) years. The median follow-up was 3.7 years and the mean (standard deviation) follow-up was 4.6 (3.6) years. Overall, 4765 (37.3\%) and $1173(9.2 \%)$ patients were followed for at least 5 and 10 years, respectively. During 58,224 person-years of follow-up, 215 patients were newly-diagnosed with prostate cancer, generating a crude incidence rate of 3.7 (95\% CI: 3.2, 4.2) per 1,000 person-years. During the study period, a total of 3,645 (28.5\%) patients were prescribed TRT, of which $3,299(90.5 \%)$ received the treatment within the first year of cohort entry.

Table 6 presents the baseline characteristics of the entire study cohort, as well as stratified by TRT use within one year after cohort entry. Compared with non-users, TRT users were less likely to be current smokers, and were more likely to have a higher body mass index. They were also more likely to have had a previous cancer, and to have used nonsteroidal anti-inflammatory drugs, aspirin, statins, and metformin. The study flow chart of the propensity score-matched analysis is presented in Supplementary Figure 2. The baseline characteristics of TRT users and non-users prior to matching are shown in Supplementary Table 2 and the propensity score distributions of the exposure groups before and after matching are presented in Supplementary Figures 3-4. Overall, 3,330 TRT users were matched to 3,330 non-users, with the exposure groups well balanced on all covariates with no standard difference exceeding 0.03 (Table 7).

Table 8 presents the results of the primary analysis. Compared with non-use, use of TRT was not associated with an overall increased risk of prostate cancer $(3.8 \vee 3.4$ per 1,000 person-years, respectively; adjusted $\mathrm{HR}=0.97,95 \% \mathrm{CI}: 0.71,1.32$ ). Similar results were observed in the propensity score-matched cohort analysis $(3.9 \vee 3.4$ per 1,000 person-years; 
adjusted $\mathrm{HR}=0.87,95 \% \mathrm{CI}: 0.56,1.36)$. Likewise, cumulative incidence curves for the exposure groups were not significantly different from each other $(\log$ rank $\mathrm{p}=0.55$;

Supplementary Figure 5). In secondary analyses, the risk of prostate cancer did not vary by TRT formulation (Supplementary Table 3). In the restricted cubic spline models assessing the association according to number of prescriptions received and time since initiation, findings were generally consistent but generated wide confidence intervals with increasing number of prescriptions and time since initiation. (Supplementary Figures 6-7).

The results of the sensitivity analyses are summarized in Figure 7 and presented in Supplementary Tables 4-7. Lengthening the exposure lag window to 2 and 3 years did not materially change the point estimate (adjusted HR $=0.99,95 \%$ CI: $0.70,1.40$ and adjusted $\mathrm{HR}=0.98,95 \% \mathrm{CI}: 0.66,1.44$, respectively). Similarly, consistent results were observed when accounting for competing risk of death from any cause (subdistribution $\mathrm{HR}=0.98$, $95 \%$ CI: $0.72,1.35$ ) or when accounting for potential time-dependent confounding in the marginal structural model (marginal HR $=0.94,95 \%$ CI: 0.69, 1.28).

The results of the detection bias analyses are summarized in Supplementary Figure 8 and presented in Supplementary Tables 8-10. Over the follow-up period, the PSA testing rate was higher among TRT users than among non-users (38.0 [95\% CI: 37.2, 38.2] v 24.8 [95\% CI: 24.36, 25.22] per 100 person-years, respectively). Removing the exposure lag window resulted in a decreased $\mathrm{HR}$ in the protective direction (adjusted $\mathrm{HR}=0.75,95 \% \mathrm{CI}$ : $0.57,0.99)$, which was due to an increase in the prostate cancer incidence rate in the nonusers. Patients with a history of PSA testing yielded a HR below the null (adjusted HR = 0.61, 95\% CI: $0.33,1.11$ ), while those with no history of PSA testing yielded a HR above the null (adjusted HR $=1.19,95 \%$ CI: 0.82, 1.72). Finally, weighting the models on the inverse probability of PSA screening yielded a lowered HR (adjusted HR $=0.73,95 \%$ CI: 0.52 , $1.01)$ 


\subsection{Discussion}

In this population-based study, the use of TRT was not associated with an increased risk of prostate cancer among men with late-onset hypogonadism, with point estimates close to the null in both the time-varying and propensity score-matched analyses. These findings remained consistent in secondary analyses assessing the association according to TRT formulation, measures of duration, as well as in several sensitivity analyses.

We also considered the impact of detection bias on our findings by conducting several additional analyses. These included removing the lag period, stratifying on PSA testing, and using inverse probability of screening weighting. Removing the exposure lag window resulted in a decreased prostate cancer risk with the use of TRT. However, this was due to an early increased detection of prostate cancer in the comparator group. It is possible that these patients did not receive TRT because of abnormal PSA levels, and were then diagnosed with prostate cancer shortly after. Thus, the inclusion of a lag period reduced this potential bias. Stratifying on prior PSA testing also yielded a protective HR for history of PSA screening and an increased HR for no history of PSA screening. Although the 95\% CIs were overlapping and included the null value, the general direction of these results is suggestive of a possible over-detection of prevalent prostate cancer cases in TRT users not previously screened for PSA. Finally, accounting for differential screening probabilities with inverse probability of screening weights resulted in a HR below the null value. Taken together, these findings suggest that TRT users are more likely to be screened for prostate cancer than nonusers and thus needs to be considered in future studies.

To date, several observational studies have investigated the association between TRT and prostate cancer, ${ }^{13-20}$ but these had several important methodological limitations. In one recent nested case-control study conducted within the male Swedish population, the use of TRT was not associated with an overall increased risk of prostate cancer (odds ratio $=1.03$, 
95\% CI: $0.90,1.17) .{ }^{18}$ In secondary analyses, less than one year of TRT use was associated with an increased risk of low- to intermediate-risk prostate cancer (defined by PSA $<20$ $\mathrm{ng} / \mathrm{mL}$, stage $\mathrm{T} 1$ to $\mathrm{T} 2$, Gleason score $\leq 7$ - odds ratio $=1.61,95 \%$ CI: $1.10,2.34)$. In contrast, more than one year of TRT use was associated with a decreased risk of high-risk or metastatic prostate cancer (defined by PSA $20-50 \mathrm{ng} / \mathrm{mL}$, stage T1 to T2, Gleason score 8-10; PSA $<50 \mathrm{ng} / \mathrm{mL}$, T3; PSA 50-100 ng/mL, T4; and metastases or PSA $>100 \mathrm{ng} / \mathrm{mL}-$ odds ratio $=0.44,95 \%$ CI: $0.32,0.61) .{ }^{18}$ While this was a well-conducted study, the authors noted that the early increase in low- to intermediate-risk prostate cancer may be indicative of detection bias. ${ }^{18}$ In contrast, the strong decreased risk observed with high-risk disease may be due to confounding by indication. Indeed, as this study was conducted within the Swedish male population, it is likely that the majority of patients included in the comparator group were non-hypogonadal men. This is particularly important given that hypogonadal men may be at a decreased risk of prostate cancer compared to healthy men. ${ }^{36}$ Furthermore, while other studies suggested no increased risk of prostate cancer with TRT, these were conducted using patient registries among exposed patients and did not compare incidence rates to a comparator group. ${ }^{13,16,17}$ In addition, these studies did not appropriately adjust for confounding factors, ${ }^{15,19}$ and were limited by short-follow up periods. ${ }^{14}$

Our study was specifically designed to address the methodological limitations of the previous studies. ${ }^{13-20}$ First, we assembled a cohort of men diagnosed with late-onset hypogonadism. This ensured that all patients in the cohort had the indication for TRT, minimizing the potential for confounding by indication. Second, we used exposure lag periods for all analyses, which is necessary for cancer latency purposes and to minimize reverse causality and detection bias. Finally, the use of the CPRD allowed us to adjust the models for several potential important confounders, such as smoking and body mass index, which are often absent in administrative databases. 
Our study has some limitations. First, the CPRD records prescriptions written by general practitioners. As such, it is unknown whether patients filled their prescriptions or whether they adhered to the treatment. While such misclassification of exposure is possible, the absence of an association with number of prescriptions received provides reassurance on the potential impact of this limitation. Second, misclassification of the outcome is possible. However, prostate cancer has been shown to be well recorded in the CPRD with a sensitivity, specificity, and positive predictive value of $0.85,0.99$ and 0.92 , respectively, when compared with England cancer registry data. ${ }^{37,38}$ Moreover, concordance rates of prostate cancer recording in the CPRD exceed $90 \%$ when compared with the National Cancer Data Repository. ${ }^{26}$ It was not possible to stratify on tumour grade and stage, as this information is not recorded in the CPRD. Third, due to the observational nature of our study, residual confounding from unknown or unmeasured confounders is possible. Reassuringly, we observed consistent findings in the marginal structural model that addressed potential timedependent confounding, as well as in the propensity score-matched analysis. Finally, although TRT prescribing and testosterone testing have increased substantially in both the US and UK, these practices have increased markedly in the US in the recent decade, especially in men with normal testosterone levels. ${ }^{39}$ Consequently, our findings may not be fully generalizable outside of the UK setting.

In summary, the results of this study indicate that the use of TRT is not associated with an increased risk of prostate cancer in men with late-onset hypogonadism. These findings should provide some reassurance on the long-term safety of TRT among men with late-onset hypogonadism. 


\subsection{References}

1. Bhasin S, Cunningham GR, Hayes FJ, Matsumoto AM, Snyder PJ, Swerdloff RS, Montori VM. Testosterone therapy in men with androgen deficiency syndromes: an Endocrine Society clinical practice guideline. J Clin Endocrinol Metab 2010;95(6):2536-59.

2. Nguyen CP, Hirsch MS, Moeny D, Kaul S, Mohamoud M, Joffe HV. Testosterone and “Age-Related Hypogonadism” — FDA Concerns. N Engl J Med 2015;373(8):689-691.

3. Snyder PJ, Bhasin S, Cunningham GR, Matsumoto AM, Stephens-Shields AJ, Cauley JA, Gill TM, Barrett-Connor E, Swerdloff RS, Wang C, Ensrud KE, Lewis CE, Farrar JT, Cella D, Rosen RC, Pahor M, Crandall JP, Molitch ME, Cifelli D, Dougar D, Fluharty L, Resnick SM, Storer TW, Anton S, Basaria S, Diem SJ, Hou X, Mohler ER, 3rd, Parsons JK, Wenger NK, Zeldow B, Landis JR, Ellenberg SS. Effects of Testosterone Treatment in Older Men. N Engl J Med 2016;374(7):611-24.

4. Administration UFaD. Drug Safety Communication: FDA cautions about using testosterone products for low testosterone due to aging. 2015.

5. Gan EH, Pattman S, S HSP, Quinton R. A UK epidemic of testosterone prescribing, 2001-2010. Clin Endocrinol (Oxf) 2013;79(4):564-70.

6. Eisenberg ML. Testosterone Replacement Therapy and Prostate Cancer Incidence. World J Men's Health 2015;33(3):125-129.

7. Sargis RM, Davis AM. Evaluation and Treatment of Male Hypogonadism. JAMA 2018;319(13):1375-1376.

8. Michaud JE, Billups KL, Partin AW. Testosterone and prostate cancer: an evidencebased review of pathogenesis and oncologic risk. Ther Adv Urol 2015;7(6):378-87. 
9. Pierorazio PM, Ferrucci L, Kettermann A, Longo DL, Metter EJ, Carter HB. Serum testosterone is associated with aggressive prostate cancer in older men: results from the Baltimore Longitudinal Study of Aging. BJU Int 2010;105(6):824-9.

10. Shaneyfelt T, Husein R, Bubley G, Mantzoros CS. Hormonal predictors of prostate cancer: a meta-analysis. J Clin Oncol 2000;18(4):847-53.

11. Cui Y, Zong H, Yan H, Zhang Y. The effect of testosterone replacement therapy on prostate cancer: a systematic review and meta-analysis. Prostate Cancer Prostatic Dis 2014;17:132.

12. Marks LS, Mazer NA, Mostaghel E, Hess DL, Dorey FJ, Epstein JI, Veltri RW, Makarov DV, Partin AW, Bostwick DG, Macairan ML, Nelson PS. Effect of testosterone replacement therapy on prostate tissue in men with late-onset hypogonadism: a randomized controlled trial. JAMA 2006;296(19):2351-61.

13. Coward RM, Simhan J, Carson CC, 3rd. Prostate-specific antigen changes and prostate cancer in hypogonadal men treated with testosterone replacement therapy. BJU Int 2009;103(9):1179-83.

14. Debruyne FM, Behre HM, Roehrborn CG, Maggi M, Wu FC, Schroder FH, Jones TH, Porst H, Hackett G, Wheaton OA, Martin-Morales A, Meuleman E, Cunningham GR, Divan HA, Rosen RC. Testosterone treatment is not associated with increased risk of prostate cancer or worsening of lower urinary tract symptoms: prostate health outcomes in the Registry of Hypogonadism in Men. BJU Int 2017;119(2):216-224.

15. Eisenberg ML, Li S, Betts P, Herder D, Lamb DJ, Lipshultz LI. Testosterone therapy and cancer risk. BJU Int 2015;115(2):317-21.

16. Feneley Mark R, Carruthers M. Is Testosterone Treatment Good for the Prostate? Study of Safety during Long-Term Treatment. J Sex Med 2012;9(8):2138-2149. 
17. Haider A, Zitzmann M, Doros G, Isbarn H, Hammerer P, Yassin A. Incidence of prostate cancer in hypogonadal men receiving testosterone therapy: observations from 5-year median followup of 3 registries. J Urol 2015;193(1):80-6.

18. Loeb S, Folkvaljon Y, Damber JE, Alukal J, Lambe M, Stattin P. Testosterone Replacement Therapy and Risk of Favorable and Aggressive Prostate Cancer. J Clin Oncol 2017;35(13):1430-1436.

19. Yassin A, Salman M, Talib RA, Yassin DJ. Is there a protective role of testosterone against high-grade prostate cancer? Incidence and severity of prostate cancer in 553 patients who underwent prostate biopsy: a prospective data register. Aging Male 2017;20(2):125-133.

20. Walsh TJ, Shores MM, Krakauer CA, Forsberg CW, Fox AE, Moore KP, Korpak A, Heckbert SR, Zeliadt SB, Kinsey CE, Thompson ML, Smith NL, Matsumoto AM. Testosterone treatment and the risk of aggressive prostate cancer in men with low testosterone levels. PLoS One 2018;13(6):e0199194.

21. Herrett E, Gallagher AM, Bhaskaran K, Forbes H, Mathur R, van Staa T, Smeeth L. Data Resource Profile: Clinical Practice Research Datalink (CPRD). Int J Epidemiol 2015;44(3):827-36.

22. Herrett E, Thomas SL, Schoonen WM, Smeeth L, Hall AJ. Validation and validity of diagnoses in the General Practice Research Database: a systematic review. Br J Clin Pharmacol 2009;69(1):4-14.

23. Jick SS, Kaye JA, Vasilakis-Scaramozza C, Garcia Rodriguez LA, Ruigomez A, Meier CR, Schlienger RG, Black C, Jick H. Validity of the general practice research database. Pharmacotherapy 2003;23(5):686-9. 
24. Jick H, Jick SS, Derby LE. Validation of information recorded on general practitioner based computerised data resource in the United Kingdom. BMJ 1991;302(6779):7668.

25. Ray WA. Evaluating medication effects outside of clinical trials: new-user designs. Am J Epidemiol 2003;158(9):915-20.

26. Boggon R, Staa Tjeerd P, Chapman M, Gallagher Arlene M, Hammad Tarek A, Richards Mike A. Cancer recording and mortality in the General Practice Research Database and linked cancer registries. Pharmacoepidemiol Drug Saf 2012;22(2):168175.

27. Margulis AV, Fortuny J, Kaye JA, Calingaert B, Reynolds M, Plana E, McQuay LJ, Atsma WJ, Franks B, de Vogel S, Perez-Gutthann S, Arana A. Validation of Cancer Cases Using Primary Care, Cancer Registry, and Hospitalization Data in the United Kingdom. Epidemiology 2018;29(2):308-313.

28. White IR, Royston P. Imputing missing covariate values for the Cox model. Stat Med 2009;28(15):1982-1998.

29. Sterne JAC, White IR, Carlin JB, Spratt M, Royston P, Kenward MG, Wood AM, Carpenter JR. Multiple imputation for missing data in epidemiological and clinical research: potential and pitfalls. BMJ 2009;338:b2393.

30. Greenland S. Dose-response and trend analysis in epidemiology: alternatives to categorical analysis. Epidemiology 1995;6(4):356-65.

31. Fine JP, Gray RJ. A Proportional Hazards Model for the Subdistribution of a Competing Risk. J Am Stat Assoc 1999;94(446):496-509.

32. Haut ER, Pronovost PJ. Surveillance bias in outcomes reporting. JAMA 2011;305(23):2462-3. 
33. Cook NR, Rosner BA, Hankinson SE, Colditz GA. Mammographic Screening and Risk Factors for Breast Cancer. Am J Epidemiol 2009;170(11):1422-1432.

34. Ross ME, Kreider AR, Huang YS, Matone M, Rubin DM, Localio AR. Propensity Score Methods for Analyzing Observational Data Like Randomized Experiments: Challenges and Solutions for Rare Outcomes and Exposures. Am J Epidemiol 2015;181(12):989-95.

35. Hernan MA, Alonso A, Logan R, Grodstein F, Michels KB, Willett WC, Manson JE, Robins JM. Observational studies analyzed like randomized experiments: an application to postmenopausal hormone therapy and coronary heart disease. Epidemiology 2008;19(6):766-79.

36. Parsons JK, Carter HB, Platz EA, Wright EJ, Landis P, Metter EJ. Serum testosterone and the risk of prostate cancer: potential implications for testosterone therapy. Cancer Epidemiol Biomarkers Prev 2005;14(9):2257-60.

37. Dregan A, Moller H, Murray-Thomas T, Gulliford MC. Validity of cancer diagnosis in a primary care database compared with linked cancer registrations in England. Population-based cohort study. Cancer Epidemiol 2012;36(5):425-429.

38. Khan NF, Harrison SE, Rose PW. Validity of diagnostic coding within the General Practice Research Database: a systematic review. Br J Gen Pract 2010;60(572):e12836.

39. Layton JB, Li D, Meier CR, Sharpless JL, Sturmer T, Jick SS, Brookhart MA. Testosterone lab testing and initiation in the United Kingdom and the United States, 2000 to 2011. J Clin Endocrinol Metab 2014;99(3):835-42. 


\subsection{Figures and tables}

\section{FIGURE LEGEND}

Figure 7. Forest plot summarizing the results of the primary and sensitivity analyses assessing the association between testosterone replacement therapy and the risk of prostate 
Figure 7

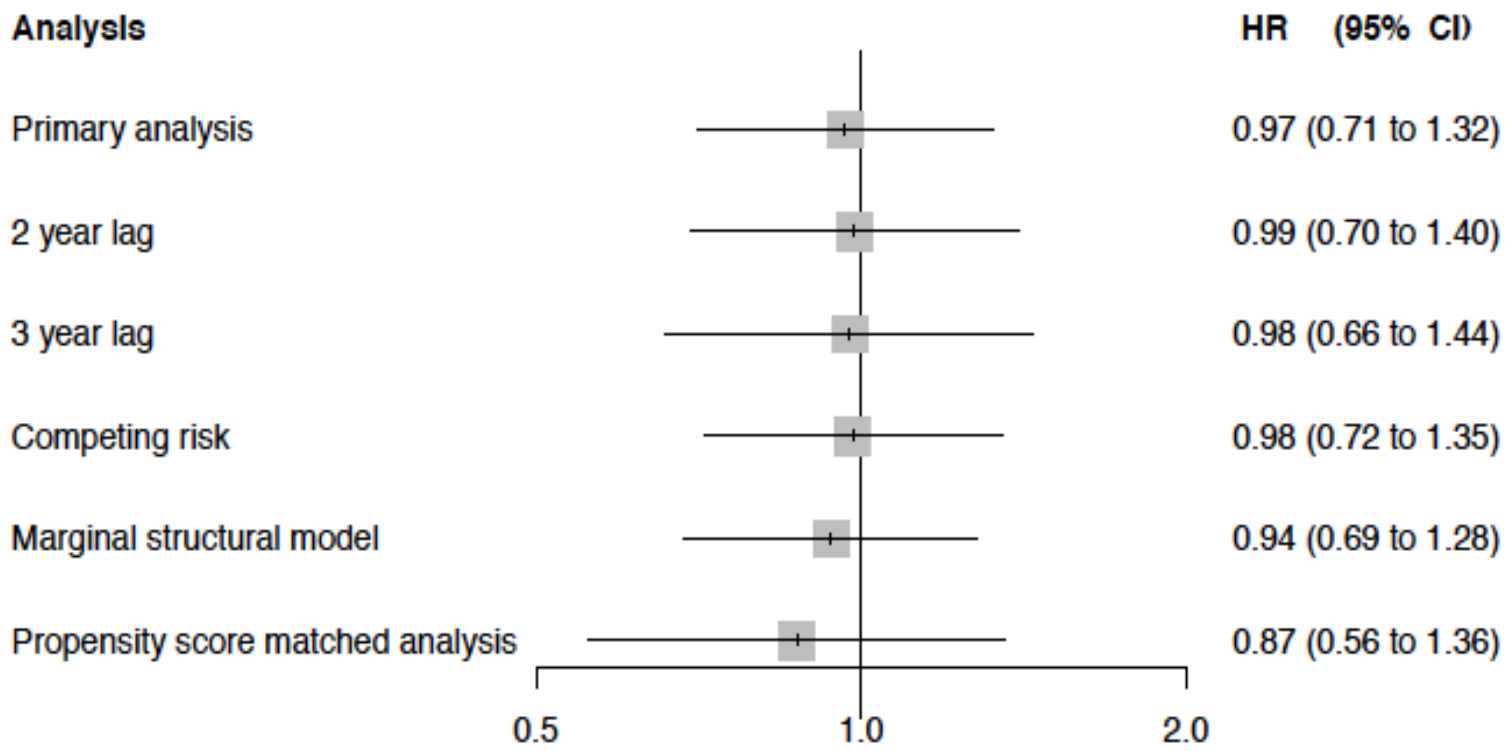


Table 6. Baseline Characteristics of the Cohort of Men Newly-Diagnosed with Hypogonadism, Overall and Stratified by Testosterone Replacement Therapy Use, United Kingdom, 1995-2017

\begin{tabular}{|c|c|c|c|c|c|c|}
\hline \multirow{3}{*}{ Characteristic } & \multicolumn{2}{|c|}{ Entire Cohort } & \multicolumn{4}{|c|}{ Testosterone replacement therapy ${ }^{a}$} \\
\hline & \multirow{2}{*}{ No. } & \multirow{2}{*}{$\%$} & \multicolumn{2}{|c|}{ Use } & \multicolumn{2}{|c|}{ Non-use } \\
\hline & & & No. & $\%$ & No. & $\%$ \\
\hline Total & 12,779 & & 3,299 & 25.8 & 9,480 & 74.2 \\
\hline Age, years ${ }^{b}$ & \multicolumn{2}{|c|}{$60.2(9.5)$} & \multicolumn{2}{|c|}{$59.6(9.0)$} & \multicolumn{2}{|c|}{$60.4(9.7)$} \\
\hline \multicolumn{7}{|l|}{ Age, years } \\
\hline $45-54$ & 4,086 & 32.0 & 1,113 & 33.7 & 2,973 & 31.4 \\
\hline $55-64$ & 4,653 & 36.4 & 1,214 & 36.8 & 3,439 & 36.3 \\
\hline $65-74$ & 2,994 & 23.4 & 770 & 23.3 & 2,224 & 23.5 \\
\hline$\geq 75$ & 1,046 & 8.2 & 202 & 6.1 & 844 & 8.9 \\
\hline History of PSA test & 4,210 & 32.9 & 1,100 & 33.3 & 3,110 & 32.8 \\
\hline PSA level, ng/mL ${ }^{\text {b c }}$ & \multicolumn{2}{|c|}{$1.7(5.2)$} & \multicolumn{2}{|c|}{$1.2(1.3)$} & \multicolumn{2}{|c|}{$1.9(6.0)$} \\
\hline $\begin{array}{l}\text { Alcohol-related } \\
\text { disorders }\end{array}$ & 1,865 & 14.6 & 492 & 14.9 & 1,373 & 14.5 \\
\hline \multicolumn{7}{|l|}{ Smoking status } \\
\hline Current & 1,767 & 13.8 & 391 & 11.9 & 1,376 & 14.5 \\
\hline Former & 5,228 & 40.9 & 1,430 & 43.4 & 3,798 & 40.1 \\
\hline Never & 5,541 & 43.4 & 1,422 & 43.1 & 4,119 & 43.5 \\
\hline Unknown & 243 & 1.9 & 56 & 1.7 & 187 & 2.0 \\
\hline \multicolumn{7}{|l|}{ Body mass index ${ }^{\mathrm{d}}$} \\
\hline$<25$ & 1,762 & 13.8 & 387 & 11.7 & 1,375 & 14.5 \\
\hline $25-30$ & 4,813 & 37.7 & 1,192 & 36.1 & 3,621 & 38.2 \\
\hline$\geq 30$ & 5,846 & 45.8 & 1,625 & 49.3 & 4,221 & 44.5 \\
\hline Unknown & 358 & 2.8 & 95 & 2.9 & 263 & 2.8 \\
\hline \multicolumn{7}{|l|}{$\begin{array}{l}\text { Charlson comorbidity } \\
\text { index }\end{array}$} \\
\hline 0 & 5,630 & 44.1 & 1,376 & 41.7 & 4,254 & 44.9 \\
\hline $1-2$ & 4,384 & 34.3 & 1,171 & 35.5 & 3,213 & 33.9 \\
\hline$\geq 3$ & 2,765 & 21.6 & 752 & 22.8 & 2,013 & 21.2 \\
\hline Previous cancer & 1,099 & 8.6 & 300 & 9.1 & 799 & 8.4 \\
\hline $\begin{array}{l}\text { Nonsteroidal anti- } \\
\text { inflammatory drugs }\end{array}$ & 6,410 & 50.2 & 1,743 & 52.8 & 4,667 & 49.2 \\
\hline Aspirin & 4,065 & 31.8 & 1,104 & 33.5 & 2,961 & 31.2 \\
\hline Statins & 5,890 & 46.1 & 1,629 & 49.4 & 4,261 & 45.0 \\
\hline Metformin & 2,354 & 18.4 & 684 & 20.7 & 1,670 & 17.6 \\
\hline
\end{tabular}

Abbreviations: PSA, prostate specific antigen.

${ }^{a}$ Use in the first year after cohort entry.

${ }^{\text {b}}$ Values are expressed as mean (standard deviation).

${ }^{\mathrm{c}}$ Only 4132 patients out of $12,779(32.3 \%)$ have a valid PSA measurement before cohort entry.

${ }^{\mathrm{d}}$ Weight $(\mathrm{kg}) /$ height $(\mathrm{m})^{2}$. 
Table 7. Baseline Characteristics of Testosterone Replacement Therapy Users Matched to Non-users in the Propensity Score-Matched Analysis, United Kingdom, 1995-2017

\begin{tabular}{|c|c|c|c|c|c|}
\hline \multirow{2}{*}{ Characteristic } & \multicolumn{2}{|c|}{ TRT use } & \multicolumn{2}{|c|}{ Non-use } & \multirow[b]{2}{*}{ Standardized difference } \\
\hline & No. & $\%$ & No. & $\%$ & \\
\hline Total & \multicolumn{2}{|l|}{3,330} & \multicolumn{2}{|l|}{3,330} & \\
\hline Age, years ${ }^{\mathrm{a}}$ & \multicolumn{2}{|c|}{$59.9(8.9)$} & \multicolumn{2}{|c|}{$60.1(9.3)$} & 0.02 \\
\hline \multicolumn{6}{|l|}{ Age, years } \\
\hline $45-54$ & 1,062 & 31.9 & 1,069 & 32.1 & 0.004 \\
\hline $55-64$ & 1,252 & 37.6 & 1,198 & 36.0 & 0.03 \\
\hline $65-74$ & 798 & 24.0 & 833 & 25.0 & 0.02 \\
\hline$\geq 75$ & 218 & 6.5 & 230 & 6.9 & 0.01 \\
\hline Alcohol-related disorders & 504 & 15.1 & 493 & 14.8 & 0.01 \\
\hline \multicolumn{6}{|l|}{ Calendar year } \\
\hline 1995-2000 & 79 & 1.2 & 79 & 1.2 & 0.00 \\
\hline 2001-2005 & 438 & 6.6 & 438 & 6.6 & 0.00 \\
\hline 2006-2010 & 1,224 & 18.4 & 1,224 & 18.4 & 0.00 \\
\hline 2011-2016 & 1,589 & 23.9 & 1,589 & 23.9 & 0.00 \\
\hline \multicolumn{6}{|l|}{ Smoking status } \\
\hline Current & 390 & 11.7 & 367 & 11.0 & 0.02 \\
\hline Former & 1,471 & 44.2 & 1,443 & 43.3 & 0.02 \\
\hline Never & 1,424 & 42.8 & 1,471 & 44.2 & 0.03 \\
\hline Unknown & 45 & 1.4 & 49 & 1.5 & 0.01 \\
\hline \multicolumn{6}{|l|}{ Body mass index ${ }^{b}$} \\
\hline$<25$ & 387 & 11.6 & 397 & 11.9 & 0.01 \\
\hline $25-30$ & 1,210 & 36.3 & 1,183 & 35.5 & 0.02 \\
\hline$\geq 30$ & 1,640 & 49.3 & 1,655 & 49.7 & 0.01 \\
\hline Unknown & 93 & 2.8 & 95 & 2.9 & 0.00 \\
\hline \multicolumn{6}{|l|}{$\begin{array}{l}\text { Charlson comorbidity } \\
\text { index }\end{array}$} \\
\hline 0 & 1,255 & 37.7 & 1,280 & 38.4 & 0.02 \\
\hline $1-2$ & 1,254 & 37.7 & 1,203 & 36.1 & 0.03 \\
\hline$\geq 3$ & 821 & 24.7 & 847 & 25.4 & 0.02 \\
\hline Previous cancer & 313 & 9.4 & 300 & 9.0 & 0.01 \\
\hline $\begin{array}{l}\text { Nonsteroidal anti- } \\
\text { inflammatory drugs }\end{array}$ & 1,785 & 53.6 & 1,814 & 54.5 & 0.02 \\
\hline Aspirin & 1,149 & 34.5 & 1,159 & 34.8 & 0.01 \\
\hline Statins & 1,748 & 52.5 & 1,753 & 52.6 & 0.00 \\
\hline Metformin & 717 & 21.5 & 732 & 22.0 & 0.01 \\
\hline
\end{tabular}

Abbreviations: TRT, testosterone replacement therapy.

${ }^{a}$ Values are expressed as mean (standard deviation).

${ }^{b}$ Weight $(\mathrm{kg}) /$ height $(\mathrm{m})^{2}$. 
Table 8. Crude and Adjusted HRs for the Association Between the Use of Testosterone Replacement Therapy and the Risk of Prostate Cancer Among Patients with Late-Onset Hypogonadism, United Kingdom, 1995-2017

\begin{tabular}{|c|c|c|c|c|c|c|c|c|}
\hline & \multirow[t]{2}{*}{ Patients } & \multirow[t]{2}{*}{ Events } & \multirow{2}{*}{$\begin{array}{c}\text { Person- } \\
\text { years }\end{array}$} & \multicolumn{2}{|c|}{ Incidence rate } & \multirow{2}{*}{$\begin{array}{c}\text { Crude } \\
\text { HR }\end{array}$} & \multicolumn{2}{|c|}{ Adjusted $H_{R}^{b}$} \\
\hline & & & & $\mathbf{I R}^{\mathbf{a}}$ & $\begin{array}{c}95 \% \\
\text { CI }\end{array}$ & & HR & $95 \% \mathrm{CI}$ \\
\hline \multicolumn{9}{|c|}{ Time-varying analysis } \\
\hline Non-use & & 162 & 42,618 & 3.8 & $3.2,4.4$ & 1.00 & 1.00 & Reference \\
\hline TRT use & & 53 & 15,606 & 3.4 & $2.5,4.4$ & 0.91 & 0.97 & $0.71,1.32$ \\
\hline \multicolumn{9}{|c|}{ Propensity score-matched analysis } \\
\hline Non-use & 3,330 & 32 & 8,225 & 3.9 & $2.7,5.5$ & & 1.00 & Reference \\
\hline TRT use & 3,339 & 48 & 13,994 & 3.4 & $2.5,4.5$ & & 0.87 & $0.56,1.36$ \\
\hline
\end{tabular}

Abbreviations: HR, hazard ratio; CI, confidence interval; TRT, testosterone replacement therapy; IR, incidence rate.

${ }^{a}$ Per 1000 Person-years.

b Adjusted for age, year of cohort entry, body mass index, alcohol-related disorders (including alcoholism, alcoholic cirrhosis of the liver, alcoholic hepatitis and hepatic failure), smoking status, cancer, Charlson Comorbidity Index, previous use of statins, aspirin, non-steroidal anti-inflammatory drugs 


\section{Testosterone Replacement Therapy and the Risk of Prostate Cancer in Men with Late-Onset Hypogonadism}

\section{Supplementary material}

Christina Santella $\mathrm{BSc}^{12}$, Christel Renoux MD $\mathrm{PhD}^{123}$, Hui Yin $\mathrm{MSc}^{1}$, Oriana H. Y. Yu MD $\mathrm{MSc}^{14}$, Laurent Azoulay $\mathrm{PhD}^{125}$

${ }^{1}$ Centre for Clinical Epidemiology, Lady Davis Institute, Jewish General Hospital, Montreal, Quebec, Canada

${ }^{2}$ Department of Epidemiology, Biostatistics, and Occupational Health, McGill University, Montreal, Quebec, Canada

${ }^{3}$ Department of Neurology and Neurosurgery, McGill University, Montreal, Quebec, Canada

${ }^{4}$ Division of Endocrinology, Jewish General Hospital, Montreal, Quebec, Canada 


\begin{tabular}{ll}
\hline Supplementary Table 1. Read Codes and Read Terms for Prostate Cancer \\
\hline Read Code & Read Term \\
\hline Prostate Cancer & Malignant neoplasm of prostate \\
B $46 . .00$ & Carcinoma in situ of prostate \\
B 834.00 & Gleason grading of prostate cancer \\
$4 \mathrm{M} 0 . .00$ & Gleason prostate grade 5-7 (medium) \\
4M01.00 & Neoplasm of uncertain behaviour of prostate \\
B 915.00 & Gleason prostate grade 2-4 (low) \\
4M00.00 & Gleason prostate grade 8-10 (high) \\
4M02.00 & Malignant neoplasm of prostate \\
B834000 & \\
\hline
\end{tabular}




\section{Supplementary Method 1: Marginal structural modelling}

To address the possibility of residual time-dependent confounding associated with timevarying exposures, we repeated the analysis using marginal structural Cox proportional hazards model. ${ }^{1,2}$ Using two pooled logistic regression models (one for the numerator and one for the denominator of the stabilized inverse-probability-of-treatment weights (IPTWs)), we estimated the conditional probability of being exposed to TRT at 30-day intervals during follow-up. The numerator treatment model included baseline covariates (listed in the manuscript) and follow-up time. The denominator model included covariates (listed in the manuscript) measured at each 30-day interval and follow-up time. In both the numerator and denominator models, follow-up time was modelled using a restricted cubic spline with five knots to reduce bias due to model misspecification from linearity assumptions. ${ }^{3}$ We also estimated inverse probability of censoring weights (IPCWs) in a similar fashion. Stabilized IPTW and IPCW for each patient in the cohort were computed using the predictive probabilities for both treatment and censoring models. The product of these stabilized IPTWs and IPCWs was then used to reweight the cohort, in which we estimated the marginal HR of prostate cancer associated with TRT use, with 95\% CIs, calculated using robust variance estimators. $^{2}$

\section{References}

1. Robins JM, Hernan MA, Brumback B. Marginal structural models and causal inference in epidemiology. Epidemiology. 2000;11(5):550-60.

2. Hernan MA, Brumback B, Robins JM. Marginal structural models to estimate the causal effect of zidovudine on the survival of HIV-positive men. Epidemiology. 2000;11(5):561-70.

3. Cole SR, Hernan MA. Constructing inverse probability weights for marginal structural models. Am J Epidemiol. 2008;168(6):656-64. 


\section{Supplementary Method 2: Inverse probability of screening weighting}

First, logistic regression was used to determine predictors of PSA screening, measured in the CPRD during each 1-year interval over the follow-up period. Predictors included: year of cohort entry, age, alcohol-related disorders (including alcoholism, alcoholic cirrhosis of the liver, alcoholic hepatitis, and hepatic failure), smoking status (current, former, never, unknown), body mass index (BMI) $\left(<25 \mathrm{~kg} / \mathrm{m}^{2}, 25-29 \mathrm{~kg} / \mathrm{m}^{2}, \geq 30 \mathrm{~kg} / \mathrm{m}^{2}\right.$, unknown), Charlson Comorbidity Index, previous cancers (other than non-melanoma skin cancer), and drug exposures previously associated with prostate cancer incidence (NSAIDs, aspirin, statins, and metformin). The predictors were combined into a single model using a pooled logistic regression.

Second, the cohort was reweighted to an overall proportion of $60 \%$ of men screened, based on the prevalence of screening within the cohort. Using this, stabilized weights were computed, with the probability of screening used in the denominator of the weights. The probability of screening was computed from the logistic regression models fit separately in each time interval. These stabilized inverse probability of screening weights were then used to estimate the HR of prostate cancer associated with TRT use, with $95 \%$ CIs. 


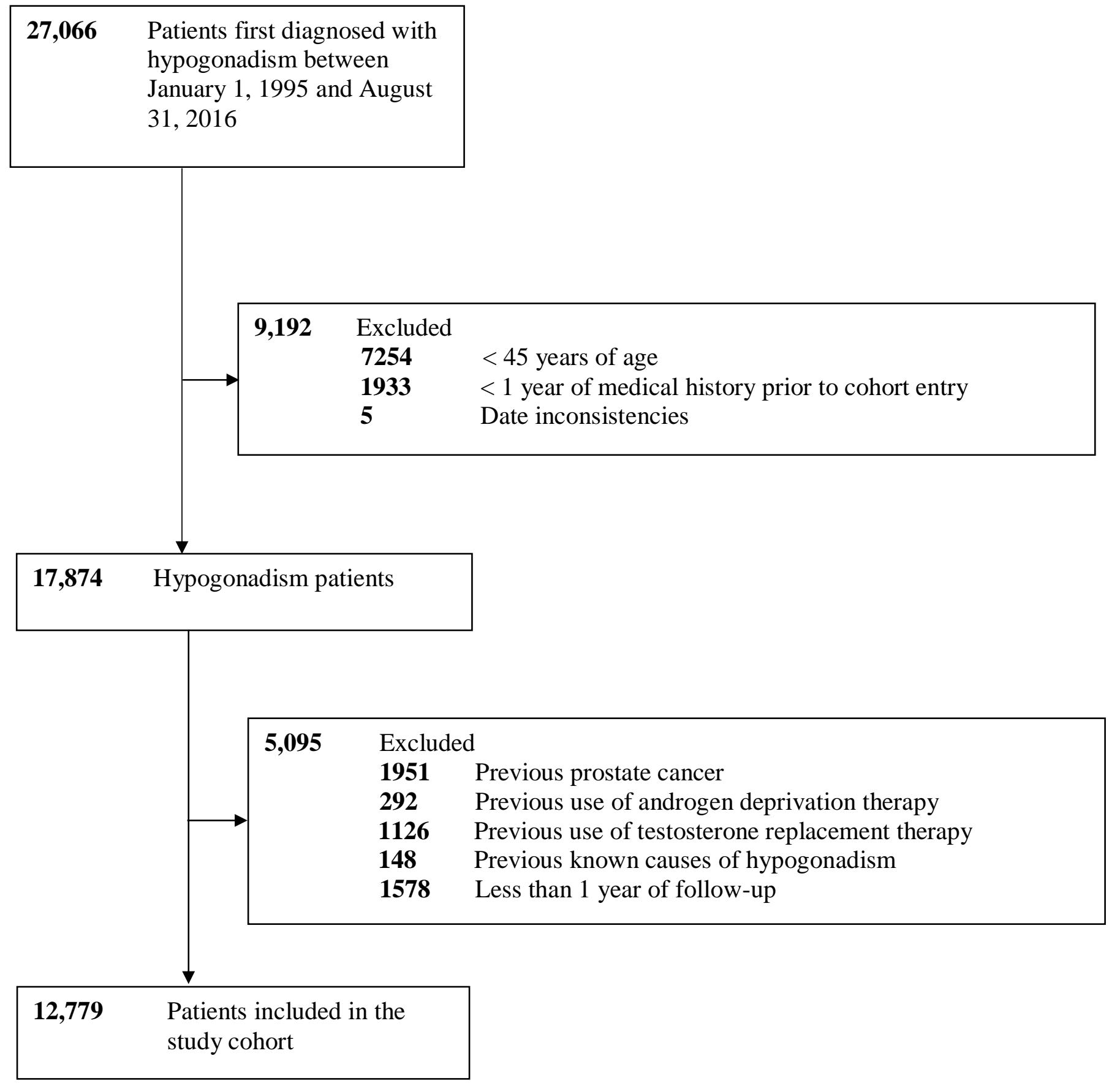

Supplementary Figure 1. Study flow chart illustrating the process for assembling the study cohort of men diagnosed with hypogonadism in the United Kingdom Clinical Practice Research Datalink between 1995 and 2016. 


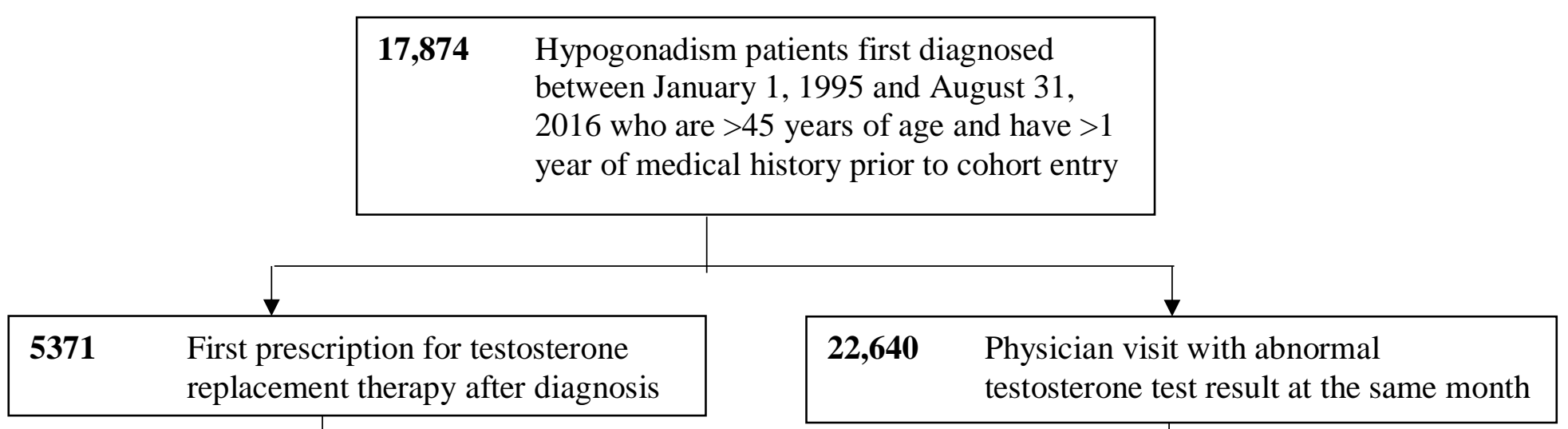

1906 Excluded

57 Previous prostate cancer

144 Previous use of androgen deprivation therapy

987 Previous use of testosterone replacement therapy before diagnosis

256 Previous known causes of hypogonadism

462 Less than 1 year of followup

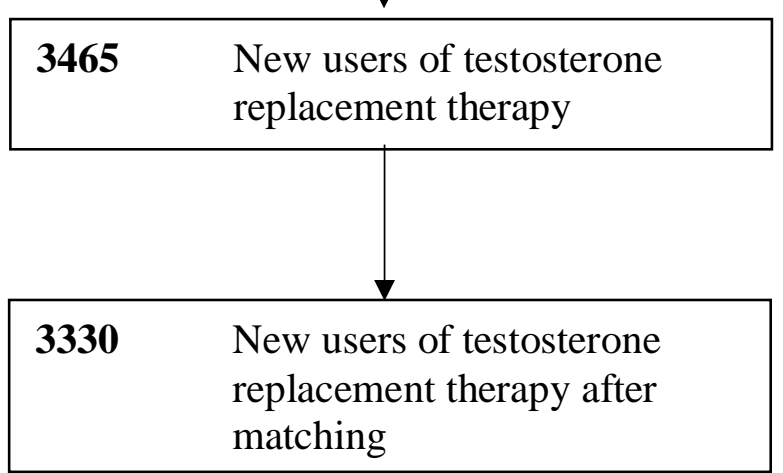

7098 Excluded

3384 Previous prostate cancer

318 Previous use of androgen

deprivation therapy

1017 Previous use of testosterone replacement therapy

287 Previous known causes of hypogonadism

2092 Less than 1 year of followup

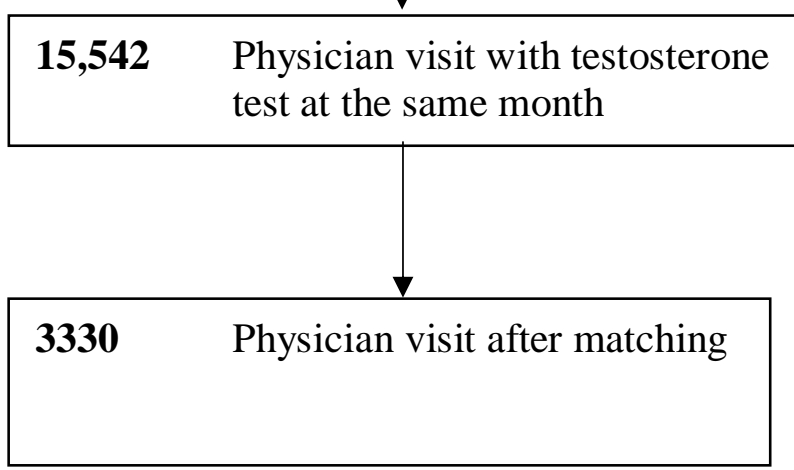

Supplementary Figure 2. Study flow chart representing the assembling of the propensity score matched cohort using the United Kingdom Clinical Practice Research Datalink. 


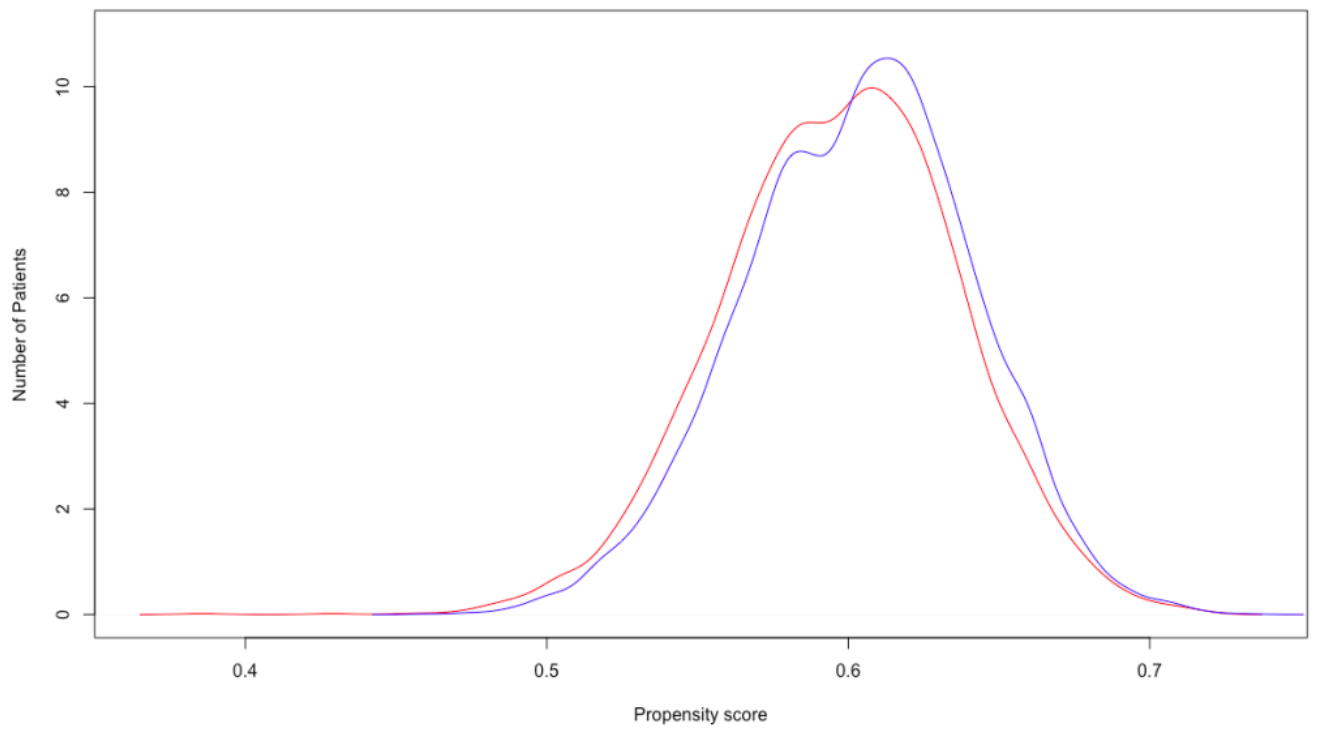

Red line: Users of testosterone replacement therapy; Blue line: Non-users of testosterone replacement therapy

Supplementary Figure 3. Propensity score distributions of users and non-users of testosterone replacement therapy prior to matching, United Kingdom, $1995-2017$.

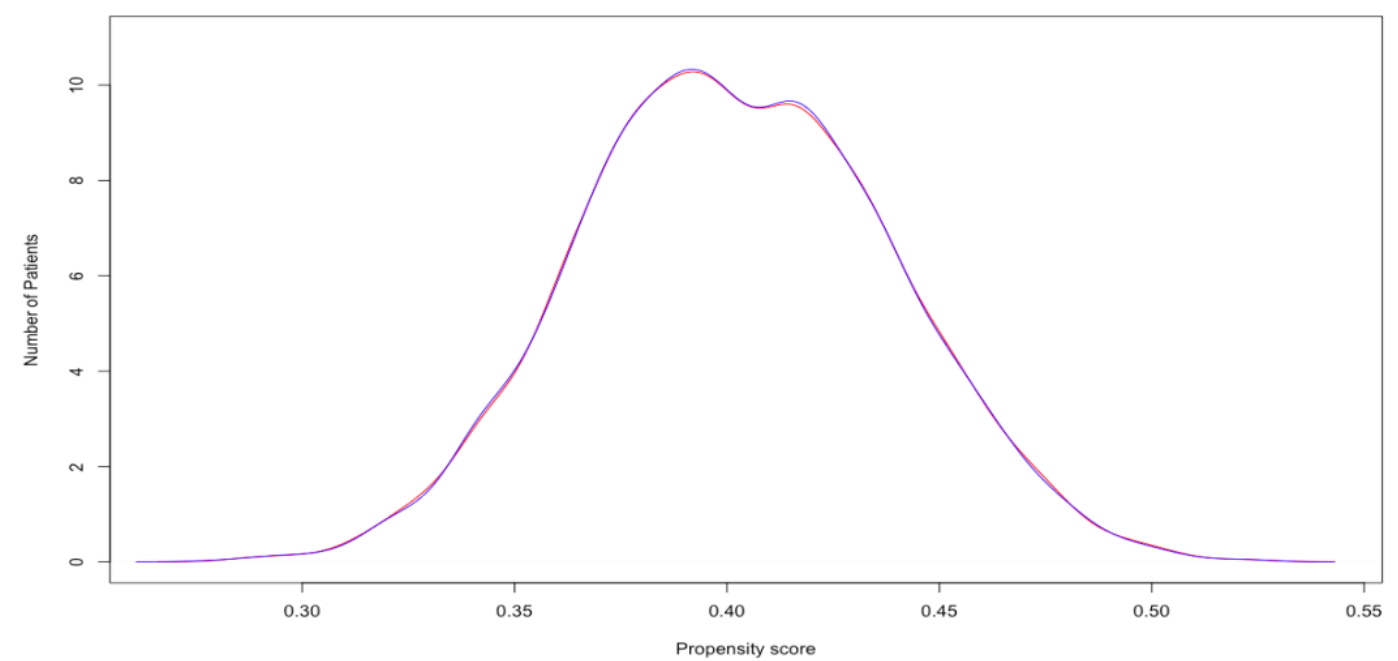

Red line: Users of testosterone replacement therapy; Blue line: Non-users of testosterone replacement therapy

Supplementary Figure 4. Propensity score distributions of users and non-users of testosterone replacement therapy after matching, United Kingdom, $1995-2017$. 


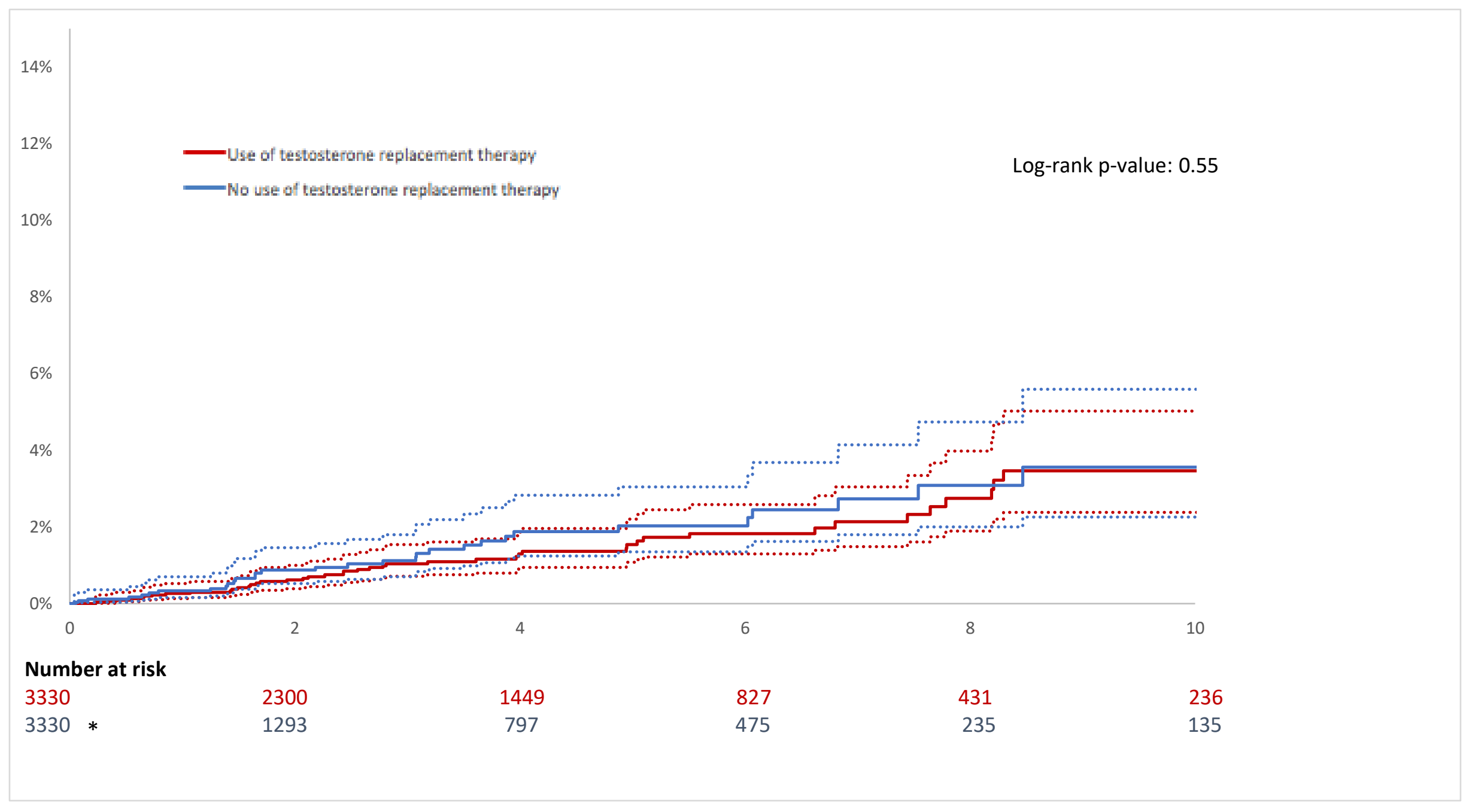

*All patients in the cohort had at least one year of follow-up.

Supplementary Figure 5. Cumulative incidence curves of prostate cancer for users of testosterone replacement therapy and non-users, United Kingdom, $1995-2017$. 
Supplementary Table 2. Baseline Characteristics of Testosterone Replacement Therapy Users and Non-

Users Prior to Matching in the Propensity Score-Matched Analysis, United Kingdom, 1995-2017

\begin{tabular}{|c|c|c|}
\hline Characteristic & TRT use & Non-use \\
\hline Total & 3,465 & 15,542 \\
\hline Age, years, mean (SD) & $59.9(8.9)$ & $60.3(9.4)$ \\
\hline Alcohol-related disorders, $\mathrm{n}(\%)$ & $523(15.1)$ & $2,347(15.1)$ \\
\hline \multicolumn{3}{|l|}{ Smoking status, n (\%) } \\
\hline Current & $412(11.9)$ & $2,086(13.4)$ \\
\hline Former & $1,520(43.9)$ & $6,513(41.9)$ \\
\hline Never & $1,485(42.9)$ & $6,692(43.1)$ \\
\hline Unknown & $48(1.4)$ & $251(1.6)$ \\
\hline \multicolumn{3}{|l|}{ Body mass index, $\mathrm{kg} / \mathrm{m}^{2}, \mathrm{n}(\%)$} \\
\hline$<25$ & $409(11.8)$ & $2008(12.9)$ \\
\hline $25-30$ & $1,249(36.1)$ & $5,723(36.8)$ \\
\hline$\geq 30$ & $1,711(49.4)$ & $7,411(47.7)$ \\
\hline Unknown & $96(2.8)$ & $400(2.6)$ \\
\hline \multicolumn{3}{|l|}{ Charlson comorbidity index, $\mathrm{n}(\%)$} \\
\hline 0 & $1,255(37.7)$ & $1,280(38.4)$ \\
\hline $1-2$ & $1,254(37.7)$ & $1,203(36.1)$ \\
\hline$\geq 3$ & $821(24.7)$ & $847(25.4)$ \\
\hline Previous cancer, n $(\%)$ & $338(9.8)$ & $1,374(8.8)$ \\
\hline Nonsteroidal anti-inflammatory drugs, n (\%) & $1,868(53.9)$ & $7,863(50.6)$ \\
\hline Aspirin, $\mathrm{n}(\%)$ & $1,205(34.8)$ & $5,123(33.0)$ \\
\hline Statins, n $(\%)$ & $1,809(52.2)$ & $7,544(48.5)$ \\
\hline Metformin, $\mathrm{n}(\%)$ & $754(21.8)$ & $3,065(19.7)$ \\
\hline
\end{tabular}

Abbreviations: SD, standard deviation; TRT, testosterone replacement therapy. 


\begin{tabular}{|c|c|c|c|c|c|}
\hline $\begin{array}{l}\text { Supplementar } \\
\text { and the Risk of }\end{array}$ & $\begin{array}{l}\text { Table } 3 . \\
\text { rostate C }\end{array}$ & $\begin{array}{l}\text { de and A } \\
\text { er, Unite }\end{array}$ & $\begin{array}{l}\text { sted HRs for the Asso } \\
\text { ingdom, 1995-2017 }\end{array}$ & ion Between the $\mathrm{L}$ & stosterone Replacement 7 \\
\hline Exposure & Events & $\begin{array}{l}\text { Person- } \\
\text { years }\end{array}$ & Incidence $(95 \% \mathrm{CI})^{\mathrm{a}}$ & Crude HR & Adjusted HR (95\% CI) ${ }^{b}$ \\
\hline Non-use & 162 & 42,618 & $3.8(3.2,4.4)$ & 1.00 [Reference] & 1.00 [Reference] \\
\hline Use & 53 & 15,606 & $3.4(2.5,4.4)$ & 0.91 & $0.97(0.71,1.32)$ \\
\hline Type of TRT & & & & & \\
\hline Injection & 11 & 3606 & $3.1(1.5,5.5)$ & 0.82 & $0.89(0.48,1.65)$ \\
\hline Patch & 5 & 1526 & $3.3(1.1,7.6)$ & 0.89 & $0.90(0.37,2.20)$ \\
\hline Tablet/capsule & 4 & 1013 & $3.9(1.1,10.1)$ & 1.09 & $0.97(0.36,2.65)$ \\
\hline Gel & 15 & 4368 & $3.4(1.9,5.7)$ & 0.92 & $0.96(0.56,1.64)$ \\
\hline Other $^{c}$ & 18 & 5093 & $3.5(2.1,5.6)$ & 0.94 & $1.05(0.64,1.72)$ \\
\hline
\end{tabular}

Abbreviations: HR, hazard ratio; CI, confidence interval; TRT, testosterone replacement therapy.

${ }^{\text {a }}$ Per 1000 Person-Years.

${ }^{\mathbf{b}}$ Adjusted for age, year of cohort entry, body mass index, alcohol-related disorders (including alcoholism, alcoholic cirrhosis of the liver, alcoholic hepatitis and hepatic flexure), smoking status, cancer, Charlson Comorbidity Index, previous use of statins, aspirin, non-steroidal anti-inflammatory drugs and metformin.

${ }^{\mathrm{C}}$ Include combination uses and switches of injection, patch, tablet/capsule, gel. 


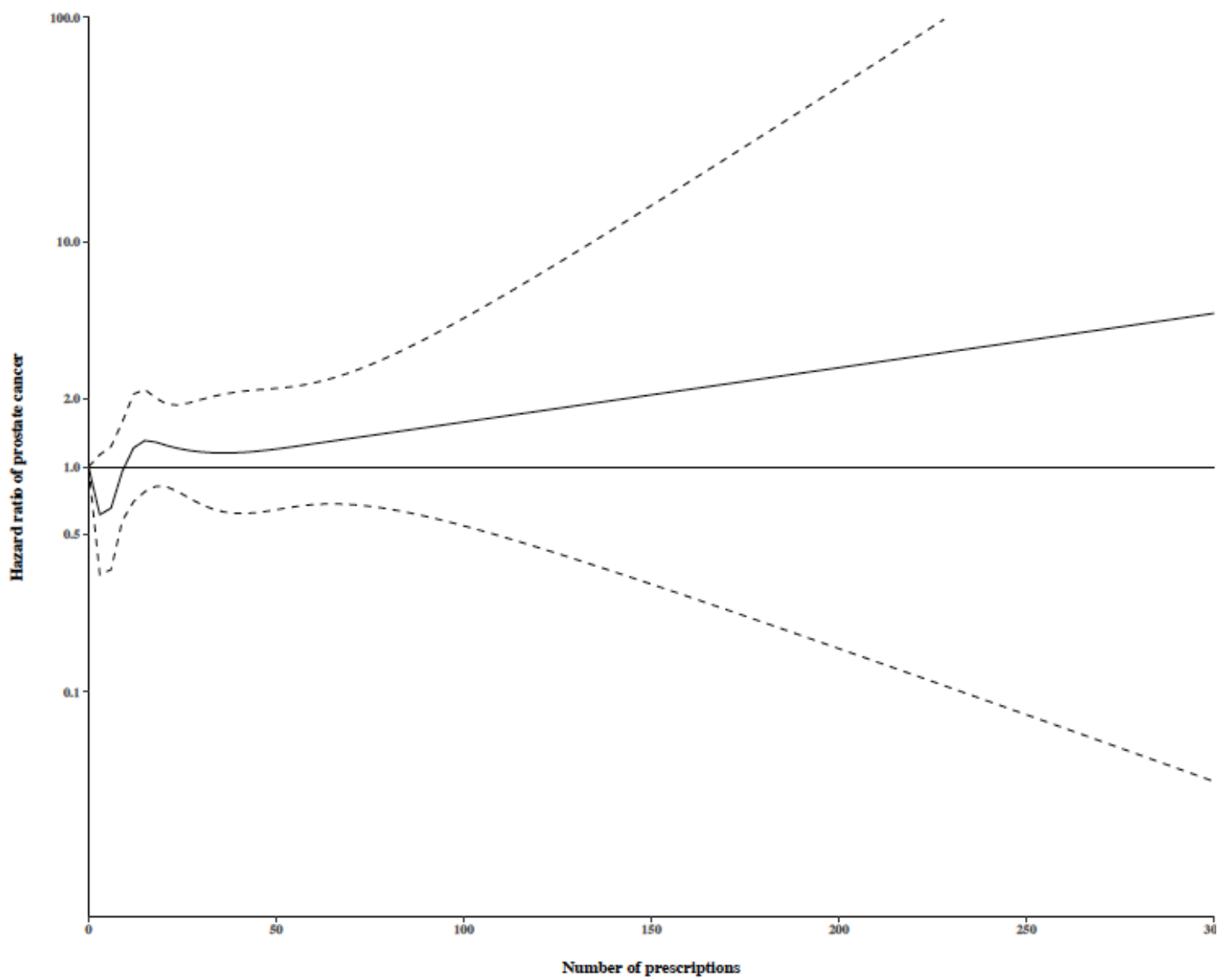

Supplementary Figure 6. Smooth restricted cubic spline curve of adjusted hazard ratio of prostate cancer as a function of the number of TRT prescriptions, United Kingdom, 1995-2017. TRT, testosterone replacement therapy. 


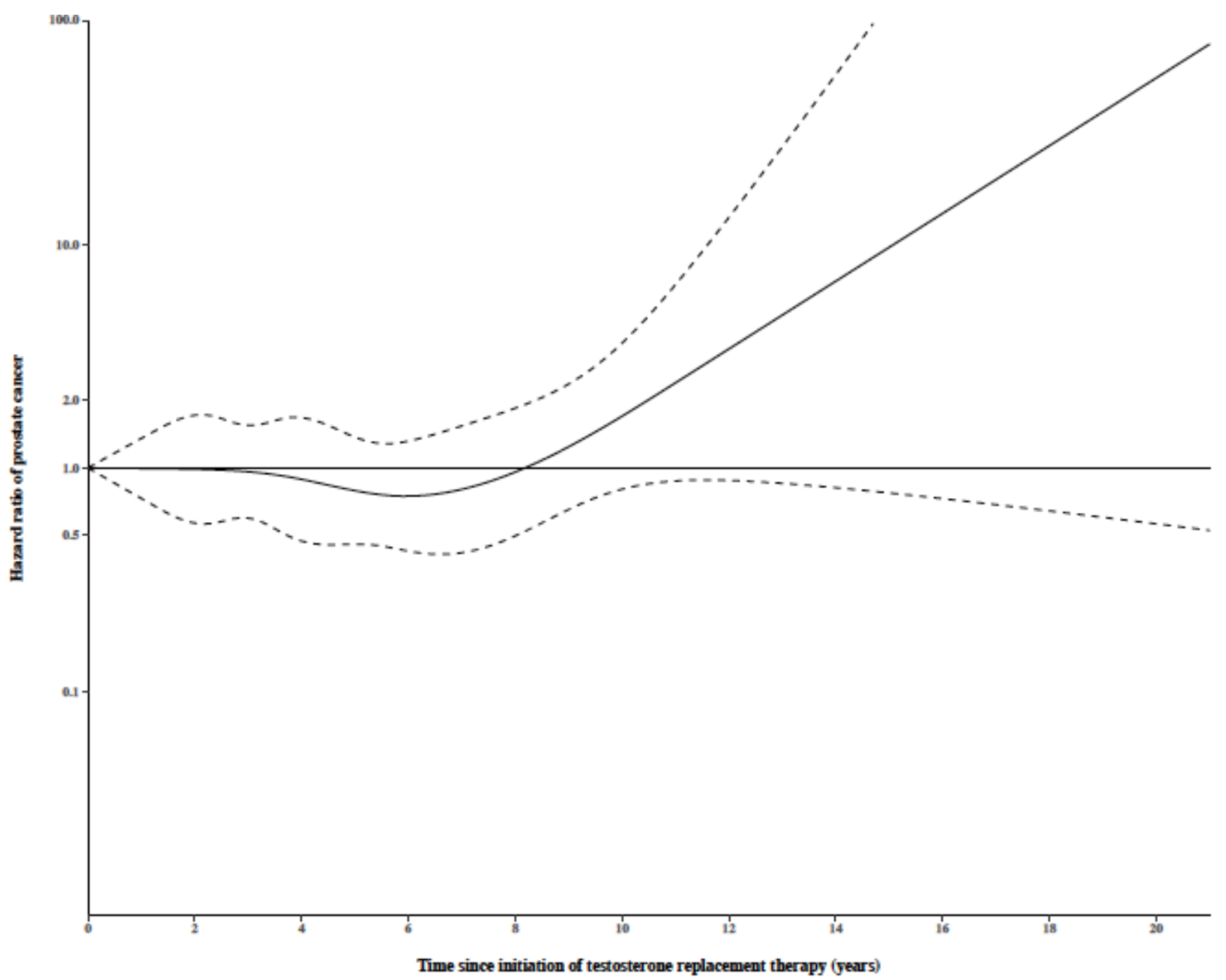

Supplementary Figure 7. Smooth restricted cubic spline curve of adjusted hazard ratio of prostate cancer as a function of time since initiation of TRT in years, United Kingdom, 1995-2017. TRT, testosterone replacement therapy. 
Supplementary Table 4. Crude and Adjusted HRs for the Association Between the Use of Testosterone Replacement Therapy and the Risk of Prostate Cancer (Lag 2 years), United Kingdom, 1995-2017

\begin{tabular}{llllll}
\hline Exposure & Events & Person-years & $\begin{array}{l}\text { Incidence rate }(\mathbf{9 5 \%} \\
\mathbf{C I}^{\mathbf{a}}\end{array}$ & Crude HR & Adjusted HR (95\% CI) $^{\mathbf{b}}$ \\
\hline Non-use & 127 & 34,188 & $3.7(3.1,4.4)$ & 1.00 [Reference] & 1.00 [Reference] \\
\hline Use & 43 & 12,247 & $3.5(2.5,4.7)$ & 0.94 & $0.99(0.70,1.40)$
\end{tabular}

Abbreviations: HR, hazard ratio; CI, confidence interval.

a Per 1000 Person-Years.

${ }^{\mathbf{b}}$ Adjusted for age, year of cohort entry, body mass index, alcohol-related disorders (including alcoholism, alcoholic cirrhosis of the liver, alcoholic hepatitis and hepatic flexure), smoking status, cancer, Charlson Comorbidity Index, previous use of statins, aspirin, non-steroidal anti-inflammatory drugs and metformin. 
Supplementary Table 5. Crude and Adjusted HRs for the Association Between the Use of Testosterone Replacement Therapy and the Risk of Prostate Cancer (Lag 3 years), United Kingdom, 1995-2017

\begin{tabular}{llllll}
\hline Exposure & Events & Person-years & Incidence rate $(\mathbf{9 5 \%} \mathbf{C I})^{\mathbf{a}}$ & Crude HR & $\begin{array}{l}\text { Adjusted HR (95\% CI) } \\
\mathbf{b}\end{array}$ \\
\hline Non-use & 101 & 27,045 & $3.7(3.0,4.5)$ & $1.00[$ Reference] & $1.00[$ Reference] \\
\hline Use & 34 & 9452 & $3.6(2.5,5.0)$ & 0.95 & $0.98(0.66,1.44)$ \\
\hline
\end{tabular}

Abbreviations: HR, hazard ratio; CI, confidence interval.

${ }^{\text {a }}$ Per 1000 Person-Years.

${ }^{b}$ Adjusted for age, year of cohort entry, body mass index, alcohol-related disorders (including alcoholism, alcoholic cirrhosis of the liver, alcoholic hepatitis and hepatic flexure), smoking status, cancer, Charlson Comorbidity Index, previous use of statins, aspirin, non-steroidal anti-inflammatory drugs and metformin. 
Supplementary Table 6. Crude and Adjusted HRs for the Association Between the Use of Testosterone Replacement Therapy and the Risk of Prostate Cancer (Competing Risk), United Kingdom, 1995-2017

\begin{tabular}{llllll}
\hline Exposure & Events & Person-years & $\begin{array}{l}\text { Incidence rate }(\mathbf{9 5 \%} \\
\text { CI) }\end{array}$ & Crude HR & $\begin{array}{l}\text { Adjusted HR (95\% CI) } \\
\text { b }\end{array}$ \\
\hline Non-use & 162 & 42,618 & $3.8(3.2,4.4)$ & $1.00[$ Reference $]$ & $1.00[$ Reference] \\
\hline Use & 53 & 15,606 & $3.4(2.5,4.4)$ & 0.92 & $0.98(0.72,1.35)$ \\
\hline
\end{tabular}

Abbreviations: HR, hazard ratio; $\mathrm{CI}$, confidence interval.

${ }^{a}$ Per 100,000 Person-Years.

b Adjusted for age, year of cohort entry, body mass index, alcohol-related disorders (including alcoholism, alcoholic cirrhosis of the liver, alcoholic hepatitis and hepatic flexure), smoking status, cancer, Charlson Comorbidity Index, previous use of statins, aspirin, non-steroidal anti-inflammatory drugs and metformin 
Supplementary Table 7. Crude and Adjusted HRs for the Association Between the Use of Testosterone Replacement Therapy and the Risk of Prostate Cancer (Marginal Structural Model), United Kingdom, 1995-2017

\begin{tabular}{llllll}
\hline Exposure & Events & Person-months & $\begin{array}{l}\text { Incidence rate }(95 \% \\
\mathbf{C I}^{\mathbf{a}}\end{array}$ & Crude HR & $\begin{array}{l}\text { Adjusted HR (95\% } \\
\text { CI) }\end{array}$ \\
\hline Non-use & 162 & 521,413 & $0.3(0.3,0.4)$ & $1.00[$ Reference $]$ & $1.00[$ Reference $]$ \\
\hline Use & 53 & 193,275 & $0.3(0.2,0.4)$ & 0.89 & $0.94(0.69,1.28)$
\end{tabular}

Abbreviations: HR, hazard ratio; $\mathrm{CI}$, confidence interval.

${ }^{\text {a }}$ Per 1000 Person-Months.

${ }^{b}$ Adjusted for age, year of cohort entry, body mass index, alcohol-related disorders (including alcoholism, alcoholic cirrhosis of the liver, alcoholic hepatitis and hepatic flexure), smoking status, cancer, Charlson Comorbidity Index, previous use of statins, aspirin, non-steroidal anti-inflammatory drugs and metformin. 
Analysls

No lag window

History of PSA testing

No history of PSA testing

Inverse probability of screening weighting

0.3
$\mathrm{HR} \quad(95 \% \mathrm{Cl})$

0.75 (0.57 to 0.99$)$

$0.61(0.33$ to 1.11$)$

$1.19(0.82$ to 1.72$)$

$0.73(0.52$ to 1.01$)$

Supplementary Figure 8. Forest plot illustrating the adjusted HRs and 95\% CIs from the results of the detection bias analyses. 
Supplementary Table 8. Crude and Adjusted HRs for the Association Between the Use of Testosterone Replacement

Therapy and the Risk of Prostate Cancer (No Lag Window), United Kingdom, 1995-2017

\begin{tabular}{llllll}
\hline Exposure & Events & Person-years & $\begin{array}{l}\text { Incidence rate (95\% } \\
\text { CI) }\end{array}$ & Crude HR & Adjusted HR (95\% CI) $^{\mathbf{b}}$ \\
\hline Non-use & 289 & 52,554 & $5.5(4.9,6.2)$ & 1.00 [Reference] & $1.00[$ Reference] \\
\hline Use & 64 & 19,541 & $3.3(2.5,4.2)$ & 0.70 & $0.75(0.57,0.99)$
\end{tabular}

Abbreviations: HR, hazard ratio; CI, confidence interval; TRT, testosterone replacement therapy.

${ }^{\text {a }}$ Per 100,000 Person-Years.

${ }^{\mathbf{b}}$ Adjusted for age, year of cohort entry, body mass index, alcohol-related disorders (including alcoholism, alcoholic cirrhosis of the liver, alcoholic hepatitis and hepatic

flexure), smoking status, cancer, Charlson Comorbidity Index, previous use of statins, aspirin, non-steroidal anti-inflammatory drugs and metformin. 
Supplementary Table 9. Crude and Adjusted HRs for the Association Between the Use of Testosterone Replacement Therapy and the Risk of Prostate Cancer (Interaction with PSA

Test), United Kingdom, 1995-2017

\begin{tabular}{|c|c|c|c|}
\hline Exposure & Without PSA test ${ }^{a}$ & With PSA test ${ }^{a}$ & P-value \\
\hline Non-use & 1.00 [Reference] & 1.00 [Reference] & \\
\hline Use & $1.19(0.82,1.72)$ & $0.61(0.33,1.11)$ & 0.17 \\
\hline
\end{tabular}


Supplementary Table 10. Crude and Adjusted HRs for the Association Between the Use of Testosterone Replacement Therapy and the Risk of Prostate Cancer (Inverse Probability of Screening Weighting), United Kingdom, 1995-2017

\begin{tabular}{|c|c|c|c|c|c|}
\hline Exposure & Events & $\begin{array}{l}\text { Person- } \\
\text { months }\end{array}$ & $\begin{array}{l}\text { Incidence rate } \\
(95 \% \mathrm{CI})^{\mathrm{a}}\end{array}$ & Crude HR & $\begin{array}{l}\text { Adjusted HR } \\
(95 \% \text { CI })^{b}\end{array}$ \\
\hline Non-use & 162 & 521,413 & $0.3(0.3,0.4)$ & $\begin{array}{l}1.00 \\
\text { [Reference] }\end{array}$ & 1.00 [Reference] \\
\hline Use & 53 & 193,275 & $0.3(0.2,0.4)$ & 0.67 & $0.73(0.52,1.01)$ \\
\hline
\end{tabular}




\section{Chapter 6: General discussion}

This thesis investigated the association between TRT and the risk of prostate cancer in men with late-onset hypogonadism. In this study, TRT use was not associated with an increased risk of prostate cancer in men with late-onset hypogonadism. Similar results were observed in the propensity score-matched analysis, which further investigated the impact of residual confounding. Moreover, findings remained consistent in secondary analyses assessing the association by type and measures of duration, as well as in several sensitivity analyses. Finally, as an ancillary analysis, the impact of detection bias was investigated by removing the lag period, stratifying on PSA testing, and using inverse probability of screening weighting. Overall, the results of the detection bias analyses suggested that TRT users were more likely to be monitored for prostate cancer than non-users.

\subsection{Clinical implications}

The overall safety profile of TRT is controversial. Particularly, it has been the subject of several safety concerns with regards to cardiovascular and cerebrovascular outcomes, venous thromboembolism, and prostate cancer. ${ }^{7,52,55,62}$ Regulatory agencies have therefore taken necessary precautions to warn the public about these risks. Indeed, Health Canada, FDA, and EMA issued product labelling changes to reflect the potential risk of cardiovascular complications with TRT use, and are urging physicians to discuss and carefully consider these risks before prescribing the therapy. ${ }^{5,42,101}$ Labelling changes have also been issued by Health Canada and the FDA warning about the potential risk of venous thromboembolism associated with TRT use. ${ }^{102,103}$ In addition, due to increasing off-label use in men with late-onset hypogonadism, the regulatory agencies required that manufacturers ensure that product labels emphasize that pathologic hypogonadism remains the sole indication for the drug. ${ }^{5}$ Finally, as an association between TRT and prostate cancer is 
biologically plausible, current treatment guidelines recommend against TRT initiation in patients with a risk of prostate cancer. ${ }^{2}$ Furthermore, they recommend that physcians closely monitor the PSA levels of patients over the course of TRT treatment. ${ }^{2}$

Given the safety warnings and current treatment guidelines for the use of TRT, this study offers some reassurance in the context of prostate cancer. In fact, the results of the detection bias analyses appear to suggest that physicians in the UK closely monitor patients using TRT. Indeed, in this study, the PSA testing rate was higher among TRT users than among non-users $(38.0 \vee 24.8)$. Thus, in light of the surge in TRT prescriptions, the findings suggest that physicians may be proceeding with caution when choosing this therapy for their patients.

In spite of these reassuring findings, it must be noted that this study was conducted using a primary care database based in the $\mathrm{UK}$, and a very specific clinical population was included. Therefore, these findings should be interpreted carefully as they may not be generalizable to other clinical contexts outside of the UK. For instance, given that TRT prescribing and testosterone testing has been shown to be substantially higher in the US compared to the UK over the recent decades, ${ }^{43}$ the results may vary if replicated in this setting.

\subsection{Future directions}

As discussed in section 6.1., TRT prescription patterns generally vary across different countries. As well, the incidence of prostate cancer tends to differ across populations, depending on factors such as race and family history ${ }^{69}$ - variables not reliably recorded in the CPRD. Thus, while the observed lack of an association between TRT and prostate cancer is reassuring, future well-conducted observational studies in other healthcare settings and populations remain necessary to confirm these findings. 


\subsubsection{Prostatic conditions}

Although there was no association observed with prostate cancer, it would be worth investigating the effect of TRT on other prostatic abnormalities, such as benign prostatic hyperplasia (BPH). Androgens play an essential role in prostate growth and $\mathrm{BPH}$ pathogenesis, and it has been shown that suppressing androgen-dependent prostate growth impedes disease progression. ${ }^{104} \mathrm{BPH}$ is associated with a number of undesirable symptoms, mainly of the urinary tract, such as urinary incontinence and incomplete bladder emptying. ${ }^{105}$ To date, there are few studies that have investigated the association between androgen supplementation and the risk of $\mathrm{BPH}$, with most evidence coming from small RCTs or case reports. ${ }^{106}$ Thus, future studies are warranted to study this potential adverse event.

\subsubsection{Androgen-driven cancers}

Finally, possible associations between TRT and other androgen-driven cancers cannot be ruled out. Indeed, some recent evidence in animals has suggested the importance of the androgen receptor in the pathogenesis of bladder cancer. ${ }^{107}$ As such, observational studies have investigated the association between androgen ablation with ADT and bladder cancer in patients with prostate cancer. ${ }^{108-110}$ Findings from these studies suggested a highly protective effect of ADT against bladder cancer. ${ }^{108-110}$ Despite several methodological limitations, these studies seem to point towards a potential association between androgens and bladder cancer. ${ }^{108-110}$ In particular, if androgen ablation has the potential to be protective against bladder cancer, then further study is warranted to investigate if androgen supplementation (i.e., TRT) can drive the development or progression of bladder cancer. 
To conclude, this study showed no association between TRT and prostate cancer, which is reassuring given the increasing number of men on this therapy and the controversial safety profile. Nonetheless, physicians should continue to monitor men over the course of TRT treatment, as a biologically plausible mechanism for the involvement of testosterone in promoting prostate cancer cannot be ruled out. For similar reasons, other prostatic and androgen-related outcomes should be considered for future research, in order to ensure that all stakeholders are aware of the potential risks associated with TRT. 


\section{Chapter 7: Conclusion}

This thesis illustrated that TRT use is not associated with an increased risk of prostate cancer in men with late-onset hypogonadism. Given the safety concerns surrounding TRT, including potentially increasing the risk of prostate cancer, these findings provide some reassurance to physicians and patients considering this therapy.

This study provides a valuable addition to the safety profile of TRT, particularly with regards to prostate cancer. Future research should be geared towards investigating this association in other health care settings, as well assessing potential associations with other prostatic diseases and androgen-driven cancers. More generally, further research needs to be conducted to clarify the real-world benefit of this therapy compared to the risk of adverse events. Ultimately, such information on the overall risk-benefit profile of TRT would aid policy-makers in making informed decisions about the use of TRT in men with late-onset hypogonadism. 


\section{Chapter 8: References}

1. Wu FC, Tajar A, Beynon JM, Pye SR, Silman AJ, Finn JD, O'Neill TW, Bartfai G, Casanueva FF, Forti G, Giwercman A, Han TS, Kula K, Lean ME, Pendleton N, Punab M, Boonen S, Vanderschueren D, Labrie F, Huhtaniemi IT. Identification of late-onset hypogonadism in middle-aged and elderly men. $N$ Engl J Med 2010;363(2):123-35.

2. Bhasin S, Brito JP, Cunningham GR, Hayes FJ, Hodis HN, Matsumoto AM, Snyder PJ, Swerdloff RS, Wu FC, Yialamas MA. Testosterone Therapy in Men With Hypogonadism: An Endocrine Society* Clinical Practice Guideline. The Journal of Clinical Endocrinology \& Metabolism 2018;103(5):1715-1744.

3. Gan EH, Pattman S, S HSP, Quinton R. A UK epidemic of testosterone prescribing, 2001-2010. Clin Endocrinol (Oxf) 2013;79(4):564-70.

4. Baillargeon J, Urban RJ, Ottenbacher KJ, Pierson KS, Goodwin JS. Trends in androgen prescribing in the united states, 2001 to 2011. JAMA Internal Medicine 2013;173(15):1465-1466.

5. Administration UFaD. Drug Safety Communication: FDA cautions about using testosterone products for low testosterone due to aging. 2015.

6. Heinlein CA, Chang C. Androgen Receptor in Prostate Cancer. Endocrine Reviews 2004;25(2):276-308.

7. Cui Y, Zong H, Yan H, Zhang Y. The effect of testosterone replacement therapy on prostate cancer: a systematic review and meta-analysis. Prostate Cancer And Prostatic Diseases 2014;17:132.

8. Marks LS, Mazer NA, Mostaghel E, Hess DL, Dorey FJ, Epstein JI, Veltri RW, Makarov DV, Partin AW, Bostwick DG, Macairan ML, Nelson PS. Effect of 
testosterone replacement therapy on prostate tissue in men with late-onset hypogonadism: a randomized controlled trial. Jama 2006;296(19):2351-61.

9. Coward RM, Simhan J, Carson CC, 3rd. Prostate-specific antigen changes and prostate cancer in hypogonadal men treated with testosterone replacement therapy. BJU Int 2009;103(9):1179-83.

10. Debruyne FM, Behre HM, Roehrborn CG, Maggi M, Wu FC, Schroder FH, Jones TH, Porst H, Hackett G, Wheaton OA, Martin-Morales A, Meuleman E, Cunningham GR, Divan HA, Rosen RC. Testosterone treatment is not associated with increased risk of prostate cancer or worsening of lower urinary tract symptoms: prostate health outcomes in the Registry of Hypogonadism in Men. BJU Int 2017;119(2):216-224.

11. Eisenberg ML, Li S, Betts P, Herder D, Lamb DJ, Lipshultz LI. Testosterone therapy and cancer risk. BJU Int 2015;115(2):317-21.

12. Feneley Mark R, Carruthers M. Is Testosterone Treatment Good for the Prostate? Study of Safety during Long-Term Treatment. The Journal of Sexual Medicine 2012;9(8):2138-2149.

13. Haider A, Zitzmann M, Doros G, Isbarn H, Hammerer P, Yassin A. Incidence of prostate cancer in hypogonadal men receiving testosterone therapy: observations from 5-year median followup of 3 registries. J Urol 2015;193(1):80-6.

14. Loeb S, Folkvaljon Y, Damber JE, Alukal J, Lambe M, Stattin P. Testosterone Replacement Therapy and Risk of Favorable and Aggressive Prostate Cancer. J Clin Oncol 2017;35(13):1430-1436.

15. Walsh TJ, Shores MM, Krakauer CA, Forsberg CW, Fox AE, Moore KP, Korpak A, Heckbert SR, Zeliadt SB, Kinsey CE, Thompson ML, Smith NL, Matsumoto AM. Testosterone treatment and the risk of aggressive prostate cancer in men with low testosterone levels. PLoS One 2018;13(6):e0199194. 
16. Yassin A, Salman M, Talib RA, Yassin DJ. Is there a protective role of testosterone against high-grade prostate cancer? Incidence and severity of prostate cancer in 553 patients who underwent prostate biopsy: a prospective data register. Aging Male 2017;20(2):125-133.

17. Handelsman DJ. Global trends in testosterone prescribing, 2000-2011: expanding the spectrum of prescription drug misuse. Med J Aust 2013;199(8):548-51.

18. Mulligan T, Frick MF, Zuraw QC, Stemhagen A, McWhirter C. Prevalence of hypogonadism in males aged at least 45 years: the HIM study. Int J Clin Pract 2006;60(7):762-9.

19. Anaissie J, DeLay KJ, Wang W, Hatzichristodoulou G, Hellstrom WJ. Testosterone deficiency in adults and corresponding treatment patterns across the globe. Translational Andrology and Urology 2017;6(2):183-191.

20. Khandwala YS, Raheem OA, Ali MA, Hsieh T-C. Variation in Practice Pattern of Male Hypogonadism: A Comparative Analysis of Primary Care, Urology, Endocrinology, and HIV Specialists. American Journal of Men's Health 2017;12(2):472-478.

21. Kumar P, Kumar N, Thakur DS, Patidar A. Male hypogonadism: Symptoms and treatment. Journal of advanced pharmaceutical technology \& research 2010;1(3):297-301.

22. Eberhard Nieschlag HMB. Testosterone: Action, Deficiency, Substitution. 2 ed Springer-Verlag Berlin Heidelberg, 1998.

23. McBride JA, Carson CC, 3rd, Coward RM. Testosterone deficiency in the aging male. Therapeutic advances in urology 2016;8(1):47-60.

24. Oh S. Disturbance in testosterone production in leydig cells by polycyclic aromatic hydevrepocarbons. Development \& reproduction 2014;18(4):187-195. 
25. Kumar P, Kumar N, Thakur DS, Patidar A. Male hypogonadism: Symptoms and treatment. J Adv Pharm Technol Res 2010;1(3):297-301.

26. Dean JD, McMahon CG, Guay AT, Morgentaler A, Althof SE, Becher EF, Bivalacqua TJ, Burnett AL, Buvat J, El Meliegy A, Hellstrom WJ, Jannini EA, Maggi M, McCullough A, Torres LO, Zitzmann M. The International Society for Sexual Medicine's Process of Care for the Assessment and Management of Testosterone Deficiency in Adult Men. J Sex Med 2015;12(8):1660-86.

27. Dohle GA, S.; Bettocchi, C. EAU guidelines on male hypogonadism. www.eau.org Accessed May 17, 2019.

28. Wu FCW. Guideline for Male Testosterone Therapy: A European Perspective. The Journal of Clinical Endocrinology \& Metabolism 2007;92(2):418-419.

29. Sargis RM, Davis AM. Evaluation and Treatment of Male Hypogonadism. Jama 2018;319(13):1375-1376.

30. Nguyen CP, Hirsch MS, Moeny D, Kaul S, Mohamoud M, Joffe HV. Testosterone and "Age-Related Hypogonadism" — FDA Concerns. New England Journal of Medicine 2015;373(8):689-691.

31. Jones TH. Late onset hypogonadism. BMJ 2009;338:b352.

32. Grossmann M. Diagnosis and treatment of hypogonadism in older men: proceed with caution. Asian journal of andrology 2010;12(6):783-786.

33. Dohle G, Arver S, Bettocchi C, Kliesch S, Punab M, De Ronde W. Guidelines on male hypogonadism. European Association of Urology 2012;2012:28.

34. Mulligan T, Frick MF, Zuraw QC, Stemhagen A, McWhirter C. Prevalence of hypogonadism in males aged at least 45 years: the HIM study. International journal of clinical practice 2006;60(7):762-769. 
35. Ramasamy R, Wilken N, Scovell JM, Kovac JR, Lipshultz LI. Hypogonadal symptoms are associated with different serum testosterone thresholds in middle-aged and elderly men. Urology 2014;84(6):1378-1382.

36. Brambilla DJ, O'Donnell AB, Matsumoto AM, McKinlay JB. Intraindividual variation in levels of serum testosterone and other reproductive and adrenal hormones in men. Clin Endocrinol (Oxf) 2007;67(6):853-62.

37. Hackett G, Kirby M, Edwards D, Jones TH, Rees J, Muneer A. UK Policy Statements on Testosterone Deficiency. International Journal of Clinical Practice 2017;71(34):e12901.

38. Bhasin S, Cunningham GR, Hayes FJ, Matsumoto AM, Snyder PJ, Swerdloff RS, Montori VM. Testosterone therapy in men with androgen deficiency syndromes: an Endocrine Society clinical practice guideline. J Clin Endocrinol Metab 2010;95(6):2536-59.

39. Hellstrom WJ, Paduch D, Donatucci CF. Importance of hypogonadism and testosterone replacement therapy in current urologic practice: a review. Int Urol Nephrol 2012;44(1):61-70.

40. Livingston M, Kalansooriya A, Hartland AJ, Ramachandran S, Heald A. Serum testosterone levels in male hypogonadism: Why and when to check-A review. International journal of clinical practice 2017;71(11):e12995.

41. Rosen RC, Seftel AD, Ruff DD, Muram D. A Pilot Study Using a Web Survey to Identify Characteristics That Influence Hypogonadal Men to Initiate Testosterone Replacement Therapy. American Journal of Men's Health 2016;12(3):567-574.

42. Agency EM. Testosterone-Containing Medicines 
43. Layton JB, Li D, Meier CR, Sharpless JL, Sturmer T, Jick SS, Brookhart MA. Testosterone lab testing and initiation in the United Kingdom and the United States, 2000 to 2011. J Clin Endocrinol Metab 2014;99(3):835-42.

44. Snyder PJ, Bhasin S, Cunningham GR, Matsumoto AM, Stephens-Shields AJ, Cauley JA, Gill TM, Barrett-Connor E, Swerdloff RS, Wang C, Ensrud KE, Lewis CE, Farrar JT, Cella D, Rosen RC, Pahor M, Crandall JP, Molitch ME, Cifelli D, Dougar D, Fluharty L, Resnick SM, Storer TW, Anton S, Basaria S, Diem SJ, Hou X, Mohler ER, 3rd, Parsons JK, Wenger NK, Zeldow B, Landis JR, Ellenberg SS. Effects of Testosterone Treatment in Older Men. N Engl J Med 2016;374(7):611-24.

45. Baillargeon J, Kuo Y-F, Westra JR, Urban RJ, Goodwin JS. Testosterone Prescribing in the United States, 2002-2016Testosterone Prescribing in the United States, 20022016Letters. JAMA 2018;320(2):200-202.

46. Bandari J, Ayyash OM, Emery SL, Wessel CB, Davies BJ. Marketing and Testosterone Treatment in the USA: A Systematic Review. Eur Urol Focus 2017;3(45):395-402.

47. Layton JB, Kim Y, Alexander GC, Emery SL. Association Between Direct-toConsumer Advertising and Testosterone Testing and Initiation in the United States, 2009-2013. Jama 2017;317(11):1159-1166.

48. Shoskes JJ, Wilson MK, Spinner ML. Pharmacology of testosterone replacement therapy preparations. Translational andrology and urology 2016;5(6):834-843.

49. Ullah MI, Riche DM, Koch CA. Transdermal testosterone replacement therapy in men. Drug design, development and therapy 2014;8:101-112.

50. Rogol AD, Tkachenko N, Bryson N. Natesto ${ }^{\mathrm{TM}}$, a novel testosterone nasal gel, normalizes androgen levels in hypogonadal men. Andrology 2016;4(1):46-54. 
51. Basaria S, Coviello AD, Travison TG, Storer TW, Farwell WR, Jette AM, Eder R, Tennstedt S, Ulloor J, Zhang A, Choong K, Lakshman KM, Mazer NA, Miciek R, Krasnoff J, Elmi A, Knapp PE, Brooks B, Appleman E, Aggarwal S, Bhasin G, HedeBrierley L, Bhatia A, Collins L, LeBrasseur N, Fiore LD, Bhasin S. Adverse Events Associated with Testosterone Administration. New England Journal of Medicine 2010;363(2):109-122.

52. Onasanya O, Iyer G, Lucas E, Lin D, Singh S, Alexander GC. Association between exogenous testosterone and cardiovascular events: an overview of systematic reviews. Lancet Diabetes Endocrinol 2016;4(11):943-956.

53. Emmelot-Vonk MH, Verhaar HJJ, Nakhai Pour HR, Aleman A, Lock TMTW, Bosch JLHR, Grobbee DE, van der Schouw YT. Effect of Testosterone Supplementation on Functional Mobility, Cognition, and Other Parameters in Older Men A Randomized Controlled Trial. JAMA 2008;299(1):39-52.

54. Finkle WD, Greenland S, Ridgeway GK, Adams JL, Frasco MA, Cook MB, Fraumeni JF, Jr., Hoover RN. Increased risk of non-fatal myocardial infarction following testosterone therapy prescription in men. PLoS One 2014;9(1):e85805.

55. Vigen R, O'Donnell CI, Baron AE, Grunwald GK, Maddox TM, Bradley SM, Barqawi A, Woning G, Wierman ME, Plomondon ME, Rumsfeld JS, Ho PM. Association of testosterone therapy with mortality, myocardial infarction, and stroke in men with low testosterone levels. Jama 2013;310(17):1829-36.

56. Loo SY, Azoulay L, Nie R, Dell'Aniello S, Yu OHY, Renoux C. Cardiovascular and Cerebrovascular Safety of Testosterone Replacement Therapy Among Aging Men with Low Testosterone Levels: A Cohort Study. The American Journal of Medicine.

57. Sharma R, Oni OA, Gupta K, Chen G, Sharma M, Dawn B, Sharma R, Parashara D, Savin VJ, Ambrose JA, Barua RS. Normalization of testosterone level is associated 
with reduced incidence of myocardial infarction and mortality in men. Eur Heart $J$ 2015;36(40):2706-15.

58. Cheetham TC, An J, Jacobsen SJ, Niu F, Sidney S, Quesenberry CP, VanDenEeden SK. Association of Testosterone Replacement With Cardiovascular Outcomes Among Men With Androgen Deficiency. JAMA Intern Med 2017;177(4):491-499.

59. Etminan M, Skeldon SC, Goldenberg SL, Carleton B, Brophy JM. Testosterone therapy and risk of myocardial infarction: a pharmacoepidemiologic study. Pharmacotherapy 2015;35(1):72-8.

60. Wallis CJ, Lo K, Lee Y, Krakowsky Y, Garbens A, Satkunasivam R, Herschorn S, Kodama RT, Cheung P, Narod SA, Nam RK. Survival and cardiovascular events in men treated with testosterone replacement therapy: an intention-to-treat observational cohort study. Lancet Diabetes Endocrinol 2016;4(6):498-506.

61. Maggi M, Wu FC, Jones TH, Jackson G, Behre HM, Hackett G, Martin-Morales A, Balercia G, Dobs AS, Arver ST, Maggio M, Cunningham GR, Isidori AM, Quinton R, Wheaton OA, Siami FS, Rosen RC. Testosterone treatment is not associated with increased risk of adverse cardiovascular events: results from the Registry of Hypogonadism in Men (RHYME). Int J Clin Pract 2016;70(10):843-852.

62. Martinez C, Suissa S, Rietbrock S, Katholing A, Freedman B, Cohen AT, Handelsman DJ. Testosterone treatment and risk of venous thromboembolism: population based case-control study. Bmj 2016;355:i5968.

63. Bray F, Ferlay J, Soerjomataram I, Siegel RL, Torre LA, Jemal A. Global cancer statistics 2018: GLOBOCAN estimates of incidence and mortality worldwide for 36 cancers in 185 countries. CA: A Cancer Journal for Clinicians 2018;68(6):394-424. 
64. Litwin MS, Tan H-J. The Diagnosis and Treatment of Prostate Cancer: A ReviewThe Diagnosis and Treatment of Prostate CancerThe Diagnosis and Treatment of Prostate Cancer. JAMA 2017;317(24):2532-2542.

65. Cancer Research UK http://www.cancerresearchuk.org/health-professional/cancerstatistics/statistics-by-cancer-type/bladder-cancer/incidence - heading-One Accessed October 2017.

66. Society CC. Canadian Cancer Statistics: a 2018 special report. 2018.

67. Gann PH. Risk factors for prostate cancer. Reviews in urology 2002;4 Suppl 5(Suppl 5):S3-S10.

68. Schrecengost R, Knudsen KE. Molecular pathogenesis and progression of prostate cancer. Seminars in oncology 2013;40(3):244-258.

69. Mazhar D, Waxman J. Prostate cancer. Postgraduate Medical Journal 2002;78(924):590.

70. Concato J, Wells CK, Horwitz RI, Penson D, Fincke G, Berlowitz DR, Froehlich G, Blake D, Vickers MA, Gehr GA, Raheb NH, Sullivan G, Peduzzi P. The Effectiveness of Screening for Prostate Cancer: A Nested Case-Control Study. Archives of Internal Medicine 2006;166(1):38-43.

71. Ilic D, Djulbegovic M, Jung JH, Hwang EC, Zhou Q, Cleves A, Agoritsas T, Dahm P. Prostate cancer screening with prostate-specific antigen (PSA) test: a systematic review and meta-analysis. BMJ 2018;362:k3519.

72. Young GJ, Harrison S, Turner EL, Walsh EI, Oliver SE, Ben-Shlomo Y, Evans S, Lane JA, Neal DE, Hamdy FC, Donovan JL, Martin RM, Metcalfe C. Prostatespecific antigen (PSA) testing of men in UK general practice: a 10-year longitudinal cohort study. BMJ open 2017;7(10):e017729-e017729. 
73. Lin K, Lipsitz R, Miller T, Janakiraman S. Benefits and Harms of Prostate-Specific Antigen Screening for Prostate Cancer: An Evidence Update for the U.S. Preventive Services Task ForceScreening for Prostate Cancer. Annals of Internal Medicine 2008;149(3):192-199.

74. Loeb S, Bjurlin MA, Nicholson J, Tammela TL, Penson DF, Carter HB, Carroll P, Etzioni R. Overdiagnosis and overtreatment of prostate cancer. European urology 2014;65(6):1046-1055.

75. Force UPST. Final Recommendation Statement: Prostate Cancer Screening. 2018.

76. Care CTFoPH. Prostate Cancer. 2014.

77. Wilt TJ, MacDonald R, Rutks I, Shamliyan TA, Taylor BC, Kane RL. Systematic Review: Comparative Effectiveness and Harms of Treatments for Clinically Localized Prostate Cancer. Annals of Internal Medicine 2008;148(6):435-448.

78. Excellence NNIfHaC. Prostate cancer: diagnosis and management. https://www.nice.org.uk/guidance/cg175 Accessed April 26, 2019.

79. Xu J, Neale AV, Dailey RK, Eggly S, Schwartz KL. Patient perspective on watchful waiting/active surveillance for localized prostate cancer. Journal of the American Board of Family Medicine : JABFM 2012;25(6):763-770.

80. Kasperzyk JL, Shappley WV, 3rd, Kenfield SA, Mucci LA, Kurth T, Ma J, Stampfer MJ, Sanda MG. Watchful waiting and quality of life among prostate cancer survivors in the Physicians' Health Study. The Journal of urology 2011;186(5):1862-1867.

81. Parsons JK, Carter HB, Platz EA, Wright EJ, Landis P, Metter EJ. Serum Testosterone and the Risk of Prostate Cancer: Potential Implications for Testosterone Therapy. Cancer Epidemiology Biomarkers \&amp;amp; Prevention 2005;14(9):2257.

82. Watts EL, Appleby PN, Perez-Cornago A, Bueno-de-Mesquita HB, Chan JM, Chen C, Cohn BA, Cook MB, Flicker L, Freedman ND, Giles GG, Giovannucci E, 
Gislefoss RE, Hankey GJ, Kaaks R, Knekt P, Kolonel LN, Kubo T, Le Marchand L, Luben RN, Luostarinen T, Männistö S, Metter EJ, Mikami K, Milne RL, Ozasa K, Platz EA, Quirós JR, Rissanen H, Sawada N, Stampfer M, Stanczyk FZ, Stattin P, Tamakoshi A, Tangen CM, Thompson IM, Tsilidis KK, Tsugane S, Ursin G, Vatten L, Weiss NS, Yeap BB, Allen NE, Key TJ, Travis RC. Low Free Testosterone and Prostate Cancer Risk: A Collaborative Analysis of 20 Prospective Studies. European Urology 2018;74(5):585-594.

83. Michaud JE, Billups KL, Partin AW. Testosterone and prostate cancer: an evidencebased review of pathogenesis and oncologic risk. Therapeutic Advances in Urology 2015;7(6):378-387.

84. Huggins CH, C.V. Studies on Prostatic Cancer: I. The Effect of Castration, of Estrogen and of Androgen Injection on Serum Phosphatases in Metastatic Carcinoma of the Prostate. The Endocrinologist 2005;15(6):335-339.

85. Bekelman JE, Mitra N, Handorf EA, Uzzo RG, Hahn SA, Polsky D, Armstrong K. Effectiveness of androgen-deprivation therapy and radiotherapy for older men with locally advanced prostate cancer. J Clin Oncol 2015;33(7):716-22.

86. Bell MA, Campbell JD, Joice G, Sopko NA, Burnett AL. Shifting the Paradigm of Testosterone Replacement Therapy in Prostate Cancer. The world journal of men's health 2018;36(2):103-109.

87. Morgentaler A, Traish AM. Shifting the paradigm of testosterone and prostate cancer: the saturation model and the limits of androgen-dependent growth. Eur Urol 2009;55(2):310-20.

88. Davidson E, Morgentaler A. Testosterone Therapy and Prostate Cancer. Urologic Clinics of North America 2016;43(2):209-216. 
89. Khera M, Crawford D, Morales A, Salonia A, Morgentaler A. A New Era of Testosterone and Prostate Cancer: From Physiology to Clinical Implications. European Urology 2014;65(1):115-123.

90. Sih R, Morley JE, Kaiser FE, Perry HM, III, Patrick P, Ross C. Testosterone Replacement in Older Hypogonadal Men: A 12-Month Randomized Controlled Trial. The Journal of Clinical Endocrinology \& Metabolism 1997;82(6):1661-1667.

91. Srinivas-Shankar U, Roberts SA, Connolly MJ, O'Connell MDL, Adams JE, Oldham JA, Wu FCW. Effects of Testosterone on Muscle Strength, Physical Function, Body Composition, and Quality of Life in Intermediate-Frail and Frail Elderly Men: A Randomized, Double-Blind, Placebo-Controlled Study. The Journal of Clinical Endocrinology \& Metabolism 2010;95(2):639-650.

92. Parsons JK, Carter HB, Platz EA, Wright EJ, Landis P, Metter EJ. Serum testosterone and the risk of prostate cancer: potential implications for testosterone therapy. Cancer Epidemiol Biomarkers Prev 2005;14(9):2257-60.

93. Suissa S. Immortal time bias in pharmaco-epidemiology. Am J Epidemiol 2008;167(4):492-9.

94. Herrett E, Gallagher AM, Bhaskaran K, Forbes H, Mathur R, van Staa T, Smeeth L. Data Resource Profile: Clinical Practice Research Datalink (CPRD). Int J Epidemiol 2015;44(3):827-36.

95. Merriel SWD, Funston G, Hamilton W. Prostate Cancer in Primary Care. Advances in therapy 2018;35(9):1285-1294.

96. Dregan A, Moller H, Murray-Thomas T, Gulliford MC. Validity of cancer diagnosis in a primary care database compared with linked cancer registrations in England. Population-based cohort study. Cancer Epidemiology 2012;36(5):425-429. 
97. Khan NF, Harrison SE, Rose PW. Validity of diagnostic coding within the General Practice Research Database: a systematic review. Br J Gen Pract 2010;60(572):e12836.

98. Dandona P, Rosenberg MT. A practical guide to male hypogonadism in the primary care setting. International journal of clinical practice 2010;64(6):682-696.

99. Hernan MA, Alonso A, Logan R, Grodstein F, Michels KB, Willett WC, Manson JE, Robins JM. Observational studies analyzed like randomized experiments: an application to postmenopausal hormone therapy and coronary heart disease. Epidemiology 2008;19(6):766-79.

100. Ross ME, Kreider AR, Huang YS, Matone M, Rubin DM, Localio AR. Propensity Score Methods for Analyzing Observational Data Like Randomized Experiments: Challenges and Solutions for Rare Outcomes and Exposures. Am J Epidemiol 2015;181(12):989-95.

101. Network ODPR. Testosterone Replacement Therapy. https://odprn.ca/research/corethemes/drug-class-reviews/testosterone-replacement-therapy/.

102. Administration UFaD. Testosterone products: FDA/CDER statement - risk of venous blood clots.

http://www.fda.gov/Safety/MedWatch/SafetyInformation/SafetyAlertsforHumanMedi calProducts/ucm402054.htm.

103. Canada H. Summary safety review - testosterone replacement products cardiovascular risk. http://www.hc-sc.gc.ca/dhp-mps/medeff/reviewsexamens/testosterone-eng.php.

104. Parsons JK, Palazzi-Churas K, Bergstrom J, Barrett-Connor E. Prospective Study of Serum Dihydrotestosterone and Subsequent Risk of Benign Prostatic Hyperplasia in 
Community Dwelling Men: The Rancho Bernardo Study. The Journal of Urology 2010;184(3):1040-1044.

105. Lee SWH, Chan EMC, Lai YK. The global burden of lower urinary tract symptoms suggestive of benign prostatic hyperplasia: A systematic review and meta-analysis. Scientific reports 2017;7(1):7984-7984.

106. Jick SS, Hagberg KW. The risk of adverse outcomes in association with use of testosterone products: a cohort study using the UK-based general practice research database. Br J Clin Pharmacol 2013;75(1):260-70.

107. Li P, Chen J, Miyamoto H. Androgen Receptor Signaling in Bladder Cancer. Cancers 2017;9(2):20.

108. Shiota M, Kiyoshima K, Yokomizo A, Takeuchi A, Kashiwagi E, Dejima T, Takahashi R, Inokuchi J, Tatsugami K, Eto M. Suppressed Recurrent Bladder Cancer after Androgen Suppression with Androgen Deprivation Therapy or 5alpha-Reductase Inhibitor. J Urol 2017;197(2):308-313.

109. Shiota M, Yokomizo A, Takeuchi A, Imada K, Kiyoshima K, Inokuchi J, Tatsugami K, Ohga S, Nakamura K, Honda H, Naito S. Secondary bladder cancer after anticancer therapy for prostate cancer: reduced comorbidity after androgendeprivation therapy. Oncotarget 2015;6(16):14710-9.

110. Izumi K, Taguri M, Miyamoto H, Hara Y, Kishida T, Chiba K, Murai T, Hirai K, Suzuki K, Fujinami K, Ueki T, Udagawa K, Kitami K, Moriyama M, Miyoshi Y, Tsuchiya F, Ikeda I, Kobayashi K, Sato M, Morita S, Noguchi K, Uemura H. Androgen deprivation therapy prevents bladder cancer recurrence. Oncotarget 2014;5(24):12665-74. 